\title{
Potential of Exosomes as Cell-Free Therapy in Articular Cartilage Regeneration: A Review
}

\author{
Chiew Yong $\mathrm{Ng}$ (D) \\ Jia Ying Chai' \\ Jhi Biau Foo $\mathbb{D D}^{2,3}$ \\ Nor Hamdan Mohamad Yahaya ${ }^{4}$ \\ Ying Yang $\mathbb{D}^{5}$ \\ Min Hwei Ng (D' \\ Jia Xian Law $\mathbb{D}^{\prime}$ \\ 'Centre for Tissue Engineering and \\ Regenerative Medicine, Faculty of \\ Medicine, Universiti Kebangsaan Malaysia \\ Medical Centre, Kuala Lumpur, 56000, \\ Malaysia; ${ }^{2}$ School of Pharmacy, Faculty of \\ Health and Medical Sciences, Taylor's \\ University, Subang Jaya, 47500, Selangor, \\ Malaysia; ${ }^{3}$ Centre for Drug Discovery \\ and Molecular Pharmacology (CDDMP), \\ Faculty of Health and Medical Sciences, \\ Taylor's University, Subang Jaya, Selangor, \\ 47500, Malaysia; ${ }^{4}$ Department of \\ Orthopaedics and Traumatology, Faculty \\ of Medicine, Universiti Kebangsaan \\ Malaysia, Kuala Lumpur, 56000, Malaysia; \\ ${ }^{5}$ School of Pharmacy and Bioengineering, \\ Keele University, Stoke-on-Trent, ST4 \\ 7QB, UK
}

\begin{abstract}
Treatment of cartilage defects such as osteoarthritis (OA) and osteochondral defect $(\mathrm{OCD})$ remains a huge clinical challenge in orthopedics. OA is one of the most common chronic health conditions and is mainly characterized by the degeneration of articular cartilage, shown in the limited capacity for intrinsic repair. OCD refers to the focal defects affecting cartilage and the underlying bone. The current OA and OCD management modalities focus on symptom control and on improving joint functionality and the patient's quality of life. Cell-based therapy has been evaluated for managing OA and OCD, and its chondroprotective efficacy is recognized mainly through paracrine action. Hence, there is growing interest in exploiting extracellular vesicles to induce cartilage regeneration. In this review, we explore the in vivo evidence of exosomes on cartilage regeneration. A total of 29 in vivo studies from the PubMed and Scopus databases were identified and analyzed. The studies reported promising results in terms of in vivo exosome delivery and uptake; improved cartilage morphological, histological, and biochemical outcomes; enhanced subchondral bone regeneration; and improved pain behavior following exosome treatment. In addition, exosome therapy is safe, as the included studies documented no significant complications. Modifying exosomal cargos further increased the cartilage and subchondral bone regeneration capacity of exosomes. We conclude that exosome administration is a potent cell-free therapy for alleviating OA and OCD. However, additional studies are needed to confirm the therapeutic potential of exosomes and to identify the standard protocol for exosome-based therapy in OA and OCD management.
\end{abstract}

Keywords: extracellular vesicle, exosome, chondrocyte, cartilage, osteoarthritis

\section{Introduction}

Osteoarthritis (OA) is a common disease linked to mobility-related disability. In 2020, an estimated 654 million people worldwide had knee OA. ${ }^{1}$ Rising obesity and population aging are the main contributors to the increasing prevalence and incidence of OA. ${ }^{2} \mathrm{OA}$ is a chronic inflammatory disease that causes the deterioration of articular cartilage, which leads to joint pain and stiffness. ${ }^{3} \mathrm{OA}$ is not confined to the articular cartilage, but also affects the synovium, subchondral bone, and joint ligaments. ${ }^{4}$ Osteochondral defect (OCD) develops when cartilage lesions caused by OA affect the subchondral bone. ${ }^{5}$ However, OCD can also be caused by traumatic injury. ${ }^{6}$

Currently, no treatment can halt the progression of OA. However, treatments are available for relieving the symptoms. Treatments for OA can be classified into nonpharmacologic, pharmacologic, surgical, and alternative therapies such as regenerative therapy. Non-pharmacologic treatments are recommended for OA caused by
Correspondence: Jia Xian Law Centre for Tissue Engineering and Regenerative Medicine, Faculty of Medicine, Universiti Kebangsaan Malaysia Medical Centre, Jalan Yaacob Latif, Cheras, Kuala Lumpur, 56000, Malaysia Tel +60391457677

Fax +60391457678

Email danieljx08@gmail.com;

lawjx@ppukm.ukm.edu.my 
modifiable risk factors (eg obesity). Weight loss is associated with improvement in cartilage structure by reducing the joint load. ${ }^{7}$ Exercise has also been proven to relieve pain and improve muscle strength in OA patients. ${ }^{8,9}$ Nevertheless, these treatments are more effective for lower limb OA. Pain is the hallmark symptom of OA. Therefore, pharmacologic treatment is mainly used for managing pain. The classical pain-relieving treatments for OA include acetaminophen and non-steroidal antiinflammatory drugs (NSAIDs). ${ }^{10}$ However, the usage of these drugs increases the risk of gastrointestinal and cardiovascular toxicity. ${ }^{11}$ The surgical approach is preferred when conservative treatments are not effective. Although most patients have improved quality of life after surgery, potential complications such as pain, infection, and poorer knee function must be taken into consideration when opting for surgical intervention. ${ }^{12}$ In addition, knee replacement implants have limited lifespans and may fail eventually. ${ }^{13}$ OCD treatment can be categorized into nonsurgical and surgical. Non-surgical treatment includes rest, joint immobilization, and pain-relieving medication. OCD can also be corrected surgically by removing the lesion, microfracture drilling, retrograde drilling, antegrade drilling, cancellous bone graft implantation, osteochondral transplantation, and autologous chondrocyte implantation. ${ }^{14}$

Regenerative therapy is a rapidly growing approach used for treating OA and OCD due to conventional therapies being unsatisfactory, only managing to provide symptom control and short-term functional improvement. The conventional therapies fail to address the underlying problem of cartilage and osteochondral bone loss. ${ }^{15}$ Several preclinical studies have proven that intra-articular injection of mesenchymal stem/stromal cells (MSCs) enhances cartilage and meniscal tissue regeneration, and slows OA progression by attenuating synovial membrane inflammation. ${ }^{16,17}$ Similarly, a few preclinical studies have reported OCD regeneration by MSCs. ${ }^{18,19}$ Clinically, intra-articular injection of adipose-derived MSCs (AD-MSCs) is safe and produces significant functional improvement in $\mathrm{OA}$ and $\mathrm{OCD}$ patients. ${ }^{20-22}$ Recently published systematic reviews have shown that MSC therapy is safe and can improve pain and joint function significantly, but the improvement in cartilage regeneration, based on structural assessment by magnetic resonance imaging (MRI), is not statistically significant.23,24 Although no major adverse effects have been reported, we should remain aware of the possible risks associated with cell therapies. These include differentiation into undesirable cell types or tissues and the protumorigenic effect of MSCs. ${ }^{25-30}$ The transplantation of autologous AD-MSCs caused renal fibrosis and inflammatory cell infiltration in the interstitium of a patient with chronic kidney disease, and the reason might be the differentiation of the multipotent stem cells recruited by the MSCs into myofibroblasts or the differentiation of the transplanted MSCs into myofibroblasts. ${ }^{31,32}$

A paradigm shift has recently occurred, as MSCs and their conditioned medium were found to have similar therapeutic effects. ${ }^{33-35}$ Many papers have summarized that the primary mechanism of action of MSC therapy is paracrine signaling via extracellular vesicles $(\mathrm{EVs}){ }^{36-38}$ The use of EVs can mitigate the risk of transdifferentiation of transplanted MSCs into the wrong cells in response to the local milieu while retaining the beneficial therapeutic effects exerted by MSC paracrine secretion. Furthermore, the use of EVs can also minimize the risk of rejection of donor stem cells and tumor formation (especially for embryonic stem cells (ESCs) and induced pluripotent stem cells (iPSCs)).

EVs can be categorized into three groups based on their biogeneses, ie microvesicles, exosomes, and apoptotic bodies. ${ }^{39}$ Lai et $\mathrm{al}^{40}$ found that the exosome is the active component in MSC-conditioned medium. Exosomes are nanosized intraluminal vesicles in multivesicular bodies (MVBs) secreted by various cell types upon MVB fusion with the plasma membrane. ${ }^{41}$ They play a major role in cell-cell communication by transferring their contents, including proteins, lipids, and nucleic acids. ${ }^{42}$ MSC-derived exosomes have drawn much attention recently for their broad therapeutic effect on various diseases such as myocardial infarction, liver fibrosis, cutaneous wound healing, and $\mathrm{OA}^{43-47} \mathrm{~A}$ recent study reported that exosomes aid bidirectional signaling between MSCs and chondrocytes for chondrogenesis, ECM deposition, and cell proliferation, suggesting that they are important in communication between native heterogeneous cell populations of cartilage tissue, and thus are the crucial paracrine factors in cartilage repair. ${ }^{48}$

Apart from identifying the biogenesis pathway, a concrete means of distinguishing the EV subtypes is absent due to the lack of techniques for purifying and specific markers for the EV subtypes. ${ }^{49}$ Moreover, the size of EVs is heterogeneous and overlap among the subtypes. ${ }^{50,51}$ In fact, the generic term "extracellular vesicles" or "EVs" should be used. ${ }^{49}$ In the present systematic review, the 
term "exosomes" essentially refers to 50-200 nm EVs, without demonstration of their origin and/or purity, with regard to the nomenclature used by the authors.

Recently, several systematic reviews reported the potential of using MSC-derived EVs to promote cartilage regeneration in preclinical in vivo studies. ${ }^{52-54}$ However, EVs derived from other cell sources have also been used for promoting cartilage regeneration. Thus, the present review was aimed at summarizing the broad literature and evidence on the effects of exosome therapy derived from all cell sources on cartilage repair. Only results from preclinical in vivo studies were considered.

\section{Literature Search, Article Selection and Data Extraction}

The literature search was conducted from December 30, 2020, to January 6, 2021, on the PubMed and Scopus databases using the following keywords: (exosome OR extracellular vesicle) AND (cartilage OR osteoarthritis OR osteochondral). We included all preclinical and clinical studies reporting the safety and efficacy of EVs on cartilage regeneration. Studies reporting only in vitro findings were excluded. We also excluded secondary literature, studies only available in abstract form, conference/proceeding papers, letters to the editor, theses, and articles written in languages other than English. Figure 1 shows the article identification and selection process. In brief, a total of 160 articles from PubMed and 284 articles from Scopus were identified. After deduplication and title and abstract screening, 79 articles were obtained for fulltext screening. Finally, a total of 29 articles published between 2016 and 2021 were included in this review. All included articles reported in vivo findings without any clinical data. Two reviewers (C.Y.N. and J.Y.C.) conducted the literature search, article selection, and data extraction independently. The methodological quality of the studies was assessed using the Systematic Review Center for Laboratory Animal Experimentation (SYRCLE) risk of bias tool. ${ }^{55}$ Meta-analysis was not performed due to the lack of quantitative data for pooling because of the

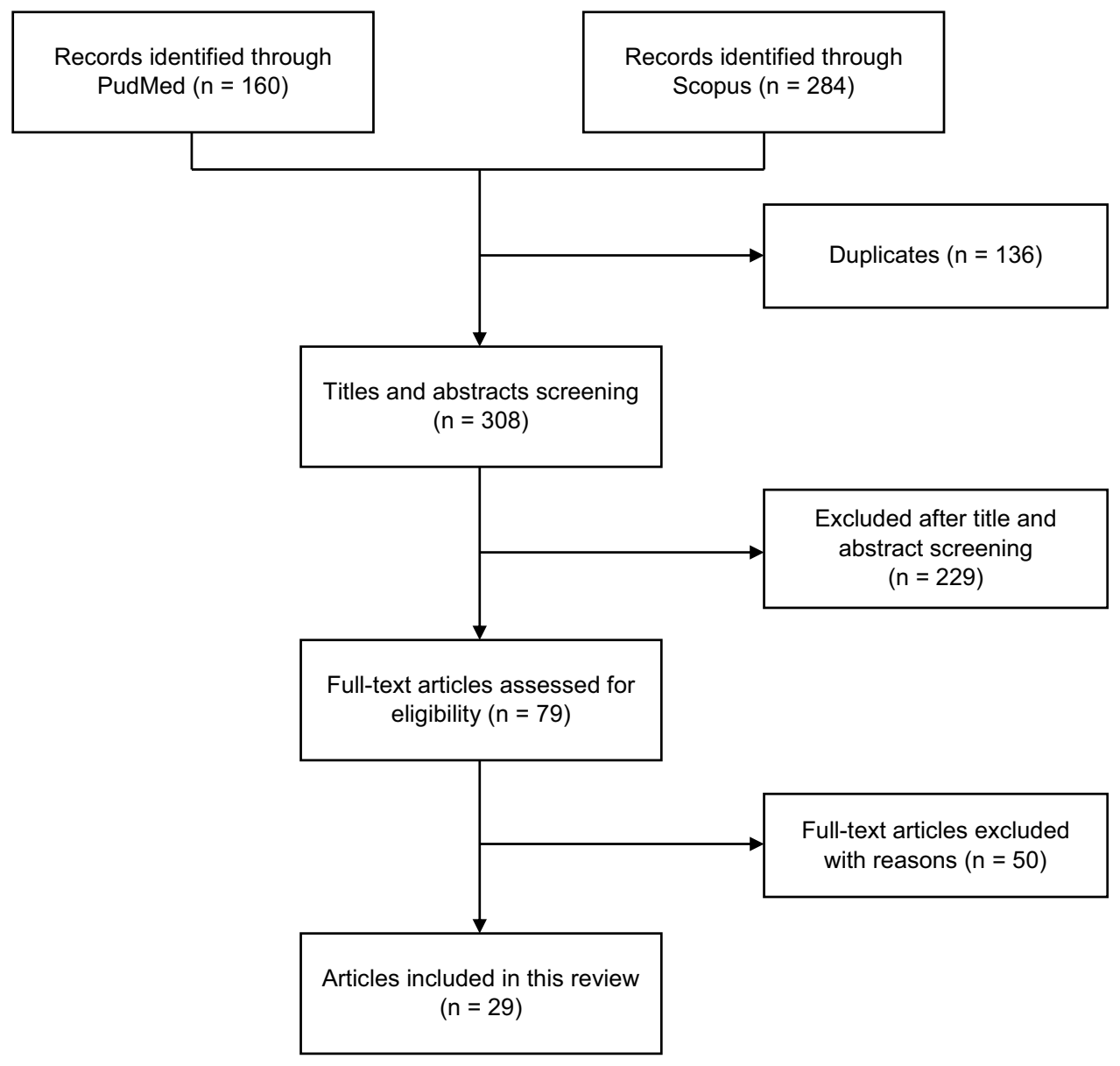

Figure I Flow diagram of article selection process. 
heterogeneity in the scoring systems and exosome isolation methods used. Thus, the results extracted were analyzed qualitatively.

\section{Results and Discussion Quality of Studies}

The included studies were graded using the SYRCLE risk of bias assessment tool. ${ }^{55}$ Table 1 summarizes the risk of bias analysis. There is no high risk of bias among the 29 included studies. All the included studies have low risk of selective outcome for reporting bias and other sources of bias were not detected. However, only nine studies $(31.0 \%)$ were assigned low risk of bias and 20 studies $(69.0 \%)$ had unclear risk of bias for baseline characteristics (ie animal species, age, gender, and weight) in selection bias. Furthermore, all studies showed unclear risk in most of the domains, including sequence generation and allocation concealment for selection bias, random housing and blinding for performance bias, random outcome assessment and blinding for detection bias, and incomplete outcome data for attrition bias. The lack of detailed documentation in the included articles resulted in a high unclear risk of bias and ambiguous methodological quality.

\section{Source of Exosomes}

Exosomes were extracted from a variety of cell sources. Seventeen studies used human exosomes, ${ }^{56-72}$ nine studies used murine exosomes, ${ }^{73-81}$ one study used rabbit exosomes, ${ }^{82}$ and two studies did not mention the cell origin $^{83,84}$ (Table 2).

Regarding cell type, 25 studies reported the use of exosomes from stem cells, namely ESC-derived MSCs (ESC-MSCs), ${ }^{61,63,68-70}$ iPSC-derived MSCs (iPSCMSCs), ${ }^{58,72}$ amniotic fluid stem cells (AFSCs) ${ }^{67}$ and other adult stem cells, including bone marrow-derived MSCs (BM-MSCs), ${ }^{56,57,59,71,73-76,78,83,84}$ synovial membrane-derived MSCs (SM-MSCs), ${ }^{60,62,72}$ infrapatellar fat pad-derived MSCs (IPFP-MSCs), ${ }^{64}$ umbilical cord-derived MSCs (UC-MSCs), ${ }^{65,66}$ polydactyly BM-derived MSCs (pBM-MSCs), ${ }^{71}$ and commercial MSCs of unknown tissue origin. ${ }^{79}$ Exosomes from primary chondrocytes, ${ }^{81}$ plateletrich plasma (PRP), ${ }^{82}$ dendritic cells, ${ }^{77}$ and serum ${ }^{80}$ were also studied.

Exosomes have similar biological functions as parental cells. ${ }^{39,85}$ Most of the studies included in this review used MSCs as the source of exosomes due to the predominant therapeutic benefits of MSCs in tissue repair and regeneration. MSCs have self-renewal, differentiation, anti-apoptotic, anti-fibrotic, pro-mitotic, anti-oxidative, and immunomodulatory properties. ${ }^{86-88}$ Besides, MSCs can be harvested from many tissue sources using minimally invasive techniques. ${ }^{89}$ MSCs can also be expanded easily for many passages without significant changes in characteristics and functionality, and produce more exosomes. ${ }^{90,91}$ Currently, the most ideal cell source of exosomes for promoting cartilage regeneration remains ambiguous. In the present review, only two studies compared the efficacy of exosomes secreted by different cell sources. $^{71,72}$ Zhu et $\mathrm{al}^{72}$ used exosomes secreted by iPSCMSCs and SM-MSCs, and found that iPSC-MSC-secreted exosomes were more effective in supporting cartilage regeneration. Neotissue of the iPSC-MSC-derived exosome-treated group presented typical hyaline features and intense type II collagen staining in the superficial and deep zones of cartilage tissue, which were comparable to the healthy cartilage in the control group. On the other hand, the SM-MSC-derived exosome-treated group exhibited moderate cartilage repair and very weak type II collagen staining in the superficial cartilage zone, but the results were nevertheless better compared to the untreated cartilage in the OA group. Zhou et $\mathrm{al}^{71}$ reported that $\mathrm{pBM}-$ MSC-secreted exosomes were more potent in facilitating cartilage repair compared to those secreted by BM-MSCs, as demonstrated by the lower Osteoarthritis Research Society International (OARSI) scores. Exosomes secreted by MSCs of different tissue sources show distinctive therapeutic results, as the exosomal cargo varies according to the tissue origin. ${ }^{92-94}$ The therapeutic potential of exosomes secreted by MSCs isolated from different tissues has been summarized in the reviews of Álvarez-Viejo, ${ }^{95}$ Nikfarjam et al, ${ }^{96}$ Yin et al, ${ }^{97}$ and Tang et al. ${ }^{98}$

\section{Modification of Exosomal Cargo for Enhancing Efficacy}

Exosomes mediate cell-cell communication by transporting bioactive lipids, proteins, and RNAs, including mRNAs, and non-coding RNAs such as microRNAs (miRNAs) and long non-coding RNAs (lncRNAs). ${ }^{99}$ We identified 15 studies that only used exosomes derived from naïve cells. ${ }^{58,61,63,67-75,81,82,84}$ All naïve exosomes promoted the repair and regeneration of damaged cartilage. Zhang et al ${ }^{69,70}$ reported that exosomal CD73 from naïve ESC-MSCs contributed to cartilage repair by inducing AKT and ERK phosphorylation in chondrocytes. Chen 


\begin{tabular}{|c|c|c|}
\hline 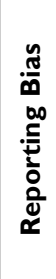 & 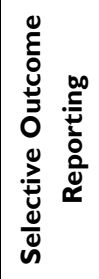 & 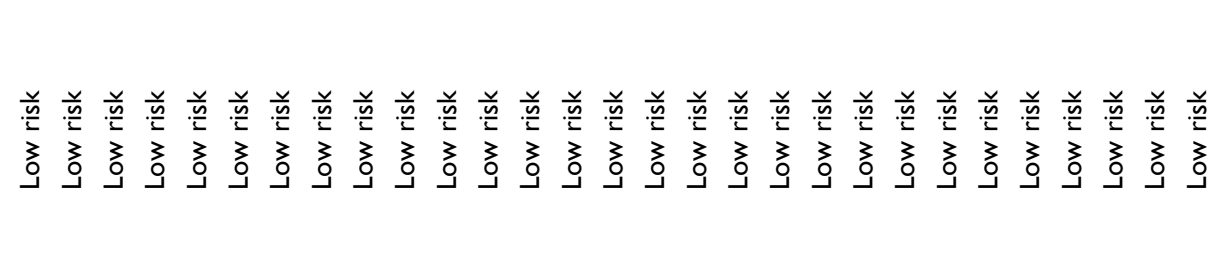 \\
\hline 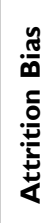 & 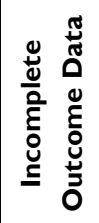 & 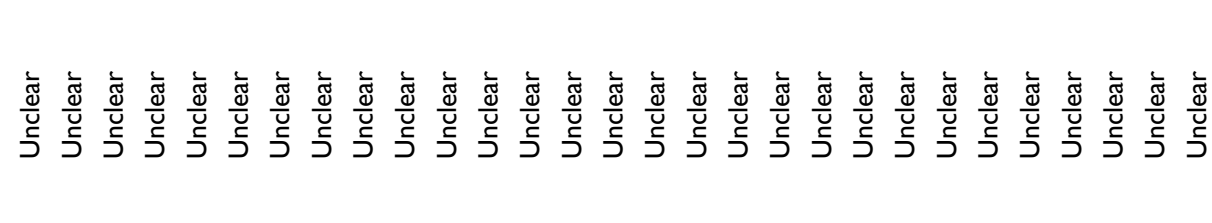 \\
\hline \multirow[b]{2}{*}{ 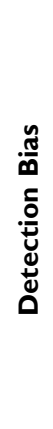 } & 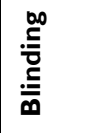 & 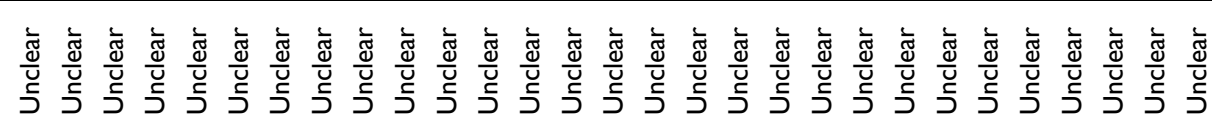 \\
\hline & 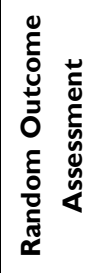 & 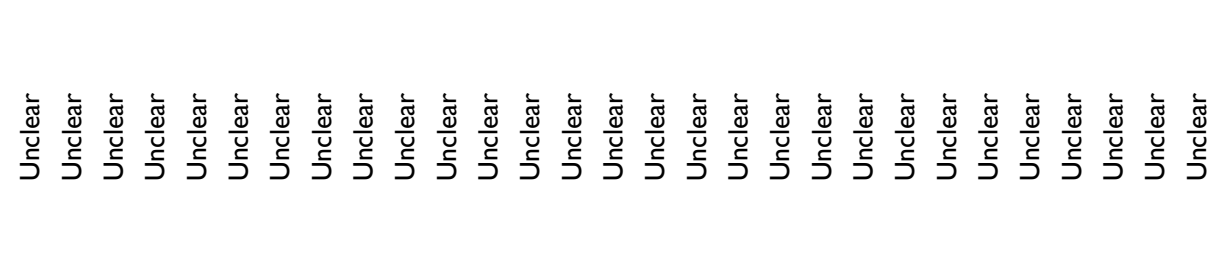 \\
\hline \multirow{2}{*}{ 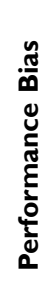 } & 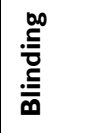 & 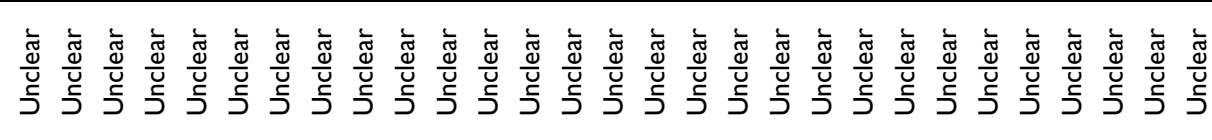 \\
\hline & 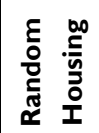 & 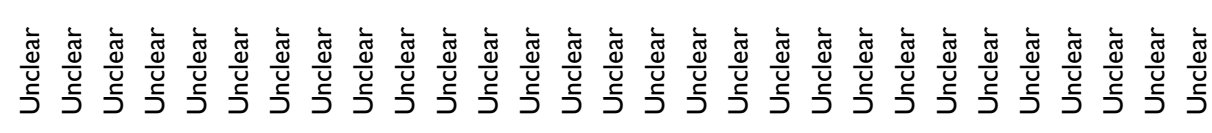 \\
\hline \multirow{3}{*}{ 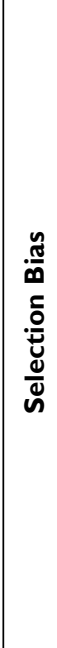 } & 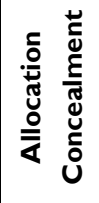 & 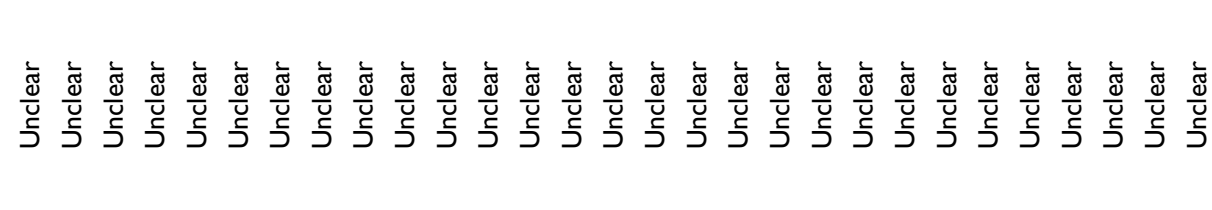 \\
\hline & 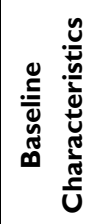 & 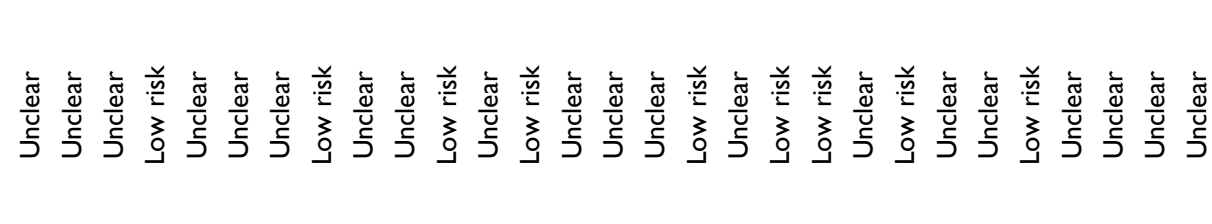 \\
\hline & 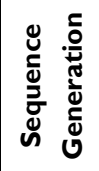 & 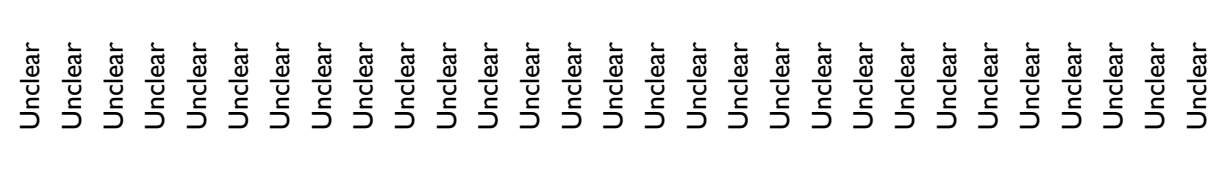 \\
\hline 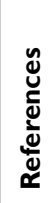 & & 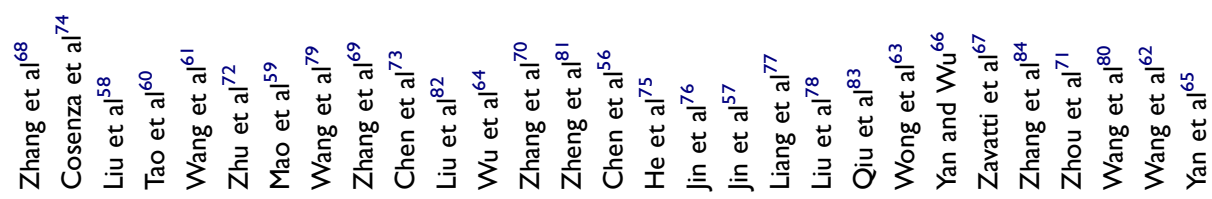 \\
\hline
\end{tabular}


Table 2 Cell Sources, Exosome Isolation, and Characterization

\begin{tabular}{|c|c|c|c|c|}
\hline References & $\begin{array}{c}\text { Cell } \\
\text { Sources }\end{array}$ & Cell Types & Exosome Isolation & Exosome Characterization \\
\hline Zhang et $\mathrm{al}^{68}$ & Human & HuES9 ESC-MSCs & $\begin{array}{l}\text { Size fractionation and TFF } \\
\text { Exosomes were stored at } \\
-20^{\circ} \mathrm{C} \text { until use }\end{array}$ & $\begin{array}{l}\text { NTA: Homogenously sized with } \\
\text { modal size of } 100 \mathrm{~nm} \\
\text { Western blot: Positive for CD8I, } \\
\text { ALIX, and TSGI0I } \\
\text { RNA detection: Majority less than } \\
300 \text { nucleotides }\end{array}$ \\
\hline Cosenza et $\mathrm{al}^{74}$ & Murine & BM-MSCs from C57BL/6 mice & Ultracentrifugation & $\begin{array}{l}\text { DLS: } 96 \mathrm{~nm} \\
\text { NTA: II } 2 \pm 6.6 \mathrm{~nm} \\
\text { Flow cytometry: Positive for CD9 } \\
\text { and CD8I }\end{array}$ \\
\hline Liu et $\mathrm{al}^{58}$ & Human & iPSC (iPSC-0I)-MSCs & $\begin{array}{l}\text { Ultracentrifugation and } \\
\text { ultrafiltration }\end{array}$ & $\begin{array}{l}\text { TEM: Spherical morphology; } 30 \text { to } 60 \\
\text { nm } \\
\text { TRPS: } 50 \text { to I50 nm } \\
\text { Western blot: Positive for CD9, } \\
\text { CD63, and CD8I }\end{array}$ \\
\hline Tao et $\mathrm{al}^{60}$ & Human & $\begin{array}{l}\text { Normal SM-MSCs and miR-I40-5p- } \\
\text { overexpressing SM-MSCs from knee } \\
\text { joint synovial membrane tissue of } 30 \text { to } \\
35 \text { years old donors }\end{array}$ & $\begin{array}{l}\text { Ultrafiltration and } \\
\text { ultracentrifugation on } 30 \% \\
\text { sucrose/D2O cushion } \\
\text { Used freshly }\end{array}$ & $\begin{array}{l}\text { TEM: Hollow spherical microvesicles } \\
\text { DLS: } 30 \text { to I50 nm } \\
\text { Western blot: Positive for CD63, } \\
\text { CD9, CD8I, and ALIX } \\
\text { RT-qPCR: Increased miR-I40-5p } \\
\text { expression level in miR-I40-5p } \\
\text { overexpressed SM-MSC-Exos }\end{array}$ \\
\hline Wang et $\mathrm{al}^{61}$ & Human & Male HI ESC-MSCs & $\begin{array}{l}\text { Ultracentrifugation } \\
\text { Exosomes were stored in } \\
\text { PBS at }-80{ }^{\circ} \mathrm{C}\end{array}$ & $\begin{array}{l}\text { TEM: Round lipid bilayer vesicles; } 38 \\
\text { to } 169 \mathrm{~nm} \\
\text { Western blot: Positive for CD63 and } \\
\text { CD9 }\end{array}$ \\
\hline \multirow[t]{2}{*}{ Zhu et $\mathrm{al}^{72}$} & Human & iPSC (CIP33)-MSCs & $\begin{array}{l}\text { Ultrafiltration } \\
\text { The exosomes aliquot was } \\
\text { stored }-80^{\circ} \mathrm{C} \text { or used } \\
\text { freshly }\end{array}$ & $\begin{array}{l}\text { TEM: Cup or round-shaped } \\
\text { TPRS: } 50 \text { to } 150 \mathrm{~nm} \\
\text { Western blot: Positive for CD9, } \\
\text { CD63, and TSGI0I }\end{array}$ \\
\hline & Human & $\begin{array}{l}\text { SM-MSCs from } 3 \text { donors ( } 2 \text { males and } \\
\text { I female, age range } 22 \text { to } 28 \text { years) }\end{array}$ & $\begin{array}{l}\text { Ultrafiltration } \\
\text { The exosomes aliquot was } \\
\text { stored }-80^{\circ} \mathrm{C} \text { or used } \\
\text { freshly }\end{array}$ & $\begin{array}{l}\text { TEM: Cup or round-shape } \\
\text { TPRS: } 50 \text { to } 150 \mathrm{~nm} \text {. } \\
\text { Western blot: Positive for CD9, } \\
\text { CD63, and TSGI0I }\end{array}$ \\
\hline Mao et $\mathrm{al}^{59}$ & Human & $\begin{array}{l}\text { Normal BM-MSCs and miR-92a-3p- } \\
\text { overexpressing BM-MSCs from } 6 \\
\text { donors ( } 3 \text { males and } 3 \text { females, ranged } \\
\text { of } 32 \text { to } 38 \text { years old) }\end{array}$ & Ultracentrifugation & $\begin{array}{l}\text { TEM: Cup-shaped or round } \\
\text { morphology; } 50 \text { to } 150 \mathrm{~nm} \\
\text { NTA: } 50 \text { to } 150 \mathrm{~nm} \text {. } \\
\text { Western blot: Positive for CD9, } \\
\text { CD63, CD8I, and HSP70 }\end{array}$ \\
\hline Wang et $\mathrm{al}^{79}$ & Murine & $\begin{array}{l}\text { Normal MSCs, TGF- } \beta \text { I stimulated } \\
\text { MSCs and miR- } 135 \mathrm{~b} \text { inhibited MSC } \\
\text { from SD rats }\end{array}$ & Exosome extraction kit & $\begin{array}{l}\text { TEM: Hollow-spherical morphology } \\
\text { Western blot: Positive for CD63, } \\
\text { CD9, and CD8I; higher CD8I and } \\
\text { ALIX levels in TGF- } \beta \text { I-MSC-Exos } \\
\text { RT-qPCR: Increased miR-I35b } \\
\text { expression level in TGF- } \beta \text { I-MSC- } \\
\text { Exos }\end{array}$ \\
\hline
\end{tabular}

(Continued) 
Table 2 (Continued).

\begin{tabular}{|c|c|c|c|c|}
\hline References & $\begin{array}{c}\text { Cell } \\
\text { Sources }\end{array}$ & Cell Types & Exosome Isolation & Exosome Characterization \\
\hline Zhang et $\mathrm{al}^{69}$ & Human & Immortalized EI-MYC I6.3 ESC-MSCs & $\begin{array}{l}\text { Size fractionation and TFF } \\
\text { Exosomes were stored at } \\
-20{ }^{\circ} \mathrm{C} \text { until use }\end{array}$ & $\begin{array}{l}\text { Size determination: Homogenously } \\
\text { sized particles; } 100 \mathrm{~nm} \text { model size } \\
\text { Western blot: Positive for CD8I, } \\
\text { ALIX, and TSGI0I } \\
\text { Flotation density: } 1.10 \text { to } 1.19 \mathrm{~g} / \mathrm{mL}\end{array}$ \\
\hline Chen et $\mathrm{al}^{73}$ & Murine & $\begin{array}{l}\text { BM-MSCs from articular cartilage from } \\
\text { femoral condyles and tibial plateau of } \\
\text { C57BL/6 mice }\end{array}$ & $\begin{array}{l}\text { Ultrafiltration and } \\
\text { ultracentrifugation on } 30 \% \\
\text { sucrose/D2O cushion }\end{array}$ & $\begin{array}{l}\text { TEM: Hollow spherical vesicles } \\
\text { DLS: } 40 \text { to } 110 \mathrm{~nm} \text { in diameter } \\
\text { Western blot: Positive for TSG I0I, } \\
\text { CD9, and CD63 }\end{array}$ \\
\hline Liu et $\mathrm{al}^{82}$ & Rabbit & $\begin{array}{l}\text { PRP isolated from whole blood of } \mathrm{New} \\
\text { Zealand white rabbits }\end{array}$ & $\begin{array}{l}\text { Membrane-based affinity } \\
\text { binding step using exoEasy } \\
\text { Maxi Kit } \\
\text { Exosomes were stored at } \\
-80^{\circ} \mathrm{C} \text { until used }\end{array}$ & $\begin{array}{l}\text { TEM: Round-shaped morphology } \\
\text { NTA: I } 45.6 \pm 50.4 \mathrm{~nm} \\
\text { Western blot: Positive for CD9, } \\
\text { CD63, CD8I, and HSPI0I }\end{array}$ \\
\hline Wu et $a^{64}$ & Human & $\begin{array}{l}\text { IPFP-MSCs from patients with primary } \\
\text { knee OA }\end{array}$ & $\begin{array}{l}\text { Precipitation (ExoQuick } \\
\text { reagent kit) or ultrafiltration } \\
\text { Exosomes were stored at } \\
-80^{\circ} \mathrm{C} \text { for further use }\end{array}$ & $\begin{array}{l}\text { No significant differences between } \\
\text { exosomes isolated from precipitation } \\
\text { and ultrafiltration } \\
\text { TEM: Sphere-shaped bilayer } \\
\text { membrane structure about } 100 \mathrm{~nm} \text { in } \\
\text { diameter } \\
\text { NTA: } 121.9 \mathrm{~nm} \\
\text { Western blot: Positive for CD8I, } \\
\text { CD9, and CD } 63 \\
\text { Flow cytometry with CiO-labeling: } 30 \\
\mathrm{~nm} \text { to } 150 \mathrm{~nm}\end{array}$ \\
\hline Zhang et $\mathrm{al}^{70}$ & Human & Immortalized EI-MYC I6.3 ESC-MSCs & $\begin{array}{l}\text { Size fractionation and TFF } \\
\text { Exosomes were stored at } \\
-20{ }^{\circ} \mathrm{C} \text { until use }\end{array}$ & $\begin{array}{l}\text { Size determination: } 100 \text { to } 200 \mathrm{~nm} \\
\text { Western blot: Positive for CD8I, } \\
\text { ALIX, and TSGI0I } \\
\text { Flotation density: } 1.10 \text { to } 1.19 \mathrm{~g} / \mathrm{mL}\end{array}$ \\
\hline Zheng et $\mathrm{al}^{81}$ & Murine & $\begin{array}{l}\text { Primary chondrocytes from knee } \\
\text { articular cartilage of } 5 \text { to } 6 \text { days old } \\
\text { C57BL/6 mice cultured in standard or } \\
\text { inflammatory environment } \\
\text { (degenerative chondrocytes) }\end{array}$ & $\begin{array}{l}\text { Ultrafiltration and } \\
\text { ultracentrifugation with } 30 \% \\
\text { sucrose/D2O }\end{array}$ & $\begin{array}{l}\text { TEM: Hollow and spherical-like } \\
\text { morphology } \\
\text { DLS: } 40 \text { to } 110 \mathrm{~nm} \\
\text { Western blot: Positive for TSGI0I, } \\
\text { CD9, and CD63 } \\
\text { Mass spectrometry: } 2409 \text { and } 2077 \\
\text { proteins were identified in primary } \\
\text { chondrocytes and degenerative } \\
\text { chondrocytes, respectively }\end{array}$ \\
\hline Chen et $\mathrm{a}^{56}$ & Human & $\begin{array}{l}\text { Normal BM-MSCs and miR-I36-5p- } \\
\text { overexpressed BM-MSCs from femur } \\
\text { bone marrow of traumatized patients }\end{array}$ & $\begin{array}{l}\text { Ultrafiltration and } \\
\text { ultracentrifugation with } 30 \% \\
\text { sucrose/D2O }\end{array}$ & $\begin{array}{l}\text { TEM: Hollow spherical microvesicles } \\
\text { DLS: } 50 \text { to } 150 \mathrm{~nm} \\
\text { Western blot: Positive for CD63, } \\
\text { CD9, CD8I, and ALIX; but very low } \\
\text { TSG I0I } \\
\text { RT-qPCR: Upregulated miR-136-5p } \\
\text { expression level in miR-136-5p } \\
\text { overexpressed BM-MSC-Exos }\end{array}$ \\
\hline
\end{tabular}

(Continued) 
Table 2 (Continued).

\begin{tabular}{|c|c|c|c|c|}
\hline References & $\begin{array}{c}\text { Cell } \\
\text { Sources }\end{array}$ & Cell Types & Exosome Isolation & Exosome Characterization \\
\hline He et $\mathrm{al}^{75}$ & Murine & BM-MSCs from SD rats & Ultracentrifugation & $\begin{array}{l}\text { TEM: Oval in shape } \\
\text { DLS: I53 nm } \\
\text { Western blot: Positive for flotillin-I, } \\
\text { TSG I0I, and CD63; negative for } \\
\text { calnexin }\end{array}$ \\
\hline Jin et $\mathrm{al}^{76}$ & Murine & $\begin{array}{l}\text { Normal BM-MSCs and miR-9-5p } \\
\text { overexpressed BM-MSCs }\end{array}$ & $\begin{array}{l}\text { Ultracentrifugation } \\
\text { Exosomes were stored at } \\
-80{ }^{\circ} \mathrm{C}\end{array}$ & $\begin{array}{l}\text { TEM: Round or tea-shaped with } \\
\text { outer membrane; } 40 \text { to } 100 \mathrm{~nm} \\
\text { Western blot: Positive for CD9, } \\
\text { TSGI0I, and CD63; negative for } \\
\text { calnexin }\end{array}$ \\
\hline Jin et $\mathrm{al}^{57}$ & Human & $\begin{array}{l}\text { Normal BM-MSCs and miRNA-26a-5p } \\
\text { overexpressed-BM-MSCs from ilium of } \\
\text { healthy volunteers }\end{array}$ & $\begin{array}{l}\text { Precipitation (ExoQuick-TC } \\
\text { reagent kit) }\end{array}$ & $\begin{array}{l}\text { TEM: Round or oval-shaped; } 30 \text { to } \\
\text { I00 nm } \\
\text { DLS: } 50 \text { to } 100 \mathrm{~nm} \\
\text { Western blot: Positive for CD63, } \\
\text { Hsp70, and CD90 } \\
\text { RT-qPCR: Upregulated miR-26a-5p } \\
\text { expression level in miR-26a-5p } \\
\text { overexpressed BM-MSC-Exos }\end{array}$ \\
\hline Liang et $\mathrm{al}^{77}$ & Murine & CAP-Lamp2b dendritic cells & $\begin{array}{l}\text { Ultracentrifugation } \\
\text { Exosomes were stored at } \\
-80{ }^{\circ} \mathrm{C} \\
\text { miR- } 140 \text { mimic is introduced } \\
\text { into exosomes by } \\
\text { electroporation }\end{array}$ & $\begin{array}{l}\text { TEM: Cup-shaped morphology; } 40 \text { to } \\
200 \mathrm{~nm} \\
\text { NTA: } 40 \text { to } 200 \mathrm{~nm} \\
\text { Western blot: Positive for CD } 63 \text { and } \\
\text { CD } 9 \\
\text { Confocal microscope: Fluorescence } \\
\text { signals of CAP-GFP-Exos }\end{array}$ \\
\hline Liu et $\mathrm{al}^{78}$ & Murine & $\begin{array}{l}\text { Normal BM-MSCs from SD rats and } \\
\text { BM-MSCs treated with kartogenin }\end{array}$ & $\begin{array}{l}\text { TFF and HPLC } \\
\text { Exosomes were stored at } \\
-80^{\circ} \mathrm{C}\end{array}$ & $\begin{array}{l}\text { TEM: Cup or round-shaped } \\
\text { morphology } \\
\text { NTA: } 50 \text { to } 200 \mathrm{~nm} \\
\text { Western blot: Positive for CD63 and } \\
\text { CD8I }\end{array}$ \\
\hline Qiu et $\mathrm{al}^{83}$ & $\begin{array}{l}\text { Not } \\
\text { reported }\end{array}$ & $\begin{array}{l}\text { Normal BM-MSCs and curcumin pre- } \\
\text { treated BM-MSCs }\end{array}$ & Ultrafiltration & $\begin{array}{l}\text { TEM: Round-shaped morphology; } 50 \\
\text { to } 150 \mathrm{~nm} \\
\text { Western blot: Positive for CD9, } \\
\text { CD63, and CD8I }\end{array}$ \\
\hline Wong et $\mathrm{al}^{63}$ & Human & EI-MYC I6.3 ESC-MSCs & $\begin{array}{l}\text { Size fractionation and TFF } \\
\text { Exosomes were stored at } \\
-20^{\circ} \mathrm{C} \text { until use }\end{array}$ & $\begin{array}{l}\text { Size determination: } 100 \text { to } 200 \mathrm{~nm} \\
\text { Western blot: Positive for CD8I, } \\
\text { ALIX, and TSGI0I }\end{array}$ \\
\hline Yan and $\mathrm{Wu}^{66}$ & Human & $\begin{array}{l}\text { UC-MSCs cultured in 2D and 3D } \\
\text { (hollow-fiber bioreactor) }\end{array}$ & $\begin{array}{l}\text { Ultracentrifugation } \\
\text { Exosomes were stored at } \\
-80^{\circ} \mathrm{C} \text { until used }\end{array}$ & $\begin{array}{l}\text { TEM: Cup-shaped morphology } \\
\text { NTA: I } 20 \text { nm } \\
\text { Western blot: Positive for CD63, } \\
\text { CD8I, and TSGI0I; negative for } \\
\text { calnexin }\end{array}$ \\
\hline Zavatti et al ${ }^{67}$ & Human & $\begin{array}{l}\text { AFSCs from pregnant women (mean } \\
\text { age of } 35.7 \text { ) between the 16th and 17th } \\
\text { weeks of gestation }\end{array}$ & $\begin{array}{l}\text { Precipitation (total exosome } \\
\text { isolation solution) }\end{array}$ & $\begin{array}{l}\text { Western blot: Positive for CD9, } \\
\text { CD63, CD8I, and Rab5 }\end{array}$ \\
\hline
\end{tabular}

(Continued) 
Table 2 (Continued).

\begin{tabular}{|c|c|c|c|c|}
\hline References & $\begin{array}{c}\text { Cell } \\
\text { Sources }\end{array}$ & Cell Types & Exosome Isolation & Exosome Characterization \\
\hline Zhang et $\mathrm{a}^{84}$ & $\begin{array}{l}\text { Not } \\
\text { reported }\end{array}$ & BM-MSCs & $\begin{array}{l}\text { Ultrafiltration and } \\
\text { ultracentrifugation with } \\
\text { sucrose cushion } \\
\text { Exosomes were stored at } \\
-80^{\circ} \mathrm{C} \text { or used freshly }\end{array}$ & $\begin{array}{l}\text { TEM: Cup-like shape } \\
\text { NTA: I } 40 \text { nm } \\
\text { Western blot: Positive for CD63, } \\
\text { CD8I, and CD9; negative for } \\
\text { cerulean }\end{array}$ \\
\hline \multirow[t]{2}{*}{ Zhou et $\mathrm{al}^{71}$} & Human & Polydactyly BM-MSCs & $\begin{array}{l}\text { Precipitation (total exosome } \\
\text { isolation kit) }\end{array}$ & $\begin{array}{l}\text { TEM: } 30 \text { to } 150 \mathrm{~nm} \\
\text { Western blot: Positive for CD63 and } \\
\text { CD9 }\end{array}$ \\
\hline & Human & BM-MSCs & $\begin{array}{l}\text { Precipitation (total exosome } \\
\text { isolation kit) }\end{array}$ & $\begin{array}{l}\text { TEM: } 30 \text { to } 150 \mathrm{~nm} \\
\text { Western blot: Positive for CD63 and } \\
\text { CD9 }\end{array}$ \\
\hline Wang et $\mathrm{a}^{80}$ & Murine & $\begin{array}{l}\text { OA serum from } O A \text { mice and sham } \\
\text { serum from sham mice }\end{array}$ & $\begin{array}{l}\text { Norgen's proprietary resin- } \\
\text { based purification (Serum } \\
\text { Exosome Purification Mini } \\
\text { Kit) } \\
\text { ATF4-OA-Exos were } \\
\text { constructed by introducing } \\
\text { ATF4 mRNA into OA-Exos } \\
\text { through electroporation. }\end{array}$ & $\begin{array}{l}\text { TEM: Spherical-shaped morphology } \\
\text { NTA: } 0 \text { to } 150 \mathrm{~nm} \\
\text { Western blot: Positive for ALIX and } \\
\text { CD63 } \\
\text { RT-qPCR: Highest expression level of } \\
\text { ATF4 in ATF4-OA-Exos, followed by } \\
\text { OA-Exos and sham-Exos }\end{array}$ \\
\hline Wang et $\mathrm{a}^{62}$ & Human & $\begin{array}{l}\text { Normal SM-MSCs and miR-155-5p- } \\
\text { overexpressing SM-MSCs }\end{array}$ & Not reported & $\begin{array}{l}\text { TEM: Cup-shaped morphology } \\
\text { NTA: } 100 \text { to } 120 \mathrm{~nm} \\
\text { Western blot: Positive for CD63 and } \\
\text { CD8I; negative for TFIIB } \\
\text { RT-qPCR: } 60 \text {-fold higher miR-155-5p } \\
\text { expression in miR-155-5p } \\
\text { overexpressed SM -MSC-Exos } \\
\text { compared to SM-MSC-Exos }\end{array}$ \\
\hline Yan et al ${ }^{65}$ & Human & $\begin{array}{l}\text { UC-MSCs cultured in static } \\
\text { environment and rotary cell culture } \\
\text { system }\end{array}$ & $\begin{array}{l}\text { Ultracentrifugation } \\
\text { Exosomes were stored at } \\
-80{ }^{\circ} \mathrm{C}\end{array}$ & $\begin{array}{l}\text { TEM: Cup-shaped morphology } \\
\text { NTA: I } 20 \mathrm{~nm} \\
\text { Western blot: Positive for CD63, } \\
\text { CD8I, and TSGI0I; low calnexin } \\
\text { RT-qPCR: Increased IncRNA HI9 } \\
\text { expression level in exosomes } \\
\text { collected from cells cultured in rotary } \\
\text { cell culture system }\end{array}$ \\
\hline
\end{tabular}

Abbreviations: AFSC, amniotic fluid stem cell; BM-MSC, bone marrow-derived mesenchymal stem/stromal cell; CAP-Lamp2b, chondrocyte-affinity peptide-lysosomeassociated membrane glycoprotein 2b; D2O, deuterium oxide; DLS, dynamic light scattering; ESC-MSC, embryonic stem cell-derived mesenchymal stem/stromal cell; Exo, exosome; IPFP-MSC, infrapatellar fat pad-derived mesenchymal stem/stromal cell; iPSC-MSC, induced pluripotent stem cell-derived mesenchymal stem/stromal cell; IncRNA, long non-coding RNA; miR, microRNA; MSC, mesenchymal stem/stromal cell; NTA, nanoparticle tracking analysis; PBS, phosphate-buffered saline; PRP, platelet-rich plasma; RT-qPCR, reverse transcription quantitative polymerase chain reaction; SD rat, Sprague Dawley rat; SM-MSC, synovial membrane-derived mesenchymal stem/stromal cell; TEM, transmission electron microscopy; TFF, tangential flow filtration; TGF- $\beta$ I, transforming growth factor beta I; TPRS, tunable resistive pulse sensing; UC-MSC, umbilical cord-derived mesenchymal stem/stromal cell.

et $\mathrm{al}^{73}$ suggested that BM-MSC-derived exosomes restored the mitochondrial dysfunction of degenerated chondrocytes by supplementing mitochondrial-related proteins. Another study noted that normal chondrocyte-derived exosomes carried proteins that involved in mitochondrial function and immune system process, which are important in alleviating OA progression. ${ }^{81}$ On the contrary, 14 articles modified and loaded exosomes with specific therapeutic agents, and reported enhanced therapeutic efficacy of cartilage regeneration compared to naïve 
exosomes. ${ }^{56,57,59,60,62,64-66,76-80,83}$ Exosomal cargo can be modified via preconditioning of the exosome-secreting cells; incubating the exosome-secreting cells with the therapeutic cargo (eg drugs, proteins, RNAs, nanomaterials); transfection of the exosome-secreting cells; and physical treatments such as electroporation, sonication, extrusion, surfactant treatment, dialysis, and freeze-thawing. ${ }^{100}$

The genomic molecules within exosomes aid the regulation of gene expression. ${ }^{101}$ Valadi et al ${ }^{102}$ were the first to discover the presence of mRNAs and miRNAs in exosomes, and indicated that exosomes could modify the protein production and gene expression of target cells by transferring exosomal mRNAs or miRNAs. Wang et al ${ }^{80}$ investigated the therapeutic effect of the activating transcription factor 4 (ATF4) gene in cartilage regeneration by introducing ATF4 mRNA into exosomes via electroporation. The effects of exosomes derived from OA serum (OA-Exos) and ATF4 mRNA-overexpressing exosomes (ATF4-OA-Exos) were compared, and showed that the ATF4-OA-Exos were more potent compared to the OAExos in preventing and alleviating cartilage degeneration via the stimulation of autophagy.

miRNAs play a critical role in the post-transcriptional regulation of a wide range of physiological processes, including cartilage homeostasis, and the pathological processes in disorders such as OA. ${ }^{103,104}$ In the past few years, there has been growing emphasis on determining the biological function of miRNAs in regenerative medicine. ${ }^{105,106}$ Given the eminent role of miRNAs in cartilage regeneration, six studies included here used transfection to upregulate specific miRNAs, ie miR-9-5p, miR26a-5p, miR-92a-3p, miR-136-5p, miR-140-5p, and miR$155-5 p$, in exosomes. ${ }^{56,57,59,60,62,76}$ All miRNA-overexpressing exosomes showed superior therapeutic potential compared to the naïve exosomes by regulating the target genes and their downstream signaling pathways in the recipient cells. Mao et $\mathrm{al}^{59}$ revealed that exosomal miR$92 \mathrm{a}-3 \mathrm{p}$ downregulated the Wnt signaling pathway via $W N T 5 A$, eventually causing lower ECM degradation. Comparing the results of exosome-treated groups with and without antagomir-miR-100-5p, Wu et $\mathrm{al}^{64}$ reported that IPFP-MSC-derived exosomes ameliorated cartilage damage and the gait patterns of OA mice by delivering miR-100-5p into the recipient chondrocytes, leading to activation of the miR-100-5p-mediated mTOR autophagy pathway. In another study, miR-140 was loaded into exosomes through electroporation, and the miR-140-overexpressing exosomes were more effective compared to the naïve exosomes in suppressing the progression of cartilage degeneration and in enhancing cartilage regeneration. ${ }^{77}$ Additionally, miR-135b was increased in exosomes secreted by transforming growth factor (TGF)- $\beta 1$-stimulated MSCs. $^{79}$ The exosomal miR-135b downregulated Sp1 protein expression, leading to better cartilage regeneration in rats with $\mathrm{OA}^{79}$

LncRNAs are involved in the transcriptional and posttranscriptional regulation of many biological processes related to cartilage development, degeneration, and regeneration, and can be transferred by exosomes to recipient cells. ${ }^{107,108}$ Yan et al studied the role of exosomal lncRNA H19 in cartilage regeneration. ${ }^{65}$ The exosomal lncRNA H19 played an important role in cartilage regeneration by promoting chondrocyte proliferation and matrix production whilst suppressing apoptosis. In vivo, injecting exosomes rich in lncRNA H19 led to greater improvement in cartilage repair, with uniform tissue, obscured boundaries, and lower T2 values on MRI analysis compared to that of cartilage tissue treated with exosomes secreted by UCMSCs transfected with small interfering RNA (siRNA) against H19. ${ }^{65}$ In that study, the 10 -fold increase in exosomal lncRNA H19 was achieved by exposing the cells to mechanical stimulus via culture in a rotary cell culture system (RCCS).

These results clearly show that exosomal cargo can be modulated by modifying the culture condition. The changes in exosomal cargo, such as higher miR-135b expression in TGF- $\beta 1$-stimulated MSC-derived exosomes and higher lncRNA H19 expression in exosomes secreted by UC-MSCs exposed to mechanical stimulus, enhanced cartilage regeneration in vivo. ${ }^{65,79}$ Additionally, preconditioning BM-MSCs with kartogenin and curcumin improved the therapeutic potential of the secreted exosomes for treating OA. ${ }^{78,83}$ However, the studies did not examine the differences in the exosomal cargos of preconditioned and naïve cells.

Apart from modulating the exosomal cargo, cell preconditioning can also stimulate exosome secretion. Yan and $\mathrm{Wu}^{66}$ collected exosomes secreted by UC-MSCs cultured in 2D and 3D (using a hollow-fiber bioreactor) conditions. The 3D culture had increased exosome yield (7.5fold higher), and the exosomes secreted by 3D-culture UC-MSCs showed more potent therapeutic effects in promoting cartilage repair compared to the exosomes secreted by the 2D-culture UC-MSCs, as indicated by the greater surface regularity and better thickness of OA cartilage in vivo. Similarly, Yan et $\mathrm{al}^{65}$ also found that UC-MSCs 
cultured in 3D conditions using a RCCS secreted exosomes with increased yield and therapeutic potential in treating OA. Consistent with this, Yang et al ${ }^{109}$ and Cao et $\mathrm{al}^{110}$ attained higher exosome yields from cells cultured in $3 \mathrm{D}$ conditions, and the exosomes showed improved therapeutic potential, albeit for different indications.

The above results demonstrate the importance of exosomal cargo modification for achieving better performance. Additionally, exosomal cargo profiling is crucial for elucidating the mechanism of action.

\section{In vivo Delivery and Exosome Uptake}

Cartilage is an avascular and alymphatic tissue. ${ }^{111}$ Thus, unlike in other tissue injuries, exosomes are not suitable for infusing intravenously for treating cartilage defects. In fact, all of the included studies administered exosomes directly to the affected joint, as intra-articular administration increases bioavailability and reduces off-target effects, thereby improving the delivery of exosomes to the cartilage and decreasing the dose of exosomes needed. ${ }^{112}$ The exosomes were either injected or encapsulated in a scaffold. Some studies used a single injection and others used multiple injections to treat cartilage injuries. Currently, it remains unclear if multiple injections are more effective compared to single injection for promoting cartilage regeneration, as none of the studies compared the therapeutic effect of single and multiple injections. Cosenza et $\mathrm{al}^{74}$ and Wang et $\mathrm{al}^{80}$ showed that the effect of exosomes from a single intra-articular injection may be month-long. This is most probably due to the direct exosome administration to the target site (cartilage is avascular and alymphatic; thus, the clearance of the injected exosomes is slower) and the exosomes might induce cellular reprogramming and remodel resident or injured cells by activating regenerative mechanisms by transferring bioactive molecules. ${ }^{113-115}$

The findings of the 29 studies are summarized in Table 3 and illustrated in Figure 2. To date, direct injection appears to be a more popular cell delivery method, as only a few studies ${ }^{58,73,78}$ used a scaffold to deliver exosomes to the injured cartilage tissues. A scaffold is beneficial for sustaining the delivery of exosomes for a longer period and also aids exosome homing to the injury site. Additionally, combining exosomes and biomaterial can create a synergistic effect to promote cartilage regeneration. Liu et $\mathrm{al}^{58}$ found that the implantation of in situ hydrogel glue with iPSC-MSC-derived exosomes was more potent for promoting cartilage regeneration compared to in situ hydrogel glue implantation and iPSC-MSC-derived exosome injection, supported by the formation of a smoother surface with fully filled regenerated tissue that integrated with the surrounding cartilage. The histological findings were supported by the results of optical coherence tomography (OCT), which displayed a uniform and well-organized articular cartilage structure in the in situ formed iPSC-MSC-exosome-hydrogel tissue patch implantation group.

In vitro studies have shown that exosomes promote chondrocyte proliferation and migration, impede chondrocyte apoptosis and the expression of pro-inflammatory markers, and restore the balance between chondrocyte catabolism and anabolism in a dose-dependent manner.69,74,78,82,116 However, no article included in the present review reported on the in vivo response to exosome dosage.

We also noted that the studies used several exosome quantitation methods, ie nanoparticle analyzer, protein quantitation assay, and enzyme-linked immunosorbent assay (ELISA). The number of exosome particles (particles/mL) was detected using nanoparticle analyzers such as nanoparticle tracking analysis (NTA) and tunable resistive pulse sensing (TRPS). Some of the studies used an ExoELISA kit to quantify exosomes based on the presence of exosome markers such as CD63. The exosome concentration was also determined by exosome protein mass concentration $(\mu \mathrm{L} / \mathrm{mL})$ using the bicinchoninic acid (BCA) or Bradford assay. Although all included studies reported that exosomes promoted cartilage repair and prevented lesion progression compared to the control group, none conducted in vivo study for identifying the optimal dosage and number of injections. Based on the different quantification methods used in the 29 included studies, the quantity of exosomes used ranged from $8 \times 10^{7}-1 \times 10^{10}$ particles and 7.5-200 $\mu \mathrm{g}$ in mouse models; $1 \times 10^{8}-1 \times$ $10^{10}$ and $1.25-100 \mu \mathrm{g}$ in rat models; and $2 \times 10^{9}-5 \times 10^{9}$ and 100-200 $\mu \mathrm{g}$ in rabbit models, and the injection number and time varied in each study.

Intercellular communication via exosomes mainly takes place through three mechanisms: (1) direct interaction of exosome ligands and receptors on target cells that activate the intracellular signaling cascades; (2) direct fusion; or (3) endocytosis. Direct fusion and endocytosis resulted in the release of exosomal contents into the cytosol. $^{117} \mathrm{Wu}$ et al, ${ }^{64} \mathrm{He}$ et al, ${ }^{75}$ Liang et al, ${ }^{77}$ and Zhang et $\mathrm{al}^{84}$ monitored exosome uptake in joint tissues. Fluorescent labeled exosomes were mainly observed in the 


\begin{tabular}{|c|c|c|c|}
\hline 总 & 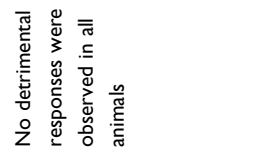 & 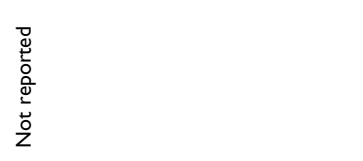 & 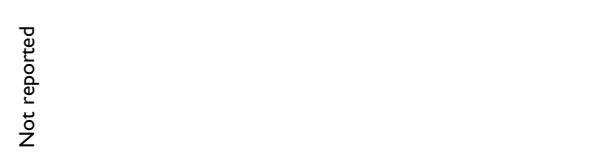 \\
\hline 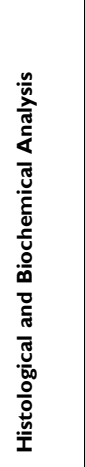 & 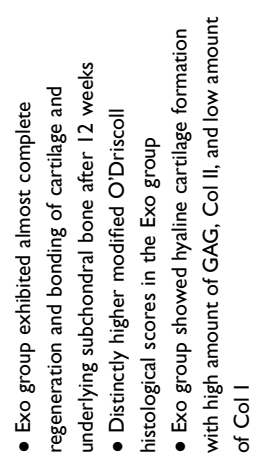 & 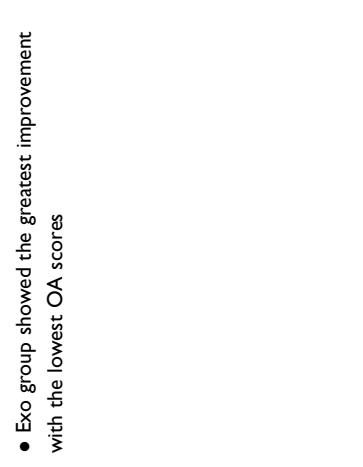 & 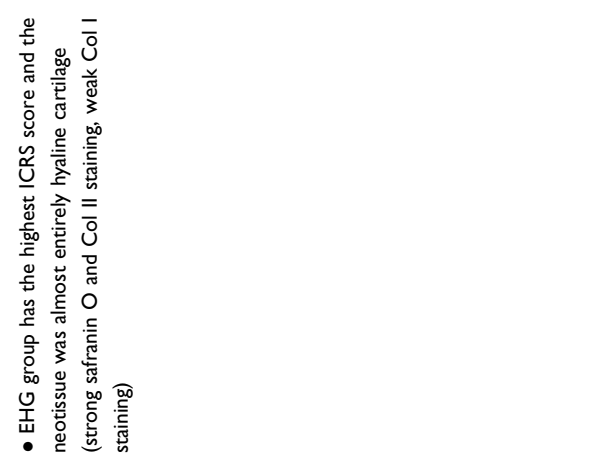 \\
\hline 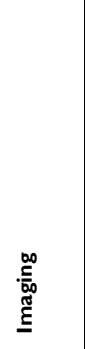 & 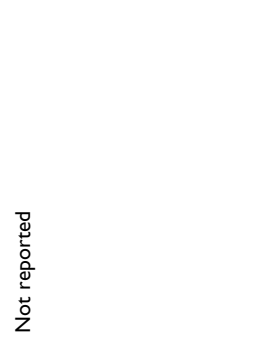 & 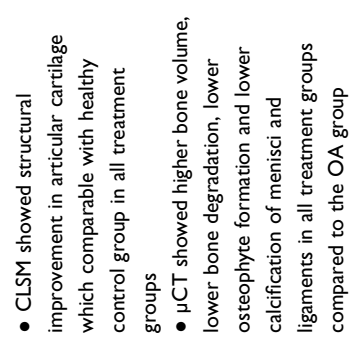 & 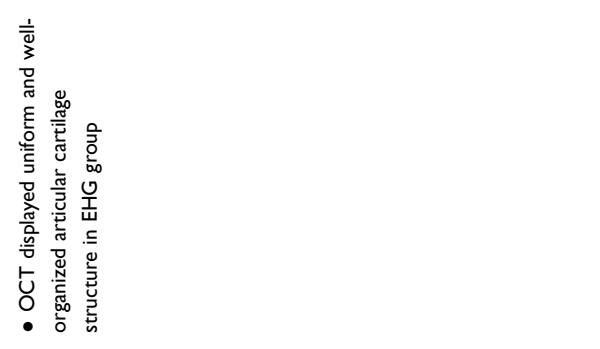 \\
\hline 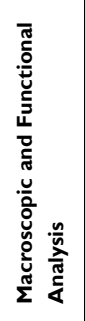 & 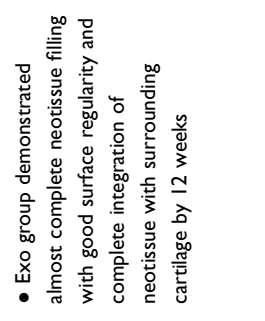 & 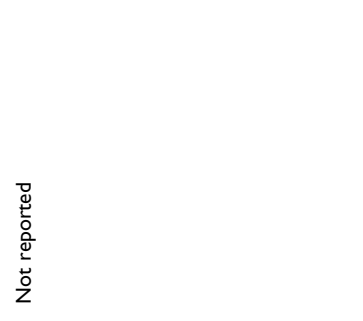 & 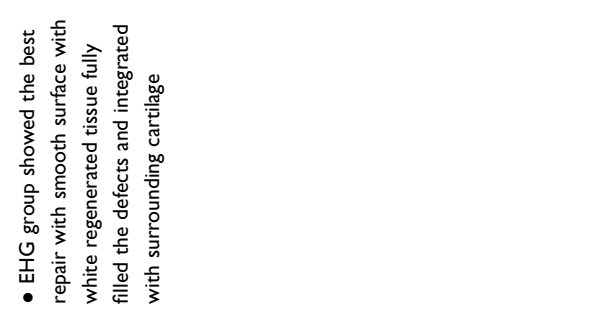 \\
\hline & 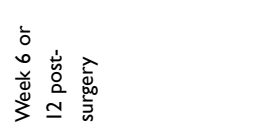 & 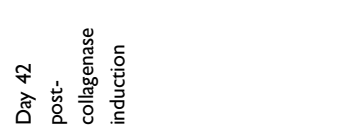 & 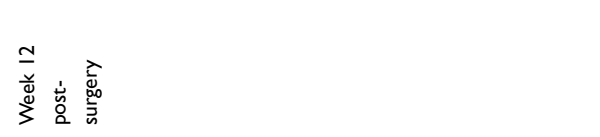 \\
\hline & 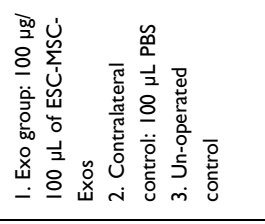 & 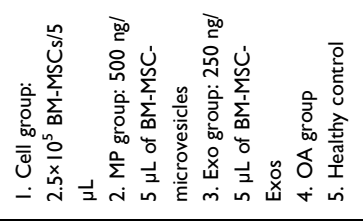 & 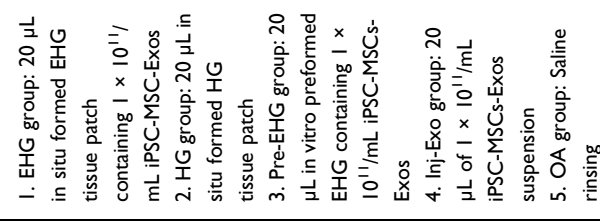 \\
\hline & 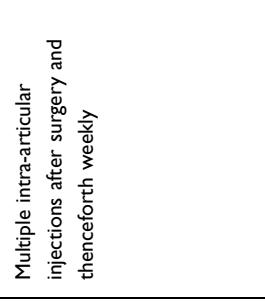 & 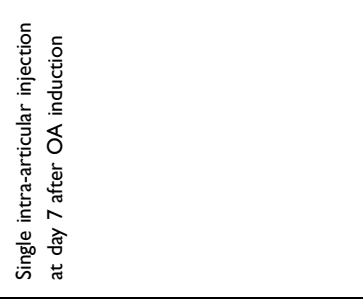 & 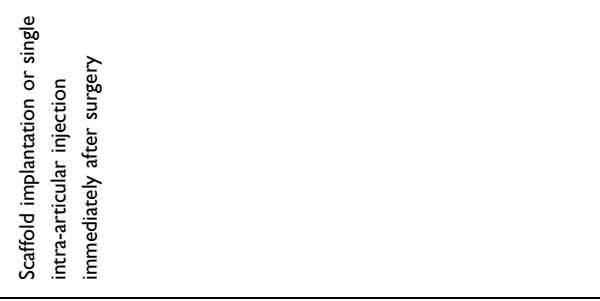 \\
\hline & 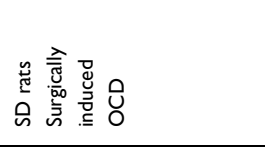 & 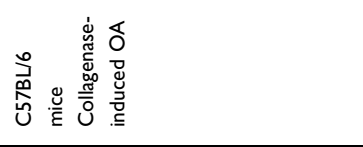 & 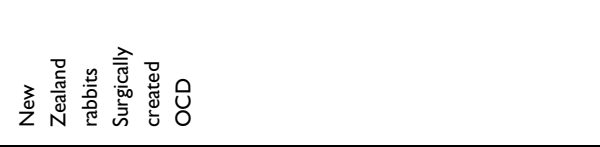 \\
\hline & 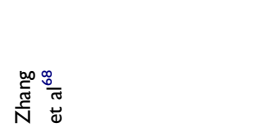 & 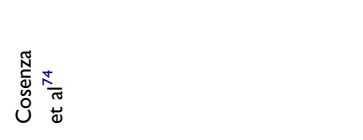 & 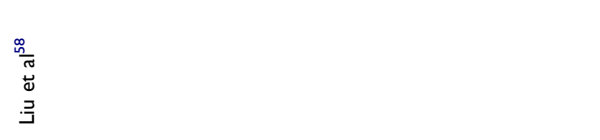 \\
\hline
\end{tabular}




\begin{tabular}{|c|c|c|}
\hline 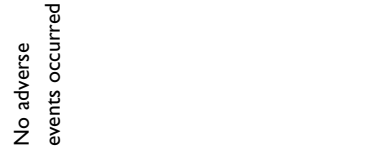 & 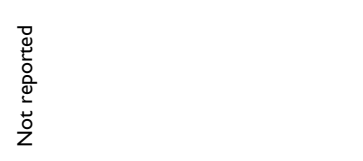 & 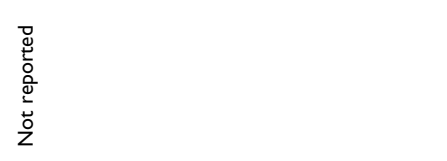 \\
\hline 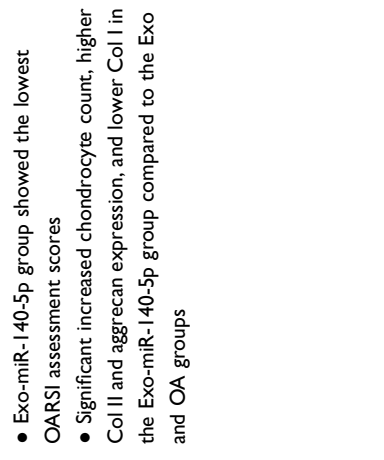 & 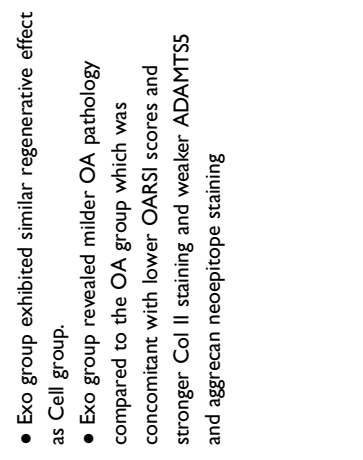 & 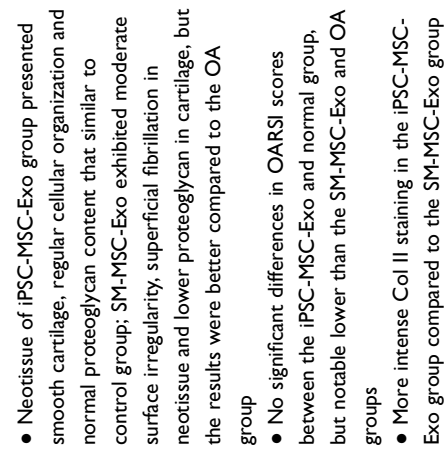 \\
\hline 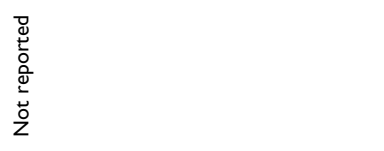 & 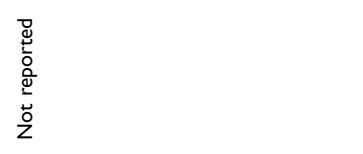 & 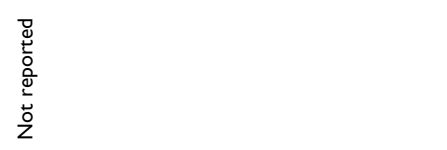 \\
\hline 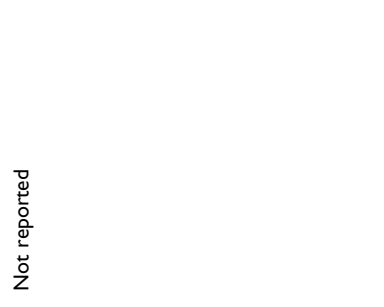 & 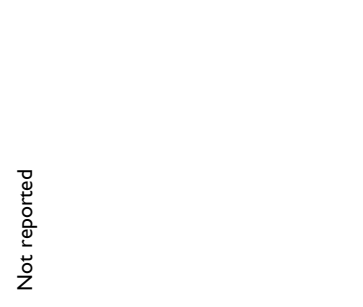 & 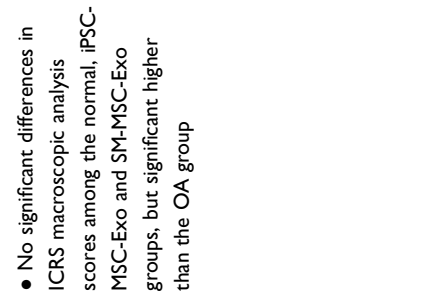 \\
\hline 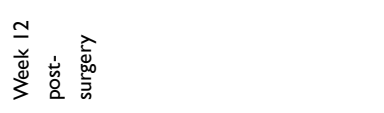 & 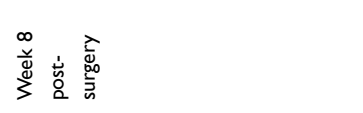 & 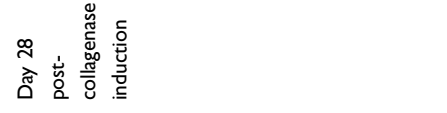 \\
\hline 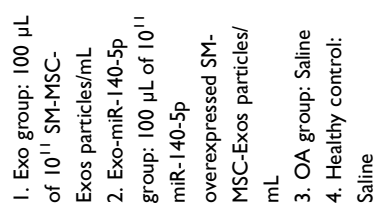 & 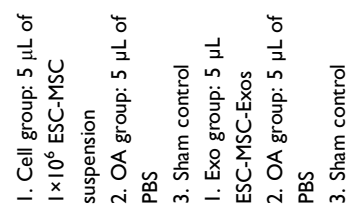 & 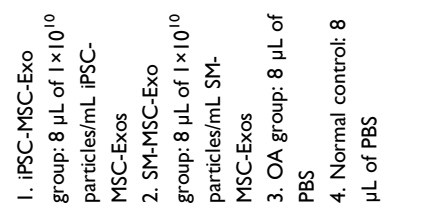 \\
\hline 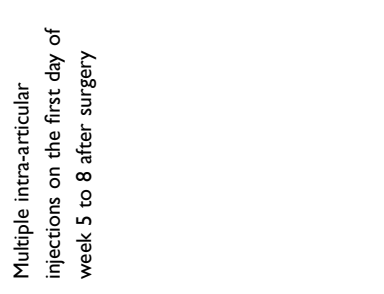 & 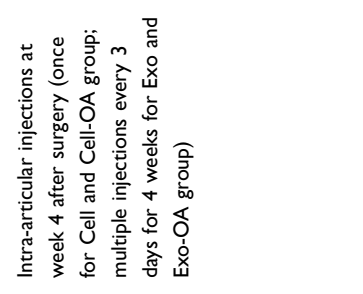 & 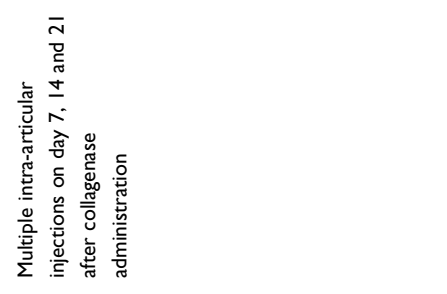 \\
\hline 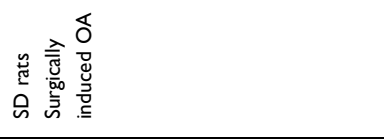 & 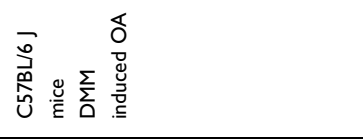 & 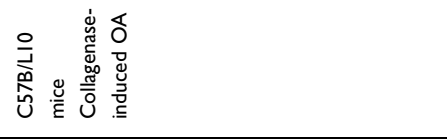 \\
\hline 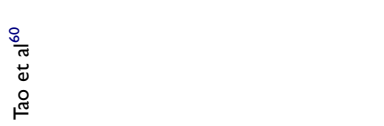 & 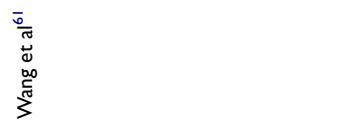 & 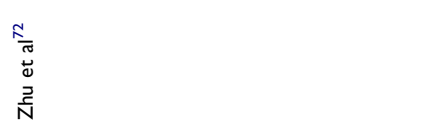 \\
\hline
\end{tabular}




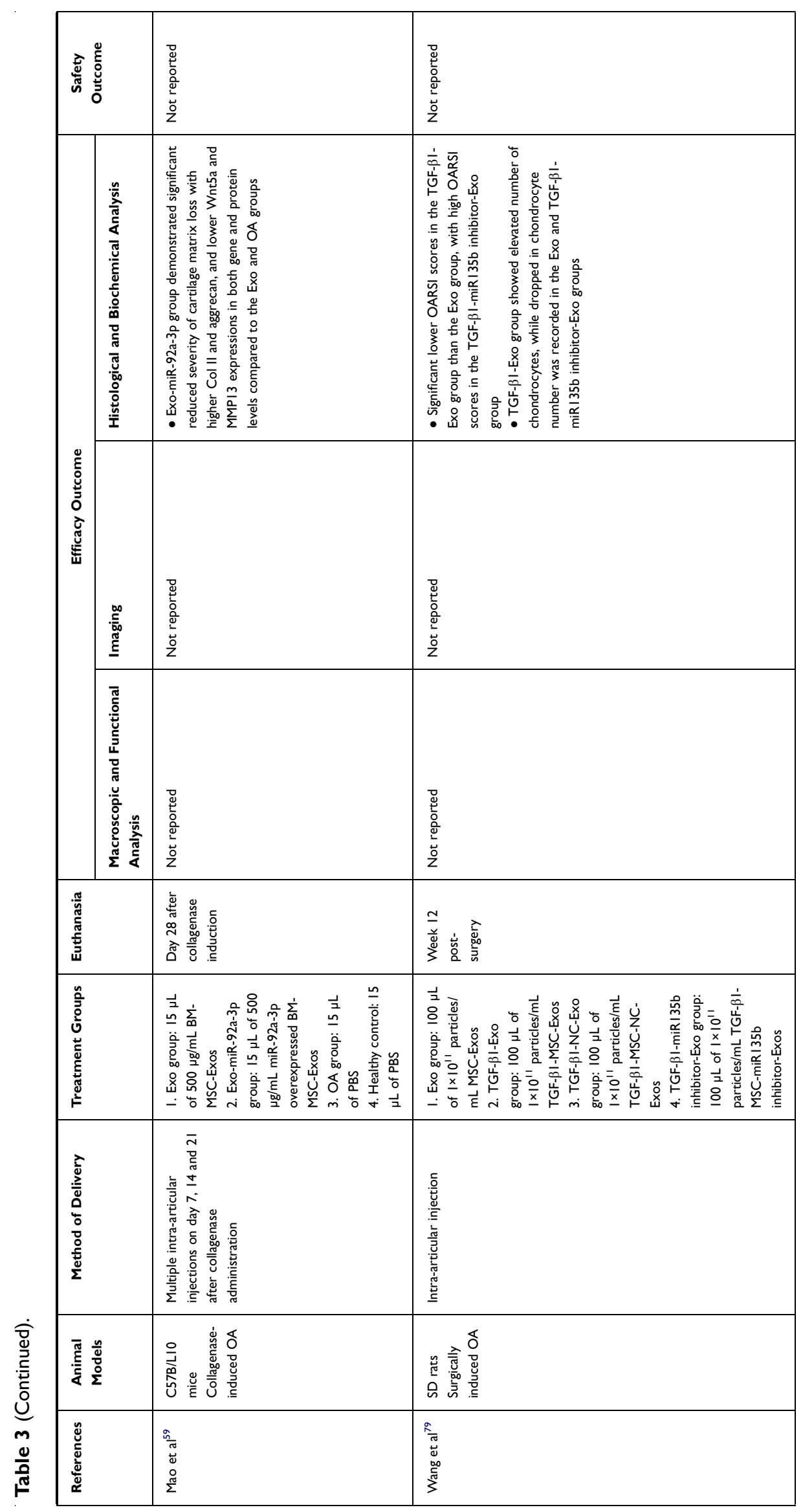




\begin{tabular}{|c|c|c|c|}
\hline 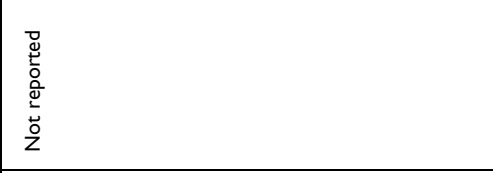 & 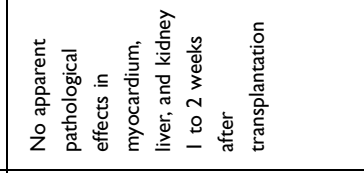 & 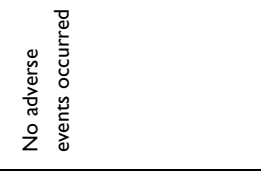 & 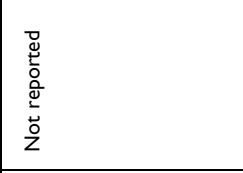 \\
\hline 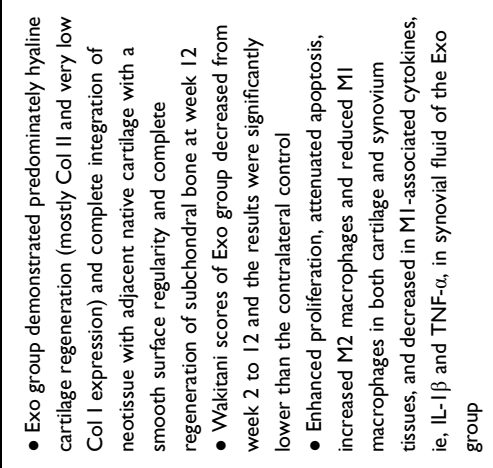 & 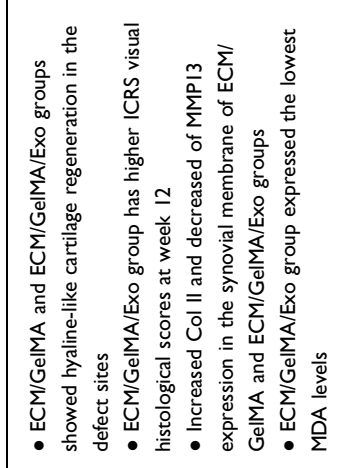 & 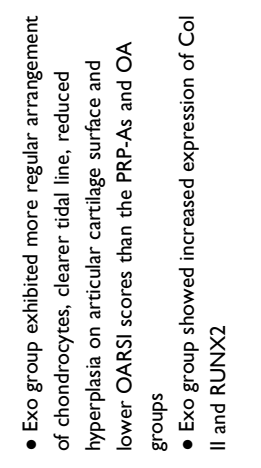 & 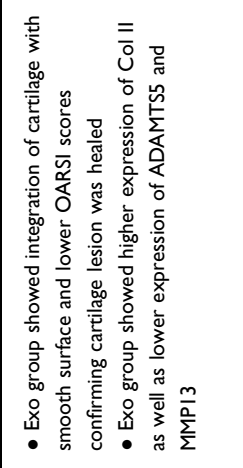 \\
\hline 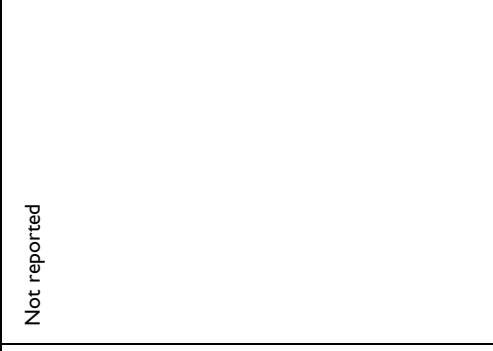 & 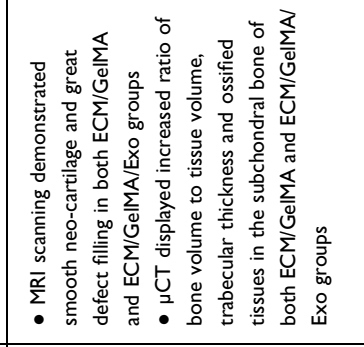 & 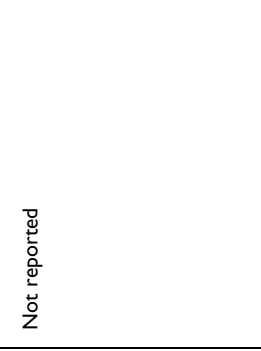 & 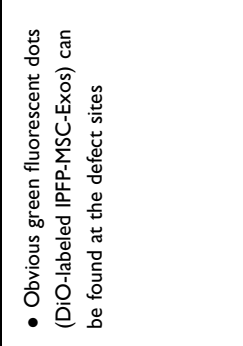 \\
\hline 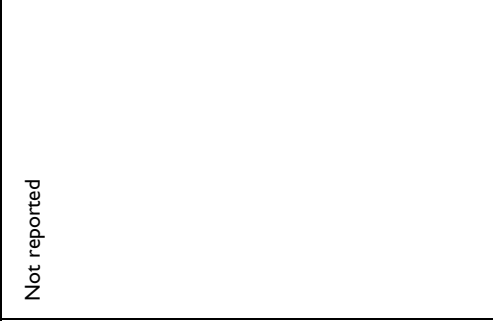 & 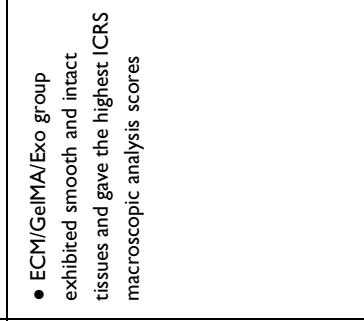 & 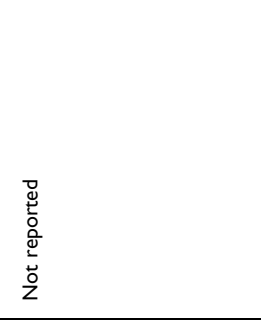 & 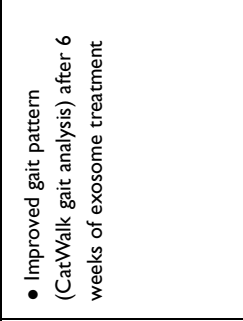 \\
\hline 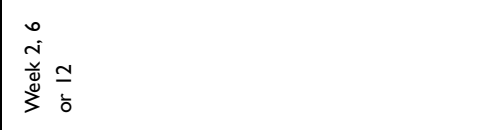 & 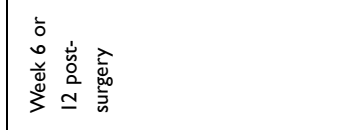 & 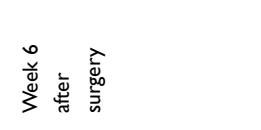 & 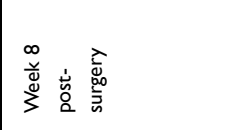 \\
\hline 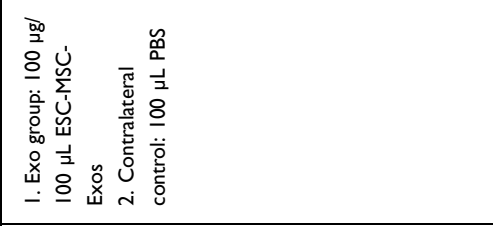 & 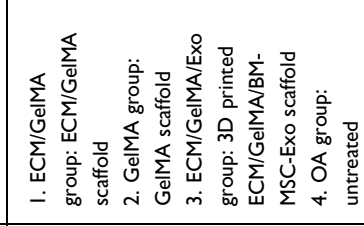 & 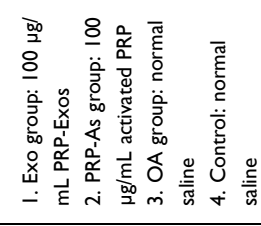 & 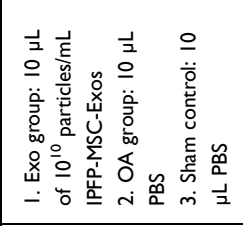 \\
\hline 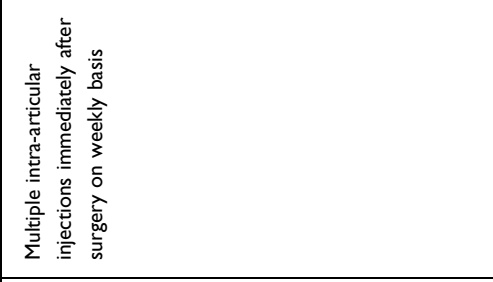 & 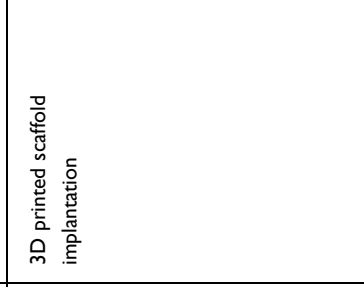 & 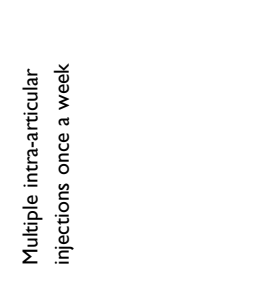 & 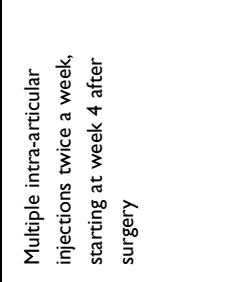 \\
\hline 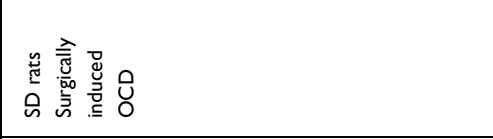 & 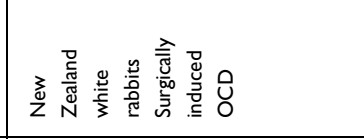 & 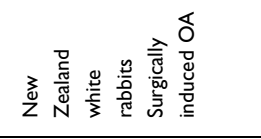 & 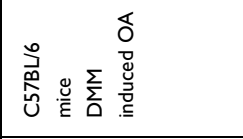 \\
\hline 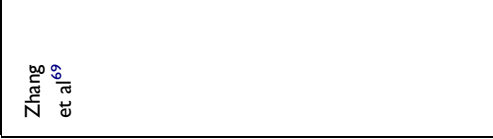 & 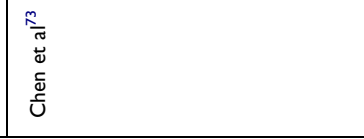 & 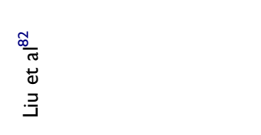 & 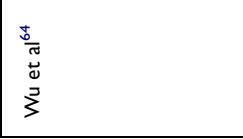 \\
\hline
\end{tabular}




\begin{tabular}{|c|c|c|c|c|}
\hline \multicolumn{2}{|c|}{ वे } & 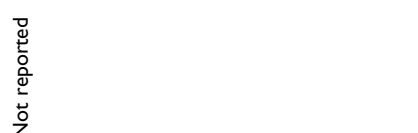 & 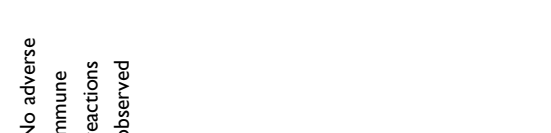 & 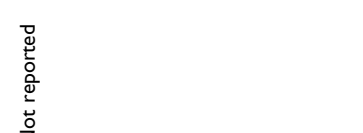 \\
\hline \multirow{3}{*}{ 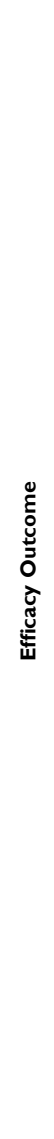 } & 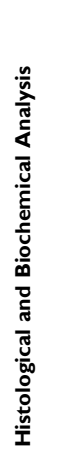 & 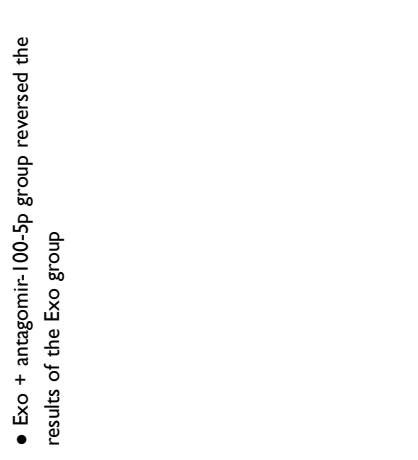 & 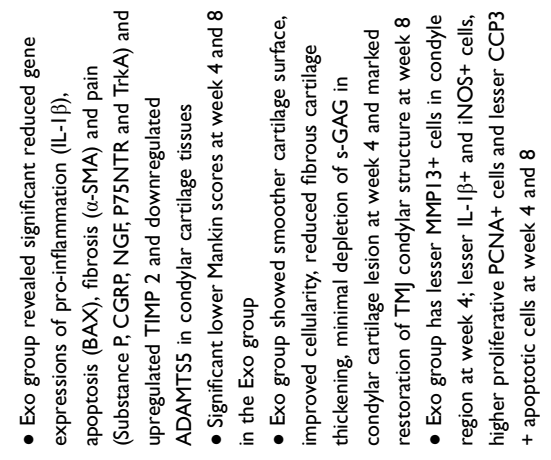 & 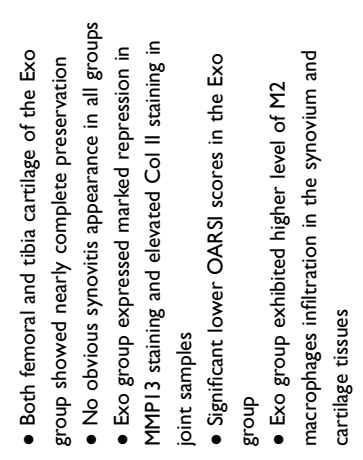 \\
\hline & 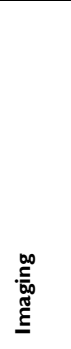 & 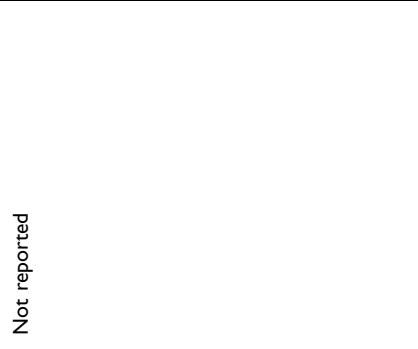 & 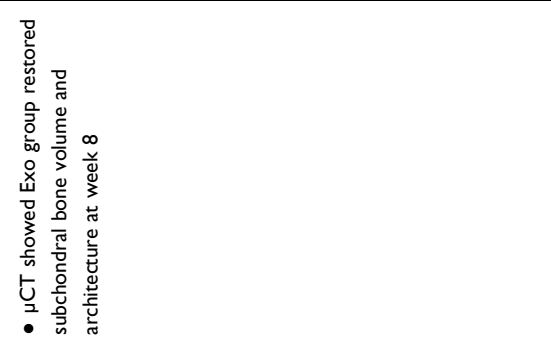 & 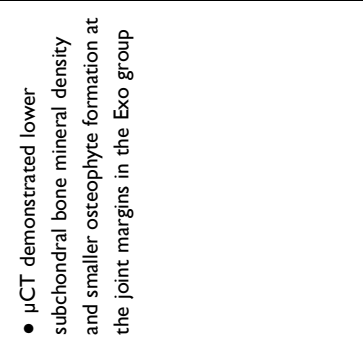 \\
\hline & 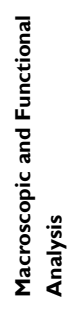 & 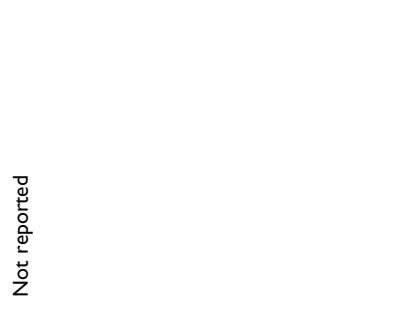 & 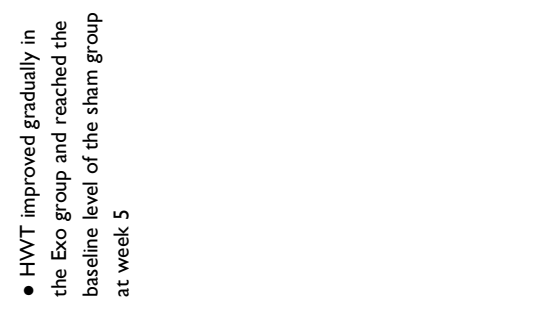 & 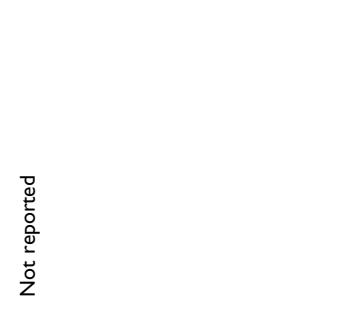 \\
\hline 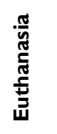 & & 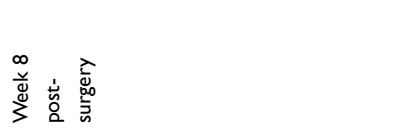 & 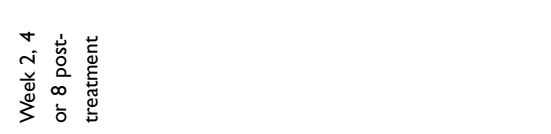 & 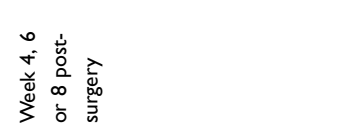 \\
\hline 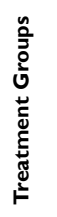 & & 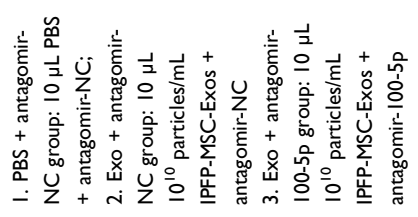 & 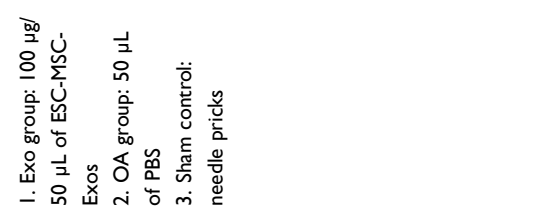 & 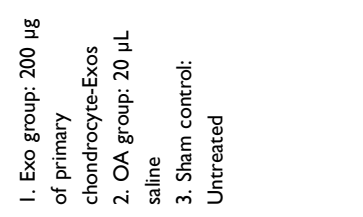 \\
\hline 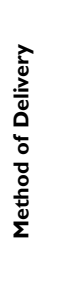 & & 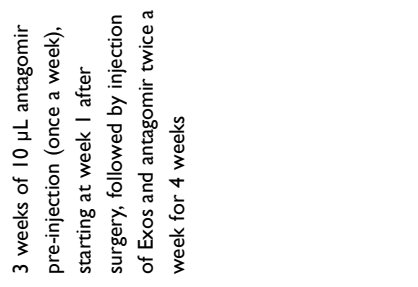 & 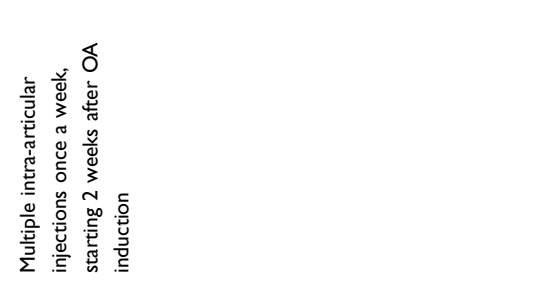 & 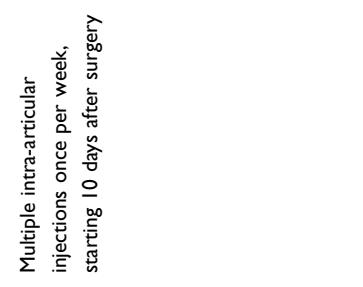 \\
\hline 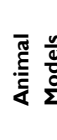 & & & 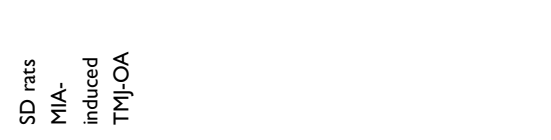 & 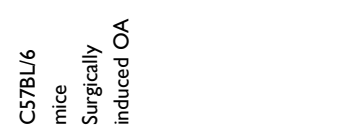 \\
\hline 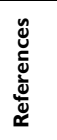 & & & 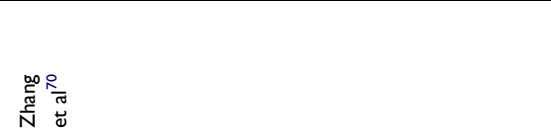 & 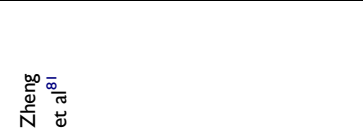 \\
\hline
\end{tabular}




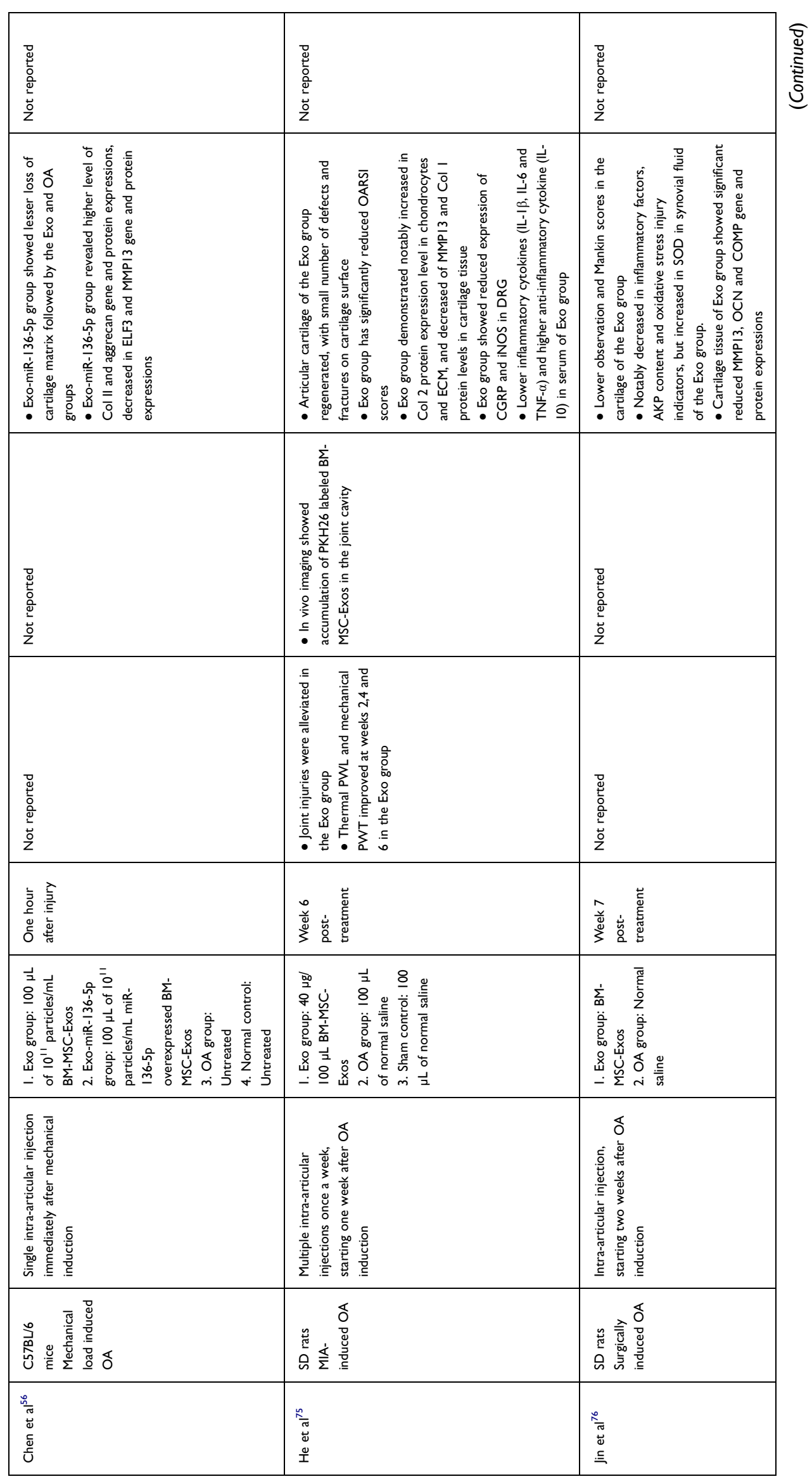




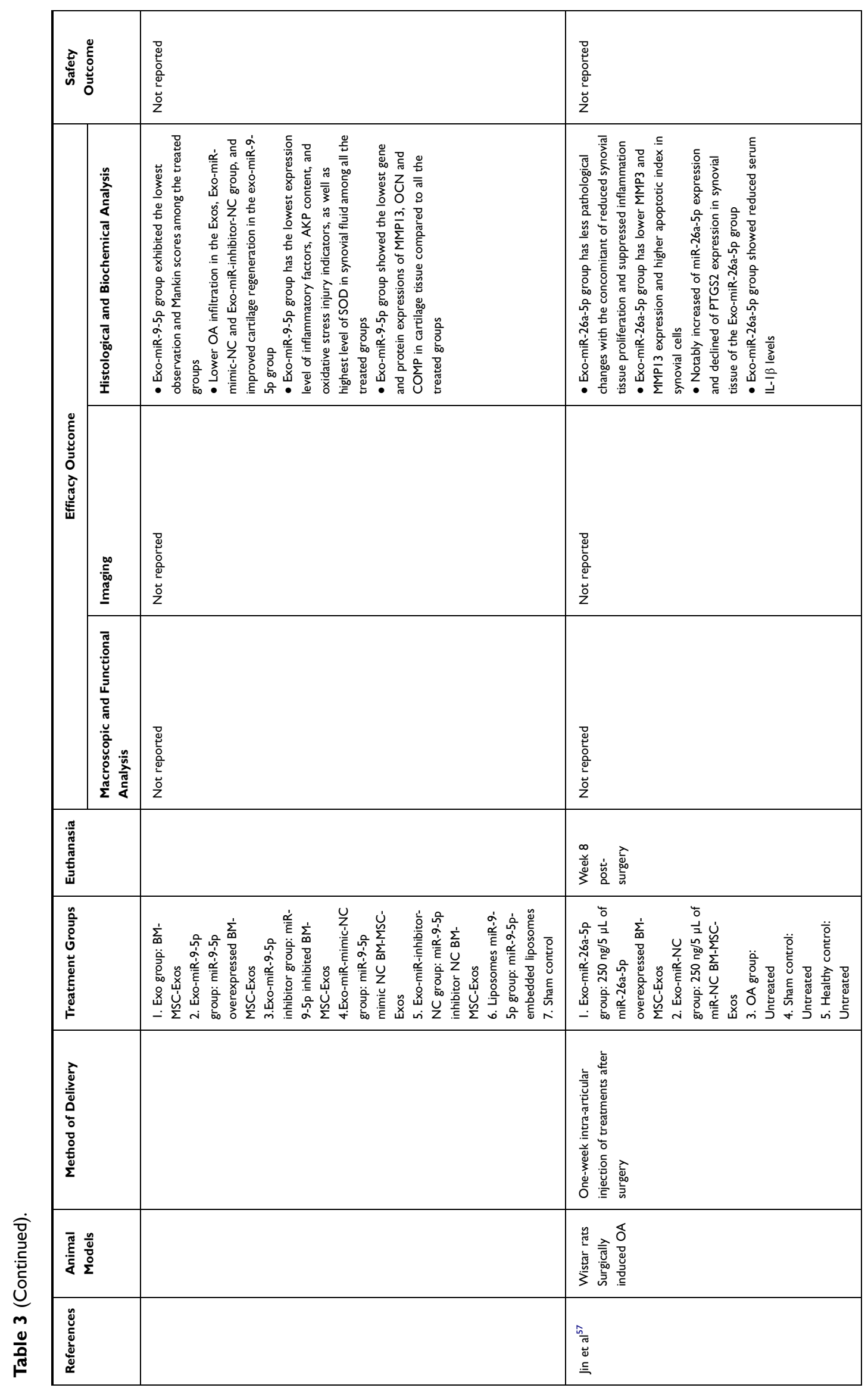




\begin{tabular}{|c|c|c|}
\hline 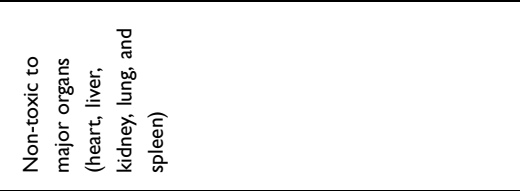 & 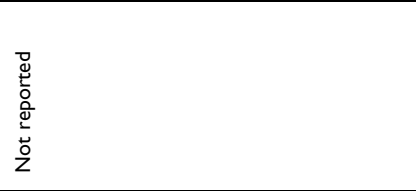 & 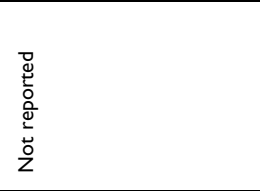 \\
\hline 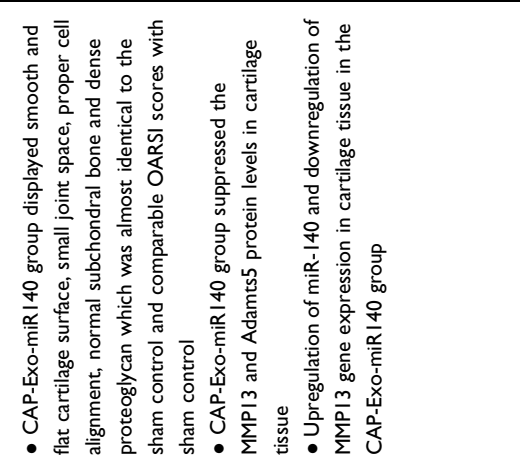 & 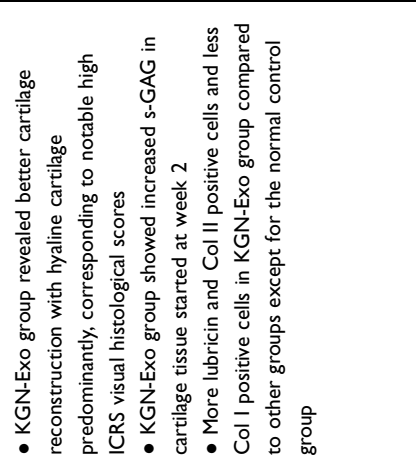 & 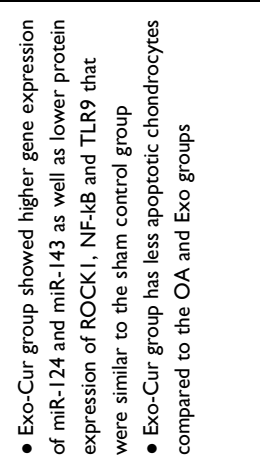 \\
\hline 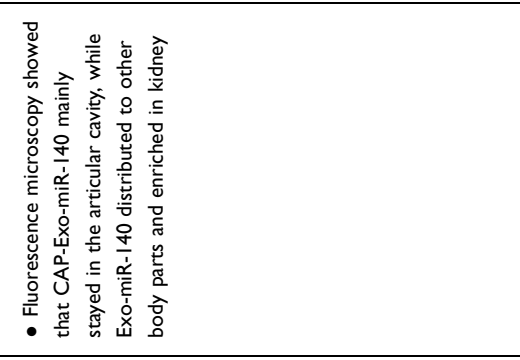 & 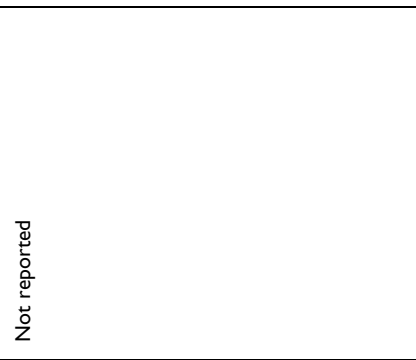 & 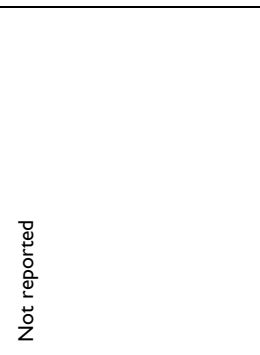 \\
\hline 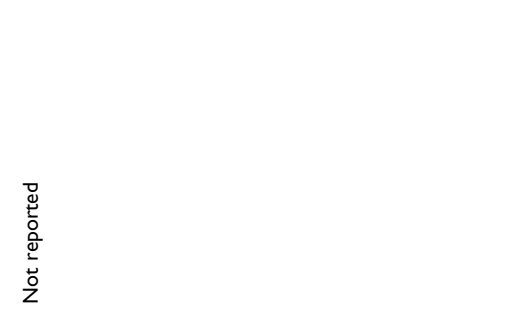 & 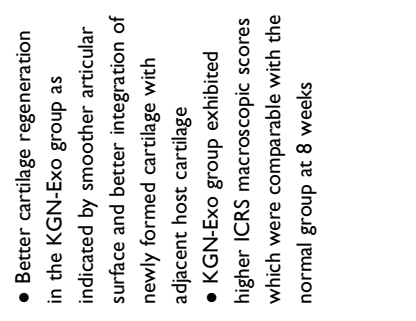 & 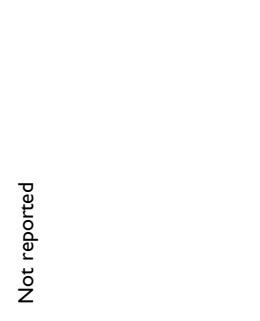 \\
\hline 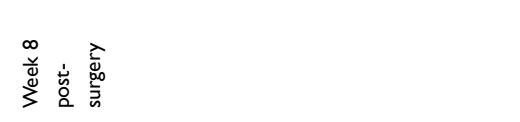 & 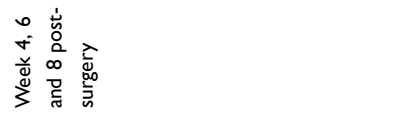 & 旁 \\
\hline 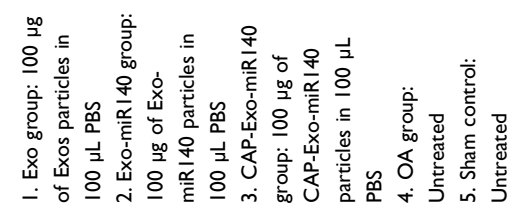 & 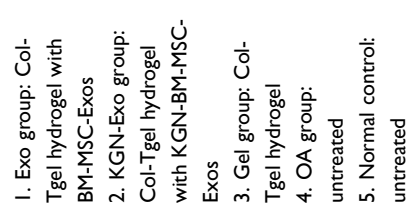 & 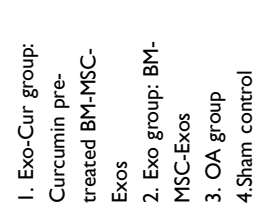 \\
\hline 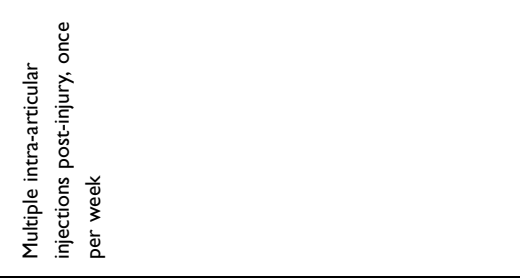 & 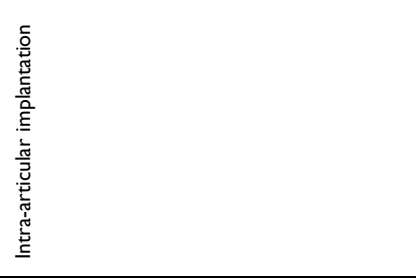 & 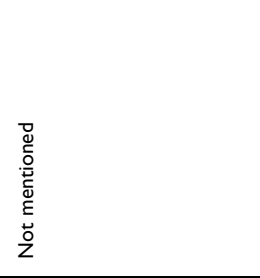 \\
\hline 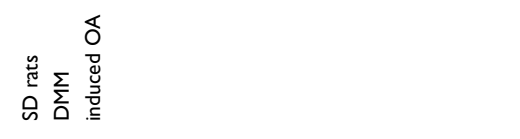 & 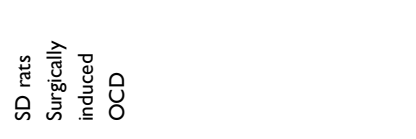 & 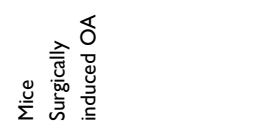 \\
\hline 长 & 总 & 总 \\
\hline
\end{tabular}




\begin{tabular}{|c|c|c|c|}
\hline ج气 & 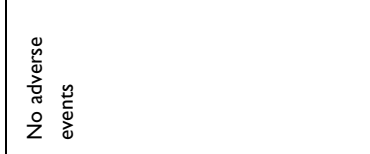 & 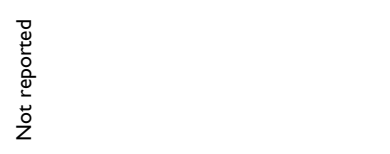 & 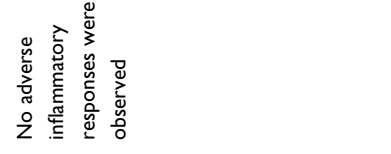 \\
\hline 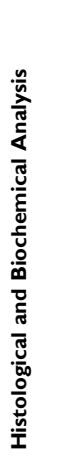 & 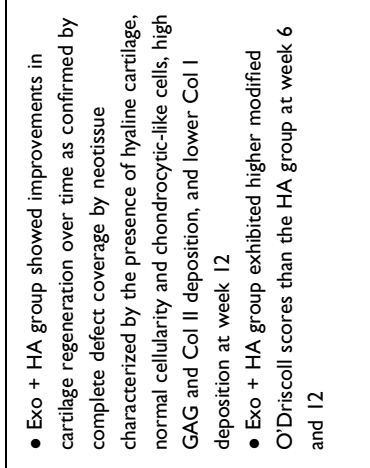 & 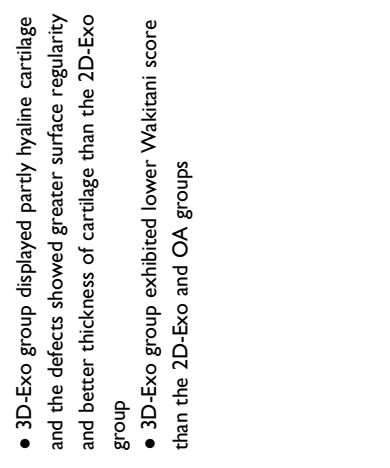 & 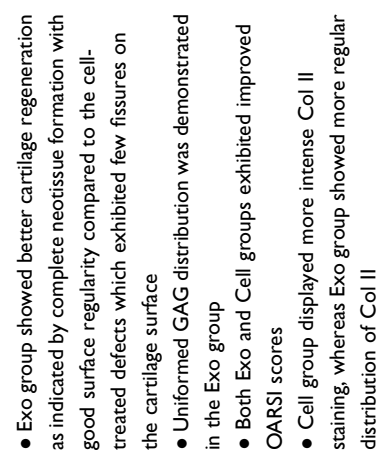 \\
\hline 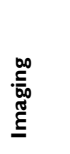 & 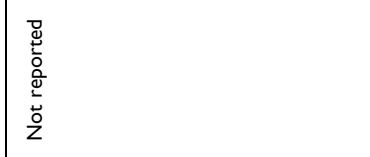 & 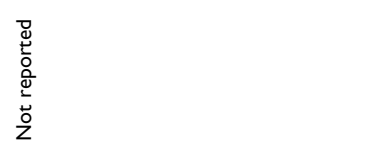 & 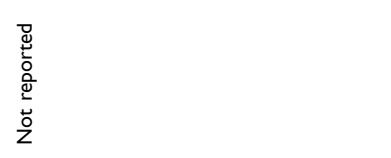 \\
\hline 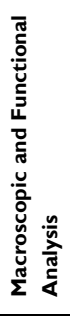 & 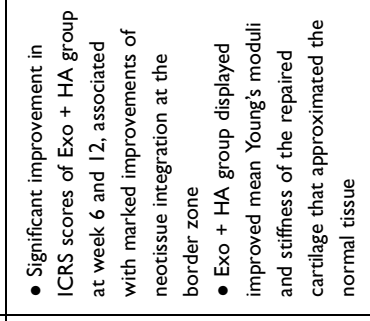 & 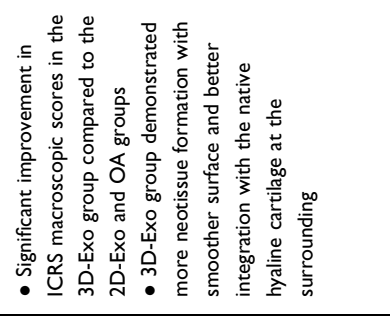 & 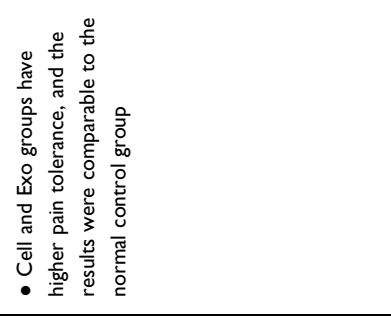 \\
\hline & 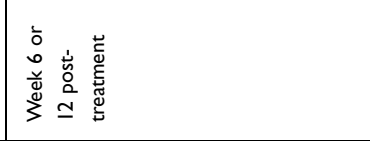 & 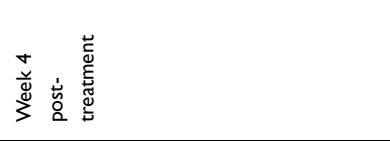 & 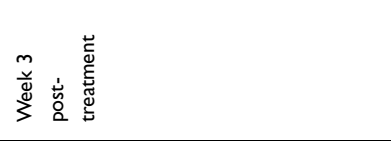 \\
\hline & 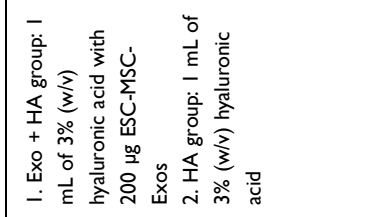 & 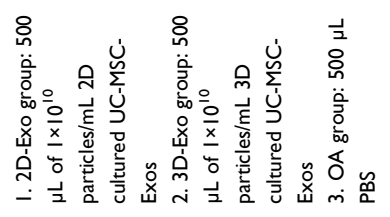 & 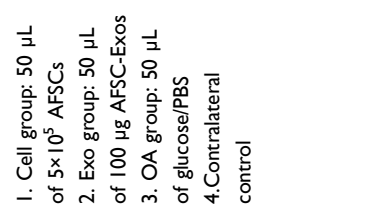 \\
\hline & 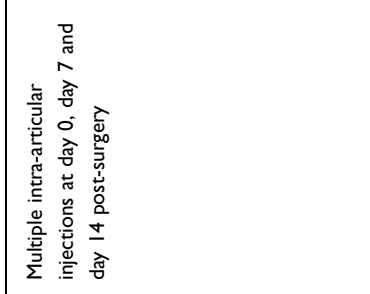 & 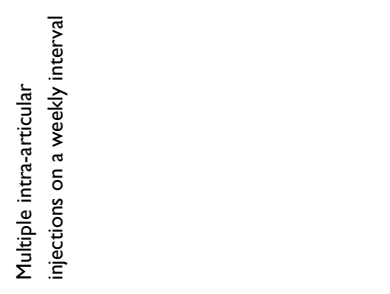 & 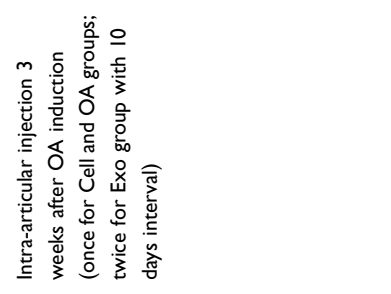 \\
\hline & 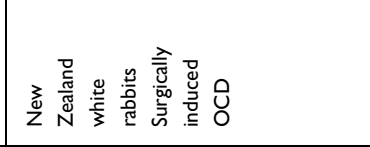 & 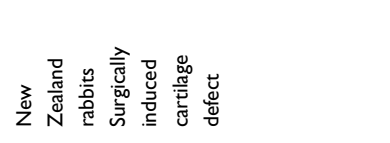 & 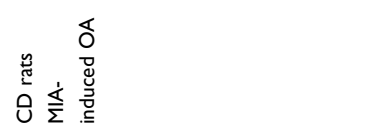 \\
\hline & 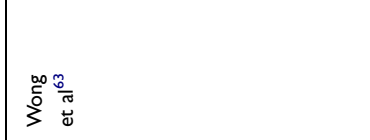 & 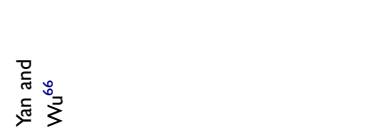 & 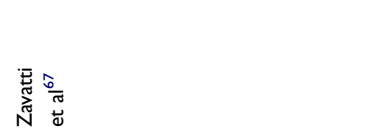 \\
\hline
\end{tabular}




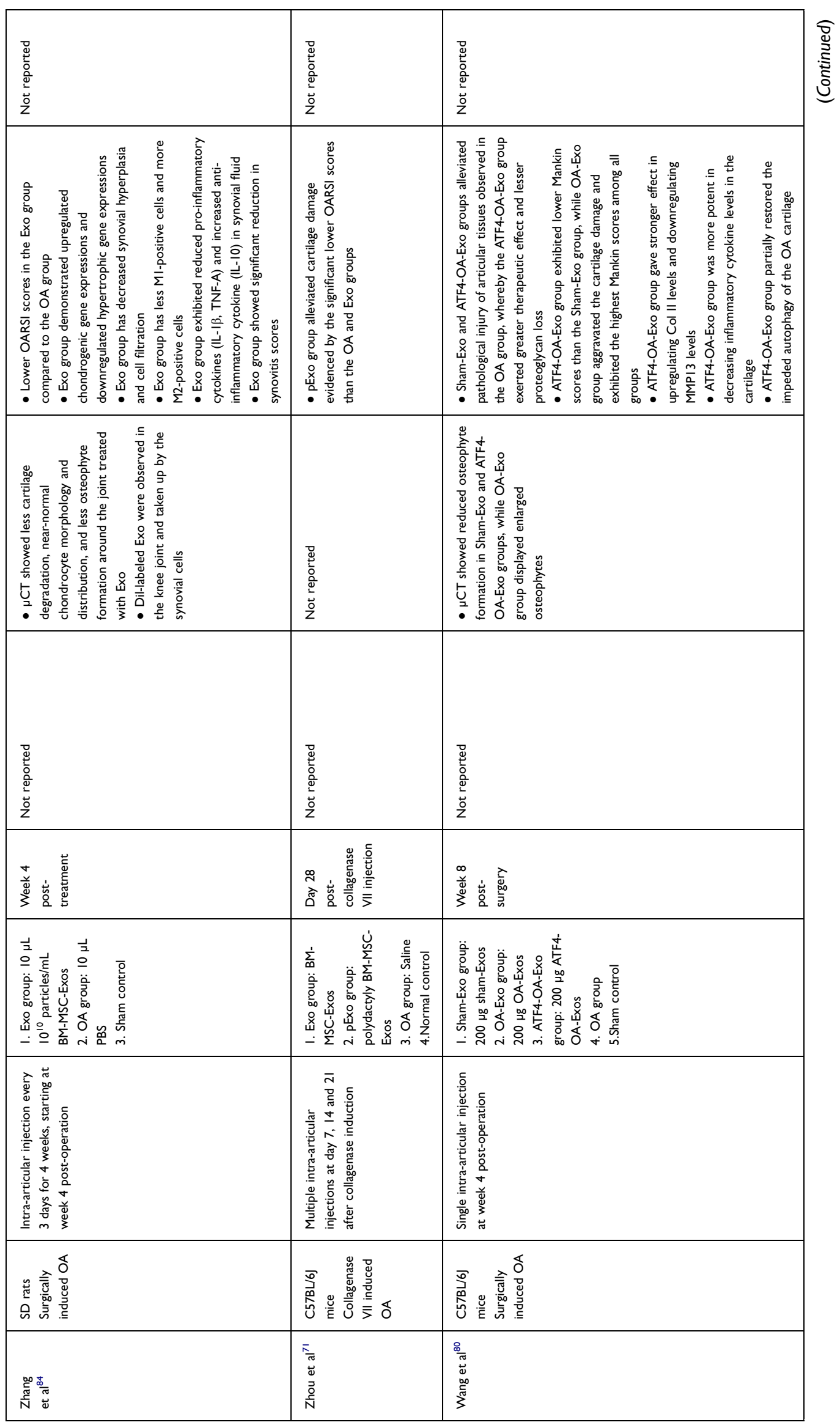




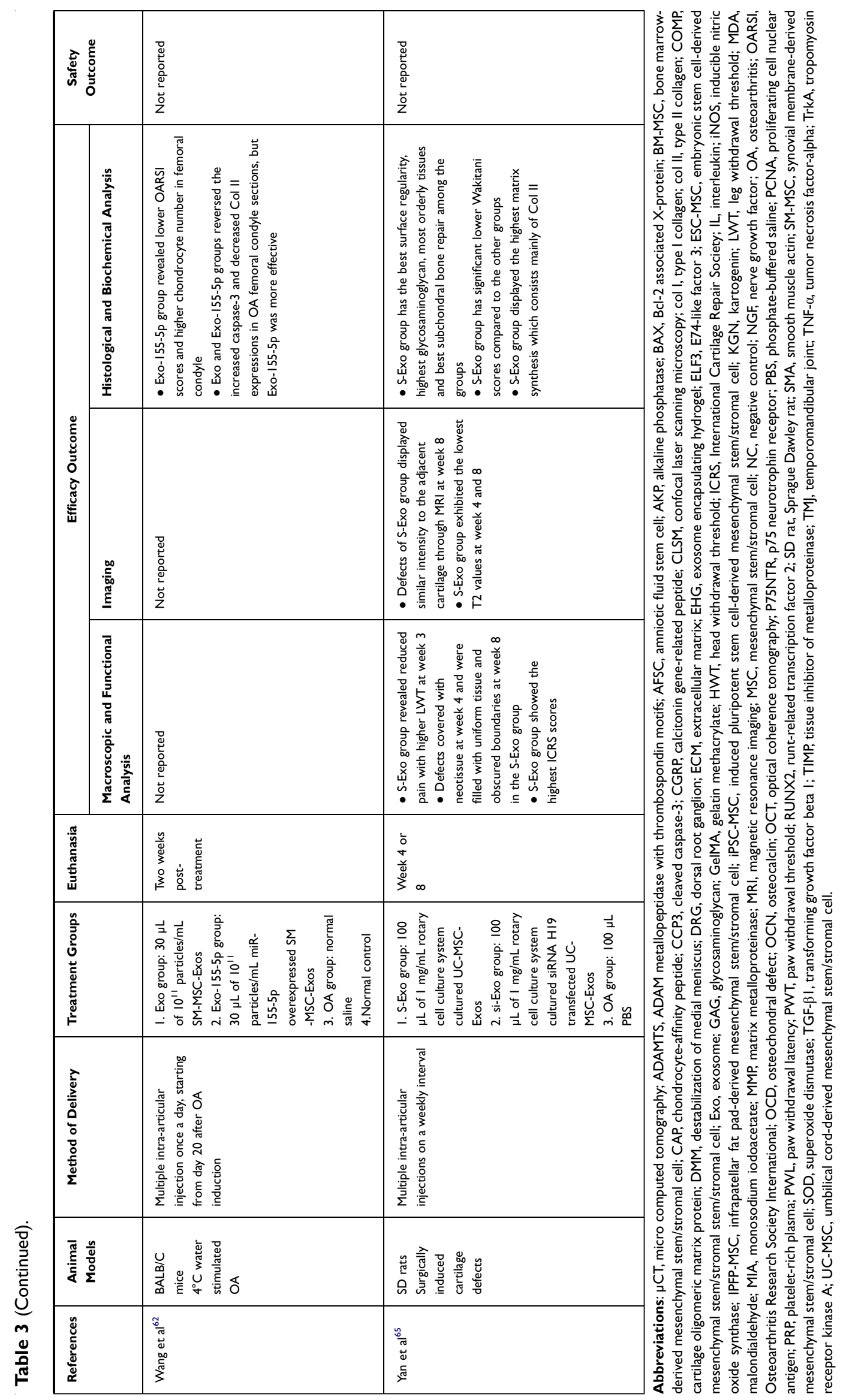



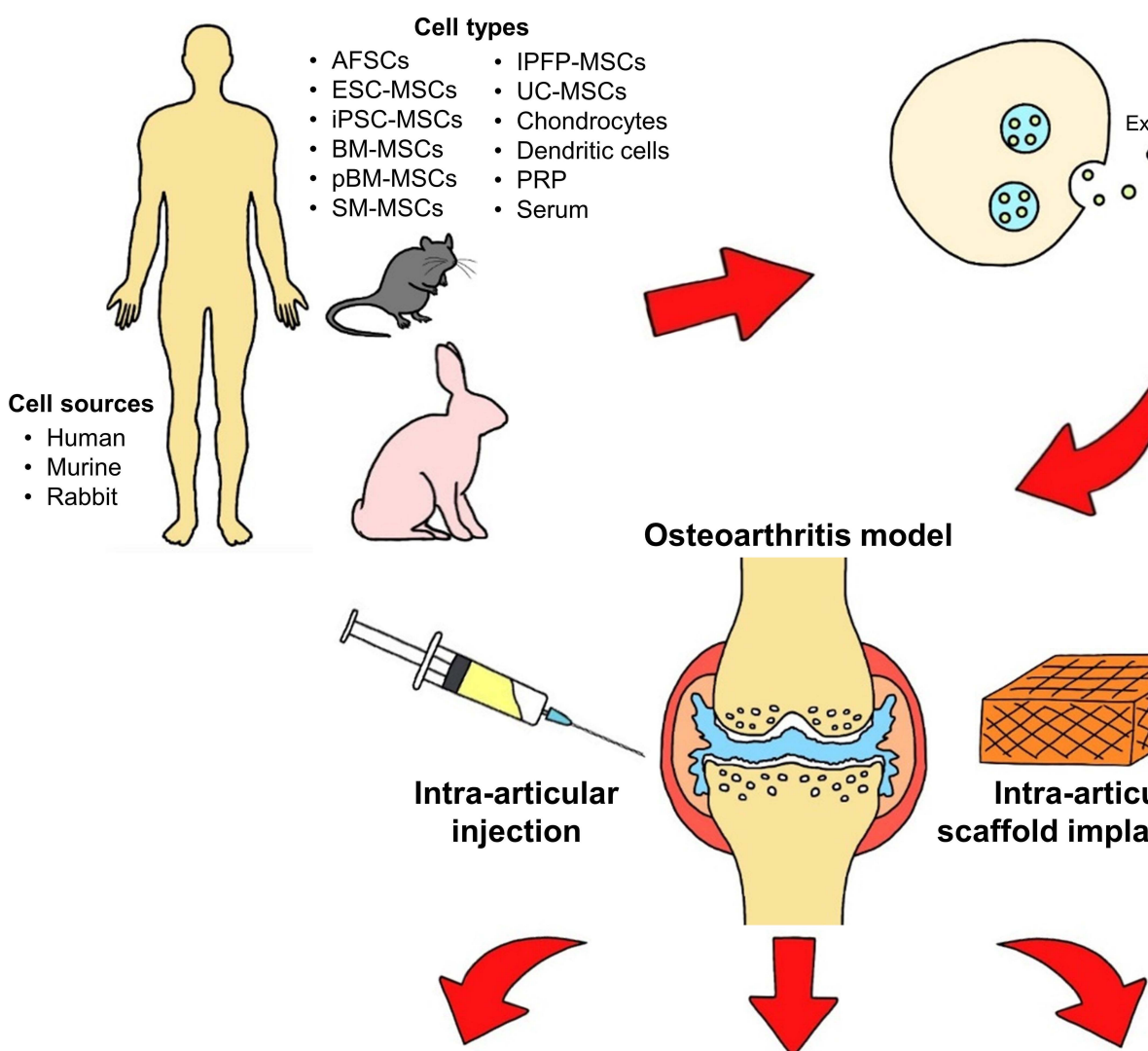

Functional analysis

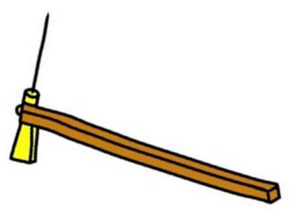

Macroscopic analysis

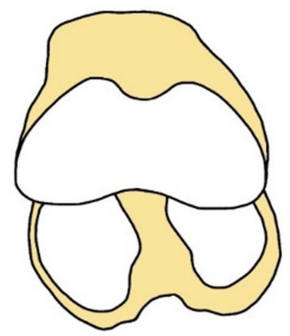

- $\uparrow$ Neotissue formation

- $\uparrow$ Macroscopic assessment

- $\downarrow$ Osteophytes

- $\uparrow$ Subchondral bone restoration

( $\uparrow$ bone volume; $\downarrow$ bone degradation)

\section{Exosome extraction}

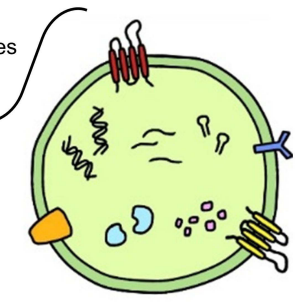

Active compounds

- miR-9-5p - miR-155-5p

- miR-26a-5p - ATF4 mRNA

- miR-92a-3p - IncRNA H19

- miR-100-5p - CD73

- miR-135b - Mitochondrial-

- miR-136-5p associated proteins

- miR-140 - Immunomodulatory

- miR-140-5p proteins
- $\uparrow \mathrm{PWL}$

- $\uparrow \mathrm{PWT} / \mathrm{HWT}$

- $\uparrow$ Mechanical strength

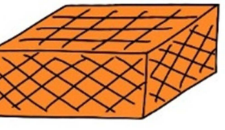

Intra-articular scaffold implantation

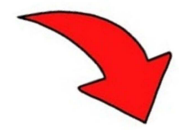

Histological and biochemical analysis

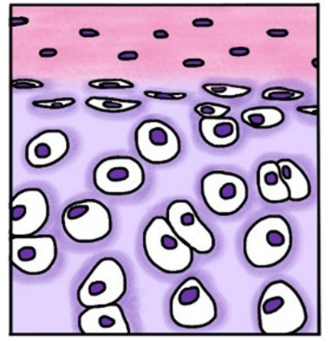

- $\uparrow$ Hyaline cartilage formation ( $\uparrow$ Col II, GAG, aggrecan; $\downarrow$ Col I, ADAMTS, MMPs)

- $\downarrow$ Matrix loss $(\downarrow$ Wnt5a)

- $\downarrow$ Cartilage degradation ( $\downarrow$ OCN, COMP, ELF3; $\uparrow$ RUNX2)

- $\uparrow$ Histological grading

- $\downarrow$ Chondrocyte apoptosis ( $\downarrow$ CCP3 + ); $\uparrow$ Chondrocyte proliferation ( $\uparrow \mathrm{PCNA}+$ ) and $\uparrow$ Chondrocyte count

- $\uparrow \mathrm{M} 2$ infiltration; $\downarrow$ M1 infiltration

- $\downarrow$ MDA level

- $\downarrow$ Neuropathic pain ( $\downarrow$ CGRP, iNOS)

- $\downarrow$ Oxidative stress and $\downarrow$ AKP content in synovial fluid

- $\downarrow$ Pro-inflammatory factors (IL-1 $1 \beta$, TNF- $\alpha$, IL-6, CRP); $\uparrow$ Anti-inflammatory factor (IL-10) in synovial fluid and serum

Figure 2 Overview of the studies. The exosomes tested in the included studies were derived from human, murine, or rabbit amniotic fluid stem cells (AFSCs), embryonic stem cell-derived mesenchymal stem/stromal cells (ESC-MSCs), induced pluripotent stem cell-derived MSCs (iPSC-MSCs), bone marrow-derived MSCs (BM-MSCs), polydactyly BM-MSCs, synovial membrane-derived MSCs (SM-MSCs), infrapatellar fat pad-derived MSCs (IPFP-MSCs), umbilical cord-derived MSCs (UC-MSCs), chondrocytes, dendritic cells, platelet-rich plasma (PRP), and serum. The exosomes were administrated to the osteoarthritic joint through intra-articular injection or scaffold implantation. The exosomal bioactive compounds played an important role in cartilage and subchondral bone repair and regeneration. Overall, exosome therapy restored joint function, reduced joint pain, and improved the joint macroscopic, histological, and biochemical features. 
articular cavity, suggesting that exosomes acted locally after intra-articular injection. Zhang et $\mathrm{al}^{84}$ noted BMMSC-derived exosomes could be taken up by synovial cells in vivo. Liang et $\mathrm{al}^{77}$ reported that dendritic cellderived exosomes were distributed to other body parts and enriched in the kidney. Exosome retention in the articular cavity was improved by fusing a chondrocyteaffinity peptide on the exosome surface. The peptide confined the exosomes to the articular cavity and facilitated exosome penetration into the middle zone of the cartilage tissue to achieve targeted delivery of exosomes to chondrocytes for better therapeutic efficacy. ${ }^{77}$ Another study reported on the improved tissue-targeting ability of modified exosomes. ${ }^{118}$

\section{Cartilage Gross Morphological and Morphometric Analysis}

Macroscopic assessment of cartilage degradation in small animals, especially mice, is technically difficult due to their small size. ${ }^{119}$ Hence, most of the included studies used rat and rabbit OA models to conduct cartilage gross morphological analysis. Eight studies graded the gross appearance of treated joints according to the International Cartilage Repair Society (ICRS) macroscopic assessment scale. ${ }^{58,63,65,66,68,72,73,78}$ Higher ICRS macroscopic assessment scores indicated morphological improvement in exosome-treated defects. Generally, the cartilage defects of the negative control group exhibited incomplete neotissue coverage, surface irregularity, and distinct border areas even at 12 weeks. On the other hand, exosome-treated cartilage defects showed much better and improved gross appearance. For example, Zhang et $\mathrm{al}^{68}$ stated that exosome-treated cartilage defects displayed almost complete neotissue filling, with good surface regularity and full integration with the surrounding cartilage at 12 weeks. Another study used confocal laser scanning microscopy (CLSM) analysis to evaluate cartilage defects, and reported improvement in articular cartilage volume and thickness, as well as lower cartilage degradation in collagenase-induced defects treated with BM-MSCs, BMMSC-derived exosomes, and BM-MSC-derived microvesicles as compared to the untreated control defects. ${ }^{74}$

Apart from gross morphological assessment, Wong et $\mathrm{al}^{63}$ also performed biomechanical assessment of regenerated cartilage tissue. The mean Young's moduli and stiffness of the repaired cartilage at the center and periphery of the defects improved significantly over time in the hyaluronic acid (HA) + ESC-MSC-derived exosome group in comparison to the HA group, suggesting that exosomes not only promote cartilage tissue morphology repair, but also contribute to functional improvement, ie better mechanical strength.

\section{Cartilage Histological Analysis}

Histological assessment is vital for determining tissue regeneration, repair, and pathological changes at the microscopic level. Various histological stains are used for identifying different cellular and tissue components. ${ }^{120}$ Hematoxylineosin (H\&E) staining is widely used for revealing cell and tissue structure, and has become a common practice in histological study. Safranin O/fast green, toluidine blue, and Alcian blue are used for examining cartilaginous and chondrogenic differentiated tissues by visualizing the proteoglycans. ${ }^{121}$ In all 29 included studies, exosome treatment contributed to notable improvements in cartilage regeneration at the histological level. The studies used multiple histological grading systems for joint repair to grade the defects, ie the OARSI, ${ }^{60-62,64,67,71,72,74,75,77,79,81,82,84}$ ICRS visual histological assessment scale, ${ }^{58,73,78}$ O'Driscoll histological cartilage repair score, ${ }^{63,68}$ Wakitani histological scoring system, ${ }^{65,66,69}$ and Mankin scoring system. ${ }^{70,76,80}$ Other than that, Jin et $\mathrm{al}^{57}$ scored the pathological changes of condylar joint and synovial tissues using a $0-3$ subjective grading system with the parameters of synovitis inflammation, synovial thickening, and subchondral bone erosion. All studies recorded improved histological scores after exosome treatment. For example, Zhang et $\mathrm{al}^{68}$ reported that ESCderived exosome-treated defects demonstrated good cartilage and subchondral bone restorations by week 6 postsurgery. Near complete regeneration and bonding of cartilage with the underlying subchondral bone, which was very similar to that of the age-matched native control, were recorded at week 12. The O'Driscoll histological cartilage repair scores were significantly higher at week 6 and 12 in the exosometreated group compared to the phosphate-buffered saline (PBS)-treated group. Similarly, Liu et $\mathrm{al}^{82}$ reported that, at week 6, articular cartilage defects treated with PRP-derived exosomes had regularly arranged chondrocytes, clearer tidal line, reduced hyperplasia, and better OARSI scores compared to defects treated with activated PRP.

Immunohistochemistry is used for detecting specific antigens in tissue sections by incubating the tissue sections with the appropriate antibody. Anabolic and catabolic markers of cartilage metabolism in regenerated tissue are identified to analyze the cartilage regeneration properties. 
Type II collagen and aggrecan, a major cartilage ECM component and a core proteoglycan of articular cartilage, respectively, are always determined for evaluating cartilage regeneration. ${ }^{122,123}$ Cartilage degradation is mostly indicated by key enzymes in cartilage matrix degradation: matrix metalloproteinases (MMPs) and ADAM metallopeptidase with thrombospondin motifs (ADAMTS). ${ }^{124}$ Generally, exosome-treated cartilage defects had upregulated type II collagen and aggrecan expression and downregulated MMP13 and ADAMTS5 expression. Wong et $\mathrm{al}^{63}$ treated surgically induced OCD with ESC-MSCderived exosomes and found that the regenerated tissue was mainly hyaline cartilage with high glycosaminoglycan (GAG) and type II collagen, as well as low type I collagen deposition. The accumulation of type I collagen is a marker of fibrocartilage formation.

Zhang et $\mathrm{al}^{69}$ reported increased proliferating cell nuclear antigen (PCNA) ${ }^{+}$cells in reparative cartilage and synovium, and decreased cleaved caspase- $3(\mathrm{CCP} 3)^{+}$ apoptotic cells on reparative cartilage, suggesting that exosomes derived from ESC-MSCs mediate cartilage repair by promoting cell proliferation and suppressing apoptosis. The research team reported similar results in a subsequent study using ESC-MSC-derived exosomes for treating temporomandibular joint $\mathrm{OA}^{70}$ Chondrocyte apoptosis may abrogate cartilage homeostasis, eventually leading to cartilage degeneration. ${ }^{125}$ Qiu et $\mathrm{al}^{83}$ and Jin et $\mathrm{al}^{57}$ used the TUNEL (terminal deoxynucleotidyl transferase dUTP nick-end labeling) assay to examine apoptosis. Qiu et $\mathrm{al}^{83}$ stated that curcumin-treated BM-MSCderived exosomes were more effective in inhibiting chondrocyte apoptosis compared to naïve BM-MSC-derived exosomes. Jin et $\mathrm{al}^{57}$ found that miR-26a-5p overexpression in BM-MSC-derived exosomes enhanced synovium fibroblast apoptosis to alleviate cartilage damage.

Furthermore, Zhang et al ${ }^{69}$ indicated that MSC-derived exosomes mediate cartilage repair by modulating the proinflammatory environment in defects, as demonstrated by the increase in $\mathrm{M} 2$ macrophages $\left(\mathrm{CD} 163^{+}\right.$cells) and reduction in $\mathrm{M} 1$ macrophages (CD86 ${ }^{+}$cells) in both cartilage and the overlying synovium in the ESC-MSC-derived exosome group, with a concomitant reduction in M1-associated cytokines, ie interleukin-1 beta (IL-1 $\beta$ ) and tumor necrosis factor-alpha (TNF- $\alpha$ ), in synovial fluid. Aside from this, exosomes induced regenerative M2 macrophage infiltration and attenuated inflammatory M1 macrophage infiltration in defect sites, evident in the higher abundance of $\mathrm{CD} 163^{+}$or arginase $-1^{+}$cells and scarcity of $\mathrm{CD} 86^{+}$, inducible nitric oxide synthase (iNOS) $)^{+}$or IL- $1 \beta^{+}$cells. ${ }^{67,70,81,84}$ The results are consistent with studies reporting that exosomes have anti-inflammatory and immunomodulatory functions for attenuating disease progression. ${ }^{126-129}$

\section{Subchondral Bone Regeneration Analysis}

OA may lead to pathophysiological changes in subchondral bone and cartilage, also known as the bone-cartilage unit, that perform complementary work in the load-bearing of joints. ${ }^{130,131}$ Microstructural alterations of subchondral bone and the osteochondral junction, including osteophytes, subchondral sclerosis, subchondral cysts, or bone marrow lesions, are observed in the different stages of OA. ${ }^{132}$ Increasing evidence has shown that subchondral bone disturbance is associated with OA initiation and progression. ${ }^{133-136}$ There is molecular crosstalk between cartilage and subchondral bone, and cartilage is partly dependent on the neighboring subchondral bone for its nutrient supply. ${ }^{137,138}$ Subchondral bone migration is involved in OCD repair. ${ }^{139}$

Among the 29 included studies, six evaluated subchondral bone regeneration. ${ }^{70,73,74,80,81,84}$ Bone parameters including bone volume (bone volume/tissue volume); bone degradation (bone surface/bone volume); osteophyte formation; meniscal or ligament calcification; and trabecular thickness, separation, and number were quantified. The six studies used micro-computed tomography $(\mu \mathrm{CT})$ to examine the joint microarchitecture and reported that exosome-treated groups showed a lower extent of osteophyte formation, whereas the groups treated with normal saline exhibited a rough joint surface with osteophytes on the bone edge. $^{70,73,74,80,81,84}$ Interestingly, osteophytes formed in the OA serum-derived exosome-treated group were impeded by the introduction of ATF4 mRNA into the OA serum-derived exosomes. ${ }^{80}$ Apart from that, Cosenza et $\mathrm{al}^{74}$ reported higher epiphyseal and subchondral bone volume, lower bone degradation, and decreased calcification of menisci and ligaments in the groups treated with BM-MSCs, BM-MSC-derived exosomes, and BM-MSCderived microvesicles. Zhang et al reported notable differences in bone volume, trabecular thickness, trabecular separation, and trabecular number at week 8 posttreatment, ${ }^{70}$ proving that ESC-MSC-derived exosomes restored subchondral bone volume and architecture in monosodium iodoacetate (MIA)-induced OA. Moreover, subchondral bone regeneration has been reported in cartilage defects treated with exosomes loaded in a scaffold. Chen et $\mathrm{al}^{73}$ reported that more ossified tissues were 
regenerated in OCD that received implantation of a 3Dprinted cartilage ECM/gelatine methacrylate (GelMA)/ BM-MSC-derived exosome scaffold.

\section{Pain Behavior Analysis}

Joint pain is the major symptom of OA. Recent studies indicate that sensory innervation in osteoarthritic subchondral bone or neuronal hypersensitivity as a result of aberrant subchondral bone remodeling during OA progression may contribute to arthritic pain. ${ }^{140,141}$ Hence, behavioral and functional assessments are important in OA evaluation. Pain cannot be measured directly in animals, but can be estimated through pain-like behaviors. ${ }^{142}$ Withdrawal response, a pain-like behavior towards a nociceptive stimulus, is the most commonly used method for examining pain in animals. ${ }^{143}$ Yan et al, ${ }^{65}$ Zhang et al, ${ }^{70}$ and $\mathrm{He}$ et al ${ }^{75}$ measured the withdrawal threshold of OA animals using the von Frey microfilament procedure, while Zavatti et al used a pressure application measurement device to do so. ${ }^{67}$ $\mathrm{He}$ et $\mathrm{al}^{75}$ also tested the paw withdrawal latency of rats treated with BM-MSC-derived exosomes using a plantar test and measured the thermal threshold. The results showed that exosome-treated OA animals have high pain tolerance levels and that the results were comparable to that of healthy control animals. Furthermore, increasing evidence supports the notion that neuropathic pain also contributes to OA pain. ${ }^{144-146} \mathrm{He}$ et $\mathrm{al}^{75}$ reported neuropathic pain in OA rats, and demonstrated that exosome injection relieved inflammatory and neuropathic pain, as shown by the decreased protein levels of calcitonin generelated peptide (CGRP) and iNOS in the dorsal root ganglion tissue.

In addition, $\mathrm{OA}$ animals may have altered gait patterns to reduce the pain from movement or loading force. ${ }^{147} \mathrm{Wu}$ et $\mathrm{al}^{64}$ performed gait analysis using the CatWalk method to measure motion-related pain in OA mice, and found that IPFP-MSC-derived exosomes ameliorated gait disturbance, indicated by the marked increase in duty cycle at week 10.

\section{Safety Profile}

Exosomes have low immunogenicity and potent immunoregulatory properties. ${ }^{148,149}$ So far, in vivo studies using single or repeated doses of exosomes have not reported severe immune reactions. ${ }^{150,151}$ Among the included studies, nine reported the safety outcome. ${ }^{60,63,67,68,70,73,77,82}$ No adverse events or inflammatory responses occurred in those studies, regardless of the cell source, ie MSC- or
non-MSC-derived exosomes, and method of administration, ie intra-articular administration in solution form or encapsulated within a scaffold. Liang et a ${ }^{77}$ demonstrated via $H \& E$ staining that dendritic cell-derived exosome injections did not cause toxicity to major organs such as the heart, kidney, lung, and spleen. Similarly, no apparent pathological effects were shown in the myocardium, liver, and kidney 1-2 weeks after 3D printed ECM/GelMA/ exosome scaffold implantation. ${ }^{73}$

The majority of the included studies used human exosomes to promote cartilage repair in animal models. No study reported adverse events related to the use of xenogeneic and allogeneic exosomes. Thus, allogeneic exosomes may be considered safe for use in humans. Nonetheless, clinical trials are needed to validate the safety of allogeneic exosomes.

\section{Cells or Exosomes?}

Previously, stem cell therapy was believed to exert its tissue repair mechanism through the replacement of injured cells. However, many studies have shown that most of the MSCs injected are trapped and cleared in the blood circulation and that only a small fraction of the transplanted cells reach the target tissues. ${ }^{152}$ Despite the low cell homing to the injured tissues, the therapeutic effect of MSCs remains significant, indicating that MSCs support tissue repair and regeneration via the secretion of paracrine factors. ${ }^{153}$

Several studies showed that exosomes have comparable therapeutic effects to cell-based therapy in managing OA. Wang et $\mathrm{al}^{61}$ reported that ESC-MSC-derived exosomes were as effective as ESC-MSCs for treating DMM (destabilization of medial meniscus)-induced OA animal models. However, the experiments were carried out sequentially, and the study compared single cell suspension injection versus multiple exosome injections. Thus, it might not be a fair comparison. According to Cosenza et $\mathrm{al}^{74}$ and Zavatti et $\mathrm{al}^{67}{ }^{67}$ cell therapy using BM-MSCs and AFSCs, respectively, promoted cartilage regeneration. However, more spectacular results were recorded when exosomes derived from these cells were used. Zavatti et $\mathrm{al}^{67}$ stated that both AFSCs and AFSC-derived exosomes improved the pain threshold of OA rats, whereby the results were comparable to that of the healthy group. However, histological and immunohistochemical analyses showed that the exosometreated group displayed better cartilage regeneration compared to the AFSC-treated group. Additionally, the lower OARSI grading scores and higher volume of cartilage tissue 
with lower fibrous connective tissue composition in the neotissue in exosome-treated defects indicated that AFSCderived exosomes were superior for repairing and regenerating cartilage tissue as compared to AFSC therapy. The AFSC-derived exosomes were also more potent for reducing osteoarthritic joint inflammation compared to AFSCs, as indicated by the presence of more M2 macrophages. Nonetheless, the OA animals received two intra-articular injections of exosomes whilst the AFSCs were only administered once, as the authors postulated that the transplanted cells may exert their therapeutic effects for a longer period, ie up to 3 weeks. Cosenza et $\mathrm{al}^{74}$ reported that single injection of BM-MSCs, BM-MSC-derived exosomes, and BM-MSC-derived microvesicles exhibited similar chondroprotective effects. Yet, exosome treatment led to greater improvement in modified Pritzker OARSI scores and reduction in osteophyte formation compared to BM-MSC and microvesicle treatments. These results suggest that exosomes might be a more effective and safer alternative to cell-based therapy for OA. Nevertheless, more studies, especially clinical trials, are needed to validate the safety and efficacy of exosome therapy.

Nowadays, many researchers advocate the transition from cell-based therapy to cell-free therapy, driven by several factors. Generally, the heterogeneity of living cells often leads to inconsistent curative effects. Longterm in vitro expansion might lead to cell dedifferentiation and senescence, thus compromising the therapeutic potential. ${ }^{154}$ Furthermore, stem cells carry the risk of mutation and tumor formation. ${ }^{155}$ Tumor formation is a hurdle to overcome for the clinical use of ESCs and iPSCs. ${ }^{156}$ Exosome therapy is a cell-free therapeutic option available for overcoming the drawbacks of cellbased therapy. Exosomes are easier to handle and store, and are less costly and less time-consuming to produce compared to cells. ${ }^{101,157}$ Furthermore, exosome dosage and potency are easier to optimize. ${ }^{37}$ Apart from that, exosomes can be developed as nanosized carriers to deliver the desired therapeutic cargo to the target cells. ${ }^{158,159}$ However, the most prominent shortcoming of exosomes is that they cannot replicate or reproduce in vivo. Coupled with their short half-life, multiple dosages might be required to achieve the desired treatment results. ${ }^{160,161}$

\section{Conclusion and Perspective}

The promising in vivo findings indicate that exosomes promote cartilage repair and regeneration, and modulate the pro-inflammatory environment, subchondral bone regeneration, and pain behavior in both OA and OCD models. More importantly, none of the included studies reported adverse events, indicating the low immunogenicity and excellent immunomodulatory property of exosomes. The modification of exosomal cargo further enhanced the therapeutic efficacy of exosomes.

On the other hand, despite many preclinical studies reporting that exosomes enhance cartilage regeneration, research on the therapeutic efficacy of exosomes for OA is still in its infancy. The exact mechanism and detailed signaling cascade mediated by exosomes in cartilage repair and regeneration are not fully understood. Hence, there should be more studies examining the mechanism of action. Moreover, exosomes demonstrate dose-dependent therapeutic efficacy in terms of promoting chondrocyte migration and proliferation, reducing chondrocyte apoptosis and pro-inflammatory markers, and restoring cartilage anabolic-catabolic marker equilibrium in vitro. However, the optimum source and dose of exosomes for OA management have not been determined in animal models. Furthermore, multiple intra-articular injections of exosomes cause pain and discomfort to the recipients and increase the risk of other complications such as inflammation, arthritis, and neuropathy. ${ }^{162}$ Encapsulating exosomes within a scaffold might reduce the number of injections needed, as it allows the controlled release of exosomes. A scaffold also provides an ECM that mimics the native cartilage tissue to facilitate regeneration. However, more studies are needed to identify a scaffold with all the desired biological and physicochemical properties that could hasten the regeneration of damaged cartilage without causing adverse events. Finally, the term "exosome" used in the studies is controversial, as the identity of exosomes cannot be confirmed through size, density, or protein markers due to the lack of specific isolation methods and characterization techniques. "Exosome" is used mostly due to perceived popularity. ${ }^{163}$ To be more precise, EVs should be defined based on their physical characteristics, biochemical composition, culture condition, and cell of origin. ${ }^{49}$

The low yield of EV production with existing harvesting methods is a challenge for clinical application. Large-scale EV production can be achieved by manipulating the culture condition, such as with a microcarrier-based 3D culture system and human platelet lysate supplementation. ${ }^{164,165}$ Batch-tobatch biological variation of $\mathrm{EV}$ therapy also cannot be ignored. To address this issue, Chen et al $^{166}$ transformed human ESC-MSCs into immortalized cells, which enabled the consistent supply of therapeutic EVs or delivery vesicles. Besides, Lian et $\mathrm{al}^{167}$ proposed a protocol for producing 
human ESC-MSCs that are reproducible and able to generate consistent batches of cells and conditioned medium on a large scale. iPSCs, iPSC-derived MSCs, and iPSC-derived MSClike mesenchymal progenitor cells could also be alternative inexhaustible EV production sources due to their unlimited proliferative potential. ${ }^{168,169}$ In addition, there is no standard protocol for ensuring exosome or EV quality.

In summary, studies examining the therapeutic efficacy of exosomes on cartilage regeneration remain limited to smallanimal models. Therefore, studies using large-animal models that are more clinically relevant should be carried out in the future to validate the safety and efficacy of EV therapy. The standardization of EV therapy is needed to achieve consistent and optimum therapeutic outcomes. More efforts are required to identify the most ideal cell source, culture condition, exosome dosage, and frequency of administration, as well as the method of administration, to achieve the best therapeutic results without causing adverse events.

\section{Abbreviations}

2D, two-dimensional; 3D, three-dimensional; ADAMTS, ADAM metallopeptidase with thrombospondin motifs; AFSC, amniotic fluid stem cell; ATF4, activating transcription factor 4; BM-MSC, bone marrow-derived mesenchymal stem/stromal cell; ECM, extracellular matrix; ELISA, enzyme-linked immunosorbent assay; ESC-MSC, embryonic stem cell-derived mesenchymal stem/stromal cell; EV, extracellular vesicle; GelMA, gelatin methacrylate; H\&E, hematoxylin-eosin; ICRS, International Cartilage Repair Society; IL-1 $\beta$, interleukin-1 beta; iNOS, inducible nitric oxide synthase; IPFP-MSC, infrapatellar fat pad-derived mesenchymal stem/stromal cell; iPSC-MSC, induced pluripotent stem cell-derived mesenchymal stem/stromal cell; IncRNA, long non-coding RNA; miR/miRNA, microRNA; MMP, matrix metalloproteinase; MRI, magnetic resonance imaging; MSC, mesenchymal stem/stromal cell; MVB, multi-vesicular bodies; OA, osteoarthritis; OARSI, Osteoarthritis Research Society International; OCD, osteochondral defect; PRP, platelet-rich plasma; RCCS, rotary cell culture system; SM-MSC, synovial membrane-derived mesenchymal stem/stromal cell; SYRCLE, Systematic Review Center for Laboratory Animal Experimentation; TGF- $\beta 1$, transforming growth factor beta 1 ; UC-MSC, umbilical cord-derived mesenchymal stem/stromal cell.

\section{Data Sharing Statement}

All data generated or analyzed during this study are included in this published article.

\section{Author Contributions}

C.Y.N. and J.Y.C. conducted the literature search, article selection, and data extraction. All authors contributed to data analysis, drafting, or revising the article, have agreed on the journal to which the article will be submitted, gave final approval of the version to be published, and agree to be accountable for all aspects of the work.

\section{Funding}

This work was supported by research grant from the Ministry of Higher Education Malaysia (FRGS/1/2020/ SKK0/UKM/02/5).

\section{Disclosure}

The authors report no conflicts of interest in this work.

\section{References}

1. Cui A, Li H, Wang D, Zhong J, Chen Y, Lu H. Global, regional prevalence, incidence and risk factors of knee osteoarthritis in population-based studies. EClinicalMedicine. 2020;29-30. doi:10.1016/j.eclinm.2020.100587

2. Mobasheri A, Batt M. An update on the pathophysiology of osteoarthritis. Ann Phys Rehabil Med. 2016;59(5-6):333-339. doi:10.1016/j.rehab.2016.07.004

3. Abramoff B, Caldera FE. Osteoarthritis: pathology, diagnosis, and treatment options. Med Clin North Am. 2020;104(2):293-311. doi:10.1016/j.mena.2019.10.007

4. Buckwalter JA, Mankin HJ. Articular cartilage: degeneration and osteoarthritis, repair, regeneration, and transplantation. Instr Course Lect. 1998;47:487-504.

5. Re'Em T, Witte F, Willbold E, Ruvinov E, Cohen S. Simultaneous regeneration of articular cartilage and subchondral bone induced by spatially presented TGF-beta and BMP-4 in a bilayer affinity binding system. Acta Biomater. 2012;8(9):32833293. doi:10.1016/j.actbio.2012.05.014

6. van Dijk CN, Reilingh ML, Zengerink M, van Bergen CJA. Osteochondral defects in the ankle: why painful? Knee Surg Sports Traumatol Arthrosc. 2010;18(5):570-580. doi:10.1007/ s00167-010-1064-x

7. Anandacoomarasamy A, Leibman S, Smith G, et al. Weight loss in obese people has structure-modifying effects on medial but not on lateral knee articular cartilage. Ann Rheum Dis. 2012;71 (1):26-32. doi:10.1136/ard.2010.144725

8. Lund $\mathrm{H}$, Weile $\mathrm{U}$, Christensen $\mathrm{R}$, et al. A randomized controlled trial of aquatic and land-based exercise in patients with knee osteoarthritis. J Rehabil Med. 2008;40(2):137-144. doi:10.2340/ 16501977-0134

9. Uthman OA, Van Der Windt DA, Jordan JL, et al. Exercise for lower limb osteoarthritis: systematic review incorporating trial sequential analysis and network meta-analysis. BMJ (Online). 2013;347(7928). doi:10.1136/bmj.f5555

10. Towheed T, Maxwell L, Judd M, Catton M, Hochberg MC, Wells GA. Acetaminophen for osteoarthritis. Cochrane Database Syst Rev. 2006;2010(1). doi:10.1002/14651858.cd004257.pub2

11. Richette P, Latourte A, Frazier A. Safety and efficacy of paracetamol and NSAIDs in osteoarthritis: which drug to recommend? Expert Opin Drug Saf. 2015;14(8):1259-1268. doi:10.1517/14740338.2015.1056776 
12. SooHoo NF, Lieberman JR, Ko CY, Zingmond DS. Factors predicting complication rates following total knee replacement. $J$ Bone Joint Surg Am. 2006;88(3):480-485. doi:10.2106/JBJS.E.00629

13. Atkinson HDE. The negatives of knee replacement surgery: complications and the dissatisfied patient. Orthop Trauma. 2017;31 (1):25-33. doi:10.1016/j.mporth.2016.09.011

14. Badekas T, Takvorian M, Souras N. Treatment principles for osteochondral lesions in foot and ankle. Int Orthop. 2013;37 (9):1697-1706. doi:10.1007/s00264-013-2076-1

15. Block TJ, Garza JR. Regenerative cells for the management of osteoarthritis and joint disorders: a concise literature review. Aesthet Surg J. 2017;37(suppl_3):S9-S15. doi:10.1093/asj/sjx015

16. Murphy JM, Fink DJ, Hunziker EB, Barry FP. Stem cell therapy in a caprine model of osteoarthritis. Arthritis Rheum. 2003;48 (12):3464-3474. doi:10.1002/art.11365

17. Desando G, Cavallo C, Sartoni F, et al. Intra-articular delivery of adipose derived stromal cells attenuates osteoarthritis progression in an experimental rabbit model. Arthritis Res Ther. 2013;15(1): R22. doi:10.1186/ar4156

18. Murata D, Kunitomi Y, Harada K, Tokunaga S, Takao S, Nakayama $\mathrm{K}$. Osteochondral regeneration using scaffold-free constructs of adipose tissue-derived mesenchymal stem cells made by a bio three-dimensional printer with a needle-array in rabbits. Regen Ther. 2020;15:77-89. doi:10.1016/j.reth.2020.05.004

19. Yamasaki A, Kunitomi Y, Murata D, et al. Osteochondral regeneration using constructs of mesenchymal stem cells made by bio three-dimensional printing in mini-pigs. J Orthop Res. 2019;37 (6):1398-1408. doi:10.1002/jor.24206

20. Lee WS, Kim HJ, Kim KI, Kim GB, Jin W. Intra-articular injection of autologous adipose tissue-derived mesenchymal stem cells for the treatment of knee osteoarthritis: a phase IIb, randomized, placebo-controlled clinical trial. Stem Cells Transl Med. 2019;8 (6):504-511. doi:10.1002/sctm.18-0122

21. Freitag J, Bates D, Wickham J, et al. Adipose-derived mesenchymal stem cell therapy in the treatment of knee osteoarthritis: a randomized controlled trial. Regen Med. 2019;14(3):213-230. doi:10.2217/rme-2018-0161

22. Freitag J, Wickham J, Shah K, Tenen A. Effect of autologous adipose-derived mesenchymal stem cell therapy in the treatment of an osteochondral lesion of the ankle. BMJ Case Rep. 2020;13 (7):e234595. doi:10.1136/bcr-2020-234595

23. Wei ZJ, Wang QQ, Cui ZG, Inadera H, Jiang X, Wu CA. Which is the most effective one in knee osteoarthritis treatment from mesenchymal stem cells obtained from different sources? - A systematic review with conventional and network meta-analyses of randomized controlled trials. Ann Transl Med. 2021;9(6):452. doi:10.21037/atm-20-5116

24. Song $\mathrm{Y}$, Zhang J, Xu H, et al. Mesenchymal stem cells in knee osteoarthritis treatment: a systematic review and meta-analysis. $J$ Orthop Transl. 2020;24:121-130. doi:10.1016/j.jot.2020.03.015

25. Lukomska B, Stanaszek L, Zuba-Surma E, Legosz P, Sarzynska $\mathrm{S}$, Drela K. Challenges and controversies in human mesenchymal stem cell therapy. Stem Cells Int. 2019;2019:e9628536. doi:10.1155/2019/9628536

26. Bonzo Di LV, Ferrero I, Cravanzola C, et al. Human mesenchymal stem cells as a two-edged sword in hepatic regenerative medicine: engraftment and hepatocyte differentiation versus profibrogenic potential. Gut. 2008;57(2):223-231. doi:10.1136/gut.2006.111617

27. Jeong JO, Han JW, Kim JM, et al. Malignant tumor formation after transplantation of short-term cultured bone marrow mesenchymal stem cells in experimental myocardial infarction and diabetic neuropathy. Circ Res. 2011;108(11):1340-1347. doi:10.1161/ CIRCRESAHA.110.239848
28. De Boeck A, Pauwels P, Hensen K, et al. Bone marrow-derived mesenchymal stem cells promote colorectal cancer progression through paracrine neuregulin 1/HER3 signalling. Gut. 2013;62 (4):550-560. doi:10.1136/gutjnl-2011-301393

29. Spaeth E, Dembinski J, Sasser A, et al. Mesenchymal stem cell transition to tumor-associated fibroblasts contributes to fibrovascular network expansion and tumor progression. PLoS One. 2009;4(4):e4992. doi:10.1371/journal.pone.0004992

30. Karnoub AE, Dash AB, Vo AP, et al. Mesenchymal stem cells within tumour stroma promote breast cancer metastasis. Nature. 2007;449(7162):557-563. doi:10.1038/nature06188

31. Kim JS, Lee JH, Kwon O, et al. Rapid deterioration of preexisting renal insufficiency after autologous mesenchymal stem cell therapy. Kidney Res Clin Pract. 2017;36(2):200-204. doi:10.23876/j. krcp.2017.36.2.200

32. Broekema M, Harmsen MC, van Luyn MJA, et al. Bone marrowderived myofibroblasts contribute to the renal interstitial myofibroblast population and produce procollagen I after ischemia/ reperfusion in rats. $J$ Am Soc Nephrol. 2007;18(1):165-175. doi:10.1681/ASN.2005070730

33. Aslam M, Baveja R, Liang OD, et al. Bone marrow stromal cells attenuate lung injury in a murine model of neonatal chronic lung disease. Am J Respir Crit Care Med. 2009;180(11):1122-1130. doi:10.1164/rccm.200902-0242OC

34. Timmers L, Lim SK, Arslan F, et al. Reduction of myocardial infarct size by human mesenchymal stem cell conditioned medium. Stem Cell Res. 2007;1(2):129-137. doi:10.1016/j. scr.2008.02.002

35. Goolaerts A, Pellan-Randrianarison N, Larghero J, et al. Conditioned media from mesenchymal stromal cells restore sodium transport and preserve epithelial permeability in an in vitro model of acute alveolar injury. Am J Physiol Lung Cell Mol Physiol. 2014;306(11):L975-L985. doi:10.1152/ ajplung.00242.2013

36. Liang X, Ding Y, Zhang Y, Tse HF, Lian Q. Paracrine mechanisms of mesenchymal stem cell-based therapy: current status and perspectives. Cell Transplant. 2014;23(9):1045-1059. doi:10.3727/096368913X667709

37. Bjørge IM, Kim SY, Mano JF, Kalionis B, Chrzanowski W. Extracellular vesicles, exosomes and shedding vesicles in regenerative medicine - a new paradigm for tissue repair. Biomater Sci. 2017;6(1):60-78. doi:10.1039/c7bm00479f

38. Zhao AG, Shah K, Cromer B, Sumer H. Mesenchymal stem cellderived extracellular vesicles and their therapeutic potential. Stem Cells Int. 2020;2020:e8825771. doi:10.1155/2020/8825771

39. Maas SLN, Breakefield XO, Weaver AM. Extracellular vesicles: unique intercellular delivery vehicles. Trends Cell Biol. 2017;27 (3):172-188. doi:10.1016/j.tcb.2016.11.003

40. Lai RC, Arslan F, Lee MM, et al. Exosome secreted by MSC reduces myocardial ischemia/reperfusion injury. Stem Cell Res. 2010;4(3):214-222. doi:10.1016/j.scr.2009.12.003

41. Colombo M, Raposo G, Théry C. Biogenesis, secretion, and intercellular interactions of exosomes and other extracellular vesicles. Annu Rev Cell Dev Biol. 2014;30(1):255-289. doi:10.1146/ annurev-cellbio-101512-122326

42. Lo Cicero A, Stahl PD, Raposo G. Extracellular vesicles shuffling intercellular messages: for good or for bad. Curr Opin Cell Biol. 2015;35:69-77. doi:10.1016/j.ceb.2015.04.013

43. Teng X, Chen L, Chen W, Yang J, Yang Z, Shen Z. Mesenchymal stem cell-derived exosomes improve the microenvironment of infarcted myocardium contributing to angiogenesis and antiinflammation. Cell Physiol Biochem. 2015;37(6):2415-2424. doi:10.1159/000438594 
44. Li T, Yan Y, Wang B, et al. Exosomes derived from human umbilical cord mesenchymal stem cells alleviate liver fibrosis. Stem Cells Dev. 2013;22(6):845-854. doi:10.1089/scd.2012.0395

45. Zhang J, Guan J, Niu X, et al. Exosomes released from human induced pluripotent stem cells-derived MSCs facilitate cutaneous wound healing by promoting collagen synthesis and angiogenesis. $J$ Transl Med. 2015;13(1):49. doi:10.1186/s12967-015-0417-0

46. Ni Z, Zhou S, Li S, et al. Exosomes: roles and therapeutic potential in osteoarthritis. Bone Res. 2020;8:25. doi:10.1038/ s41413-020-0100-9

47. Toh WS, Lai RC, Hui JHP, Lim SK. MSC exosome as a cell-free MSC therapy for cartilage regeneration: implications for osteoarthritis treatment. Semin Cell Dev Biol. 2017;67:56-64. doi:10.1016/j.semcdb.2016.11.008

48. Kim YG, Park U, Park BJ, Kim K. Exosome-mediated bidirectional signaling between mesenchymal stem cells and chondrocytes for enhanced chondrogenesis. Biotechnol Bioprocess Eng. 2019;24(5):734-744. doi:10.1007/s12257-019-0332-y

49. Théry C, Witwer KW, Aikawa E, et al. Minimal information for studies of extracellular vesicles 2018 (MISEV2018): a position statement of the international society for extracellular vesicles and update of the MISEV2014 guidelines. J Extracell Vesicles. 2018;7 (1):1535750. doi:10.1080/20013078.2018.1535750

50. Yáñez-Mó M, Siljander PRM, Andreu Z, et al. Biological properties of extracellular vesicles and their physiological functions. $J$ Extracell Vesicles. 2015;4(1):27066. doi:10.3402/jev.v4.27066

51. Willms E, Cabañas C, Mäger I, Wood MJA, Vader P. Extracellular vesicle heterogeneity: subpopulations, isolation techniques, and diverse functions in cancer progression. Front Immunol. 2018;9:738. doi:10.3389/fimmu.2018.00738

52. Zhang B, Tian X, Qu Z, Liu J, Yang L, Zhang W. Efficacy of extracellular vesicles from mesenchymal stem cells on osteoarthritis in animal models: a systematic review and meta-analysis. Nanomedicine (Lond). 2021;16(15):1297-1310. doi:10.2217/ nnm-2021-0047

53. Tan SSH, Tjio CKE, Wong JRY, et al. Mesenchymal stem cell exosomes for cartilage regeneration: a systematic review of preclinical in vivo studies. Tissue Eng Part B Rev. 2021;27(1):1-13. doi:10.1089/ten.TEB.2019.0326

54. To K, Romain K, Mak C, Kamaraj A, Henson F, Khan W. The treatment of cartilage damage using human mesenchymal stem cell-derived extracellular vesicles: a systematic review of in vivo studies. Front Bioeng Biotechnol. 2020;8:580. doi:10.3389/ fbioe. 2020.00580

55. Hooijmans CR, Rovers MM, de Vries RBM, Leenaars M, Ritskes-Hoitinga M, Langendam MW. SYRCLE's risk of bias tool for animal studies. BMC Med Res Methodol. 2014;14(1):43. doi:10.1186/1471-2288-14-43

56. Chen X, Shi Y, Xue P, Ma X, Li J, Zhang J. Mesenchymal stem cell-derived exosomal microRNA-136-5p inhibits chondrocyte degeneration in traumatic osteoarthritis by targeting ELF3. Arthritis Res Ther. 2020;22(1):256. doi:10.1186/s13075-02002325-6

57. Jin Z, Ren J, Qi S. Human bone mesenchymal stem cells-derived exosomes overexpressing microRNA-26a-5p alleviate osteoarthritis via down-regulation of PTGS2. Int Immunopharmacol. 2020;78:105946. doi:10.1016/j.intimp.2019.105946

58. Liu X, Yang Y, Li Y, et al. Integration of stem cell-derived exosomes with in situ hydrogel glue as a promising tissue patch for articular cartilage regeneration. Nanoscale. 2017;9(13):44304438. doi:10.1039/c7nr00352h

59. Mao G, Zhang Z, Hu S, et al. Exosomes derived from miR-92a$3 p$-overexpressing human mesenchymal stem cells enhance chondrogenesis and suppress cartilage degradation via targeting WNT5A. Stem Cell Res Ther. 2018;9(1):247. doi:10.1186/ s13287-018-1004-0
60. Tao SC, Yuan T, Zhang YL, Yin WJ, Guo SC, Zhang CQ. Exosomes derived from miR-140-5p-overexpressing human synovial mesenchymal stem cells enhance cartilage tissue regeneration and prevent osteoarthritis of the knee in a rat model. Theranostics. 2017;7(1):180-195. doi:10.7150/thno.17133

61. Wang Y, Yu D, Liu Z, et al. Exosomes from embryonic mesenchymal stem cells alleviate osteoarthritis through balancing synthesis and degradation of cartilage extracellular matrix. Stem Cell Res Ther. 2017;8(1):189. doi:10.1186/s13287-017-0632-0

62. Wang Z, Yan K, Ge G, et al. Exosomes derived from miR-155$5 \mathrm{p}$-overexpressing synovial mesenchymal stem cells prevent osteoarthritis via enhancing proliferation and migration, attenuating apoptosis, and modulating extracellular matrix secretion in chondrocytes. Cell Biol Toxicol. 2021;37(1):85-96. doi:10.1007/ s10565-020-09559-9

63. Wong KL, Zhang S, Wang M, et al. Intra-articular injections of mesenchymal stem cell exosomes and hyaluronic acid improve structural and mechanical properties of repaired cartilage in a rabbit model. Arthroscopy. 2020;36(8):2215-2228.e2. doi:10.1016/j.arthro.2020.03.031

64. Wu J, Kuang L, Chen C, et al. MiR-100-5p-abundant exosomes derived from infrapatellar fat pad MSCs protect articular cartilage and ameliorate gait abnormalities via inhibition of mTOR in osteoarthritis. Biomaterials. 2019;206:87-100. doi:10.1016/j. biomaterials.2019.03.022

65. Yan L, Liu G, Wu X. Exosomes derived from umbilical cord mesenchymal stem cells in mechanical environment show improved osteochondral activity via upregulation of LncRNA H19. J Orthop Transl. 2021;26:111-120. doi:10.1016/j. jot.2020.03.005

66. Yan L, Wu X. Exosomes produced from 3D cultures of umbilical cord mesenchymal stem cells in a hollow-fiber bioreactor show improved osteochondral regeneration activity. Cell Biol Toxicol. 2020;36(2):165-178. doi:10.1007/s10565-019-09504-5

67. Zavatti M, Beretti F, Casciaro F, Bertucci E, Maraldi T. Comparison of the therapeutic effect of amniotic fluid stem cells and their exosomes on monoiodoacetate-induced animal model of osteoarthritis. BioFactors. 2020;46(1):106-117. doi:10.1002/ biof. 1576

68. Zhang S, Chu WC, Lai RC, Lim SK, Hui JHP, Toh WS. Exosomes derived from human embryonic mesenchymal stem cells promote osteochondral regeneration. Osteoarthritis Cartilage. 2016;24 (12):2135-2140. doi:10.1016/j.joca.2016.06.022

69. Zhang S, Chuah SJ, Lai RC, Hui JHP, Lim SK, Toh WS. MSC exosomes mediate cartilage repair by enhancing proliferation, attenuating apoptosis and modulating immune reactivity. Biomaterials. 2018;156:16-27. doi:10.1016/j.biomaterials.201 7.11.028

70. Zhang S, Teo KYW, Chuah SJ, Lai RC, Lim SK, Toh WS. MSC exosomes alleviate temporomandibular joint osteoarthritis by attenuating inflammation and restoring matrix homeostasis. Biomaterials. 2019;200:35-47. doi:10.1016/j.biomaterials.201 9.02.006

71. Zhou X, Liang $\mathrm{H}, \mathrm{Hu} \mathrm{X}$, et al. BMSC-derived exosomes from congenital polydactyly tissue alleviate osteoarthritis by promoting chondrocyte proliferation. Cell Death Discov. 2020;6(1):142. doi:10.1038/s41420-020-00374-Z

72. Zhu Y, Wang Y, Zhao B, et al. Comparison of exosomes secreted by induced pluripotent stem cell-derived mesenchymal stem cells and synovial membrane-derived mesenchymal stem cells for the treatment of osteoarthritis. Stem Cell Res Ther. 2017;8(1):64. doi:10.1186/s13287-017-0510-9

73. Chen P, Zheng L, Wang Y, et al. Desktop-stereolithography 3D printing of a radially oriented extracellular matrix/mesenchymal stem cell exosome bioink for osteochondral defect regeneration. Theranostics. 2019;9(9):2439-2459. doi:10.7150/thno.31017 
74. Cosenza S, Ruiz M, Toupet K, Jorgensen C, Noël D. Mesenchymal stem cells derived exosomes and microparticles protect cartilage and bone from degradation in osteoarthritis. $\mathrm{Sci}$ Rep. 2017;7(1):16214. doi:10.1038/s41598-017-15376-8

75. He L, He T, Xing J, et al. Bone marrow mesenchymal stem cellderived exosomes protect cartilage damage and relieve knee osteoarthritis pain in a rat model of osteoarthritis. Stem Cell Res Ther. 2020;11(1):276. doi:10.1186/s13287-020-01781-w

76. Jin Z, Ren J, Qi S. Exosomal miR-9-5p secreted by bone marrowderived mesenchymal stem cells alleviates osteoarthritis by inhibiting syndecan-1. Cell Tissue Res. 2020;381(1):99-114. doi:10.1007/s00441-020-03193-X

77. Liang $\mathrm{Y}, \mathrm{Xu} \mathrm{X}, \mathrm{Li} \mathrm{X}$, et al. Chondrocyte-targeted microRNA delivery by engineered exosomes toward a cell-free osteoarthritis therapy. ACS Appl Mater Interfaces. 2020;12(33):36938-36947. doi:10.1021/acsami.0c10458

78. Liu C, Li Y, Yang Z, Zhou Z, Lou Z, Zhang Q. Kartogenin enhances the therapeutic effect of bone marrow mesenchymal stem cells derived exosomes in cartilage repair. Nanomedicine (Lond). 2020;15(3):273-288. doi:10.2217/nnm-2019-0208

79. Wang $\mathrm{R}, \mathrm{Xu} \mathrm{B}, \mathrm{Xu} \mathrm{H}$. TGF- $\beta 1$ promoted chondrocyte proliferation by regulating $\mathrm{Sp} 1$ through $\mathrm{MSC}$-exosomes derived miR135b. Cell Cycle. 2018;17(24):2756-2765. doi:10.1080/ 15384101.2018.1556063

80. Wang Y, He SH, Liang X, Zhang XX, Li S-S, Li TF. ATF4modified serum exosomes derived from osteoarthritic mice inhibit osteoarthritis by inducing autophagy. IUBMB Life. 2021;73 (1):146-158. doi:10.1002/iub.2414

81. Zheng L, Wang Y, Qiu P, et al. Primary chondrocyte exosomes mediate osteoarthritis progression by regulating mitochondrion and immune reactivity. Nanomedicine (Lond). 2019;14 (24):3193-3212. doi:10.2217/nnm-2018-0498

82. Liu X, Wang L, Ma C, Wang G, Zhang Y, Sun S. Exosomes derived from platelet-rich plasma present a novel potential in alleviating knee osteoarthritis by promoting proliferation and inhibiting apoptosis of chondrocyte via Wnt/ $\beta$-catenin signaling pathway. J Orthop Surg Res. 2019;14(1):470. doi:10.1186/s13018-019-1529-7

83. Qiu B, Xu X, Yi P, Hao Y. Curcumin reinforces MSC-derived exosomes in attenuating osteoarthritis via modulating the miR-124/ NF-kB and miR-143/ROCK1/TLR9 signalling pathways. J Cell Mol Med. 2020;24(18):10855-10865. doi:10.1111/jcmm.15714

84. Zhang J, Rong Y, Luo C, Cui W. Bone marrow mesenchymal stem cell-derived exosomes prevent osteoarthritis by regulating synovial macrophage polarization. Aging (Albany NY). 2020;12 (24):25138-25152. doi:10.18632/aging.104110

85. Cai J, Wu J, Wang J, et al. Extracellular vesicles derived from different sources of mesenchymal stem cells: therapeutic effects and translational potential. Cell Biosci. 2020;10(1):69. doi:10.1186/s13578-020-00427-x

86. Liau LL, Al-Masawa ME, Koh B, et al. The potential of mesenchymal stromal cell as therapy in neonatal diseases. Front Pediatr. 2020;8:591693. doi:10.3389/fped.2020.591693

87. Looi QH, Eng SP, Liau LL, et al. Mesenchymal stem cell therapy for sports injuries-from research to clinical practice. Sains Malays. 2020;49(4):825-838. doi:10.17576/jsm-2020-4904-12

88. Gao F, Chiu SM, Motan DAL, et al. Mesenchymal stem cells and immunomodulation: current status and future prospects. Cell Death Dis. 2016;7(1):e2062. doi:10.1038/cddis.2015.327

89. Pittenger MF, Discher DE, Péault BM, Phinney DG, Hare JM, Caplan AI. Mesenchymal stem cell perspective: cell biology to clinical progress. NPJ Regen Med. 2019;4(1):22. doi:10.1038/ s41536-019-0083-6

90. Lian J, Lv S, Liu C, et al. Effects of serial passage on the characteristics and cardiac and neural differentiation of human umbilical cord Wharton's jelly-derived mesenchymal stem cells Stem Cells Int. 2016;2016:9291013. doi:10.1155/2016/9291013
91. Liau LL, Looi QH, Chia WC, Subramaniam T, Ng MH, Law JX. Treatment of spinal cord injury with mesenchymal stem cells. Cell Biosci. 2020;10:112. doi:10.1186/s13578-020-00475-3

92. Lopez-Verrilli MA, Caviedes A, Cabrera A, Sandoval S, Wyneken U, Khoury M. Mesenchymal stem cell-derived exosomes from different sources selectively promote neuritic outgrowth. Neuroscience. 2016;320:129-139. doi:10.1016/j.neuroscience.2016.01.061

93. Del Fattore A, Luciano R, Saracino R, et al. Differential effects of extracellular vesicles secreted by mesenchymal stem cells from different sources on glioblastoma cells. Expert Opin Biol Ther. 2015;15(4):495-504. doi:10.1517/14712598.2015.997706

94. Katsuda T, Tsuchiya R, Kosaka N, et al. Human adipose tissuederived mesenchymal stem cells secrete functional neprilysinbound exosomes. Sci Rep. 2013;3(1):1197. doi:10.1038/ srep01197

95. Álvarez-viejo M. Mesenchymal stem cells from different sources and their derived exosomes: a pre-clinical perspective. World $J$ Stem Cells. 2020;12(2):100. doi:10.4252/wjsc.v12.i2.100

96. Nikfarjam S, Rezaie J, Zolbanin NM, Jafari R. Mesenchymal stem cell derived-exosomes: a modern approach in translational medicine. J Transl Med. 2020;18(1):449. doi:10.1186/s12967020-02622-3

97. Yin K, Wang S, Zhao RC. Exosomes from mesenchymal stem/ stromal cells: a new therapeutic paradigm. Biomark Res. 2019;7 (1):8. doi:10.1186/s40364-019-0159-X

98. Tang Y, Zhou Y, Li H-J. Advances in mesenchymal stem cell exosomes: a review. Stem Cell Res Ther. 2021;12(1):71. doi:10.1186/s13287-021-02138-7

99. Kourembanas S. Exosomes: vehicles of intercellular signaling, biomarkers, and vectors of cell therapy. Annu Rev Physiol. 2015;77(1):13-27. doi:10.1146/annurev-physiol-021014-071641

100. Fu S, Wang Y, Xia X, Zheng JC. Exosome engineering: current progress in cargo loading and targeted delivery. NanoImpact. 2020;20:100261. doi:10.1016/j.impact.2020.100261

101. Gholami L, Nooshabadi VT, Shahabi S, et al. Extracellular vesicles in bone and periodontal regeneration: current and potential therapeutic applications. Cell Biosci. 2021;11(1):16. doi:10.1186/ s13578-020-00527-8

102. Valadi H, Ekström K, Bossios A, Sjöstrand M, Lee JJ, Lötvall JO. Exosome-mediated transfer of mRNAs and microRNAs is a novel mechanism of genetic exchange between cells. Nat Cell Biol. 2007;9(6):654-659. doi:10.1038/ncb1596

103. Wu C, Tian B, Qu X, et al. MicroRNAs play a role in chondrogenesis and osteoarthritis (review). Int J Mol Med. 2014;34 (1):13-23. doi:10.3892/ijmm.2014.1743

104. Mihanfar A, Shakouri SK, Khadem-Ansari MH, et al. Exosomal miRNAs in osteoarthritis. Mol Biol Rep. 2020;47(6):4737-4748. doi:10.1007/s11033-020-05443-1

105. Peng B, Chen Y, Leong KW. MicroRNA delivery for regenerative medicine. Adv Drug Deliv Rev. 2015;88:108-122. doi:10.1016/j. addr.2015.05.014

106. Schwarzenbach H, Gahan PB. MicroRNA shuttle from cell-tocell by exosomes and its impact in cancer. Noncoding RNA. 2019;5(1). doi:10.3390/ncrna5010028

107. Conigliaro A, Costa V, Lo Dico A, et al. CD90+ liver cancer cells modulate endothelial cell phenotype through the release of exosomes containing H19 lncRNA. Mol Cancer. 2015;14(1):155. doi:10.1186/s12943-015-0426-X

108. Zhang $C$, Wang $P$, Jiang $P$, et al. Upregulation of lncRNA HOTAIR contributes to IL- $\beta$-induced MMP overexpression and chondrocytes apoptosis in temporomandibular joint osteoarthritis. Gene. 2016;586(2):248-253. doi:10.1016/j.gene.2016.04.016

109. Yang L, Zhai Y, Hao Y, Zhu Z, Cheng G. The regulatory functionality of exosomes derived from hUMSCs in 3D culture for Alzheimer's disease therapy. Small. 2019;16:3. doi:10.1002/ smll.201906273 
110. Cao J, Wang B, Tang T, et al. Three-dimensional culture of MSCs produces exosomes with improved yield and enhanced therapeutic efficacy for cisplatin-induced acute kidney injury. Stem Cell Res Ther. 2020;11(1):206. doi:10.1186/s13287-020-01719-2

111. Liau LL, Hassan MN, Tang YL, Ng MH, Law JX. Feasibility of human platelet lysate as an alternative to foetal bovine serum for in vitro expansion of chondrocytes. Int J Mol Sci. 2021;22 (3):1269. doi:10.3390/ijms22031269

112. Evans $\mathrm{CH}$, Kraus VB, Setton LA. Progress in intra-articular therapy. Nat Rev Rheumatol. 2014;10(1):11-22. doi:10.1038/ nrrheum.2013.159

113. Pinheiro A, Silva AM, Teixeira JH, et al. Extracellular vesicles: intelligent delivery strategies for therapeutic applications. J Control Release. 2018;289:56-69. doi:10.1016/j.jconrel.2018.09.019

114. Patil M, Henderson J, Luong H, Annamalai D, Sreejit G, Krishnamurthy P. The art of intercellular wireless communications: exosomes in heart disease and therapy. Front Cell Dev Biol. 2019;7:315. doi:10.3389/fcell.2019.00315

115. Quesenberry PJ, Aliotta J, Deregibus MC, Camussi G. Role of extracellular RNA-carrying vesicles in cell differentiation and reprogramming. Stem Cell Res Ther. 2015;6(1):153. doi:10.1186/s13287-015-0150-x

116. Qi H, Liu DP, Xiao DW, Tian DC, Su YW, Jin SF. Exosomes derived from mesenchymal stem cells inhibit mitochondrial dysfunction-induced apoptosis of chondrocytes via p38, ERK, and Akt pathways. In Vitro Cell Dev Biol Anim. 2019;55(3):203-210. doi:10.1007/s11626-019-00330-x

117. De Jong OG, Van Balkom BWM, Schiffelers RM, Bouten CVC, Verhaar MC. Extracellular vesicles: potential roles in regenerative medicine. Front Immunol. 2014;5:608. doi:10.3389/ fimmu.2014.00608

118. Wang Y, Yao J, Cai L, et al. Bone-targeted extracellular vesicles from mesenchymal stem cells for osteoporosis therapy. Int J Nanomedicine. 2020;15:7967-7977. doi:10.2147/IJN. S263756

119. Glasson SS, Chambers MG, Berg WBVD, Little CB. The OARSI histopathology initiative - recommendations for histological assessments of osteoarthritis in the mouse. Osteoarthritis Cartilage. 2010;18:S17-S23. doi:10.1016/j. joca.2010.05.025

120. Paramitha D, Fakhrul Ulum M, Purnama A, Wicaksono D, Noviana D, Hermawan H. Monitoring degradation products and metal ions in vivo. In: Narayan R, editor. Monitoring and Evaluation of Biomaterials and Their Performance in vivo. Sawston: Woodhead Publishing; 2016:19-43. doi:10.1016/B9780-08-100603-0.00002-X

121. Bergholt NL, Lysdahl H, Lind M, Foldager CB. A standardized method of applying toluidine blue metachromatic staining for assessment of chondrogenesis. Cartilage. 2019;10(3):370-374. doi:10.1177/1947603518764262

122. Henrotin Y, Sanchez C, Bay-Jensen AC, Mobasheri A. Osteoarthritis biomarkers derived from cartilage extracellular matrix: current status and future perspectives. Ann Phys Rehabil Med. 2016;59(3):145-148. doi:10.1016/j.rehab.2016.03.004

123. Roughley PJ, Mort JS. The role of aggrecan in normal and osteoarthritic cartilage. J Exp Orthop. 2014;1(1):8. doi:10.1186/ s40634-014-0008-7

124. Hoshi H, Akagi R, Yamaguchi S, et al. Effect of inhibiting MMP13 and ADAMTS5 by intra-articular injection of small interfering RNA in a surgically induced osteoarthritis model of mice. Cell Tissue Res. 2017;368(2):379-387. doi:10.1007/ s00441-016-2563-y

125. Hwang HS, Kim HA. Chondrocyte apoptosis in the pathogenesis of osteoarthritis. Int J Mol Sci. 2015;16(11):26035. doi:10.3390/ ijms161125943
126. Liu H, Liang Z, Wang F, et al. Exosomes from mesenchymal stromal cells reduce murine colonic inflammation via a macrophage-dependent mechanism. JCI Insight. 2019;4(24):131273. doi:10.1172/jci.insight. 131273

127. Li X, Liu L, Yang J, et al. Exosome derived from human umbilical cord mesenchymal stem cell mediates miR-181c attenuating burn-induced excessive inflammation. EBioMedicine. 2016;8:7282. doi:10.1016/j.ebiom.2016.04.030

128. Zhang B, Yin Y, Lai RC, Tan SS, Choo ABH, Lim SK. Mesenchymal stem cells secrete immunologically active exosomes. Stem Cells Dev. 2014;23(11):1233-1244. doi:10.1089/ scd.2013.0479

129. Lee C, Mitsialis SA, Aslam M, et al. Exosomes mediate the cytoprotective action of mesenchymal stromal cells on hypoxiainduced pulmonary hypertension. Circulation. 2012;126 (22):2601-2611. doi:10.1161/CIRCULATIONAHA.112.114173

130. Li G, Yin J, Gao J, et al. Subchondral bone in osteoarthritis: insight into risk factors and microstructural changes. Arthritis Res Ther. 2013;15(6):223. doi:10.1186/ar4405

131. Hu W, Chen Y, Dou C, Dong S. Microenvironment in subchondral bone: predominant regulator for the treatment of osteoarthritis. Ann Rheum Dis. 2020;80(4):413-422. doi:10.1136/ annrheumdis-2020-218089

132. Donell S. Subchondral bone remodelling in osteoarthritis. EFORT Open Rev. 2019;4(6):221-229. doi:10.1302/2058-5241.4.180102

133. Bellido M, Lugo L, Roman-Blas JA, et al. Improving subchondral bone integrity reduces progression of cartilage damage in experimental osteoarthritis preceded by osteoporosis. Osteoarthritis Cartilage. 2011;19(10):1228-1236. doi:10.1016/j.joca.2011.07.003

134. Hayami T, Pickarski M, Zhuo Y, Wesolowski GA, Rodan GA, Duong LT. Characterization of articular cartilage and subchondral bone changes in the rat anterior cruciate ligament transection and meniscectomized models of osteoarthritis. Bone. 2006;38(2):234243. doi:10.1016/j.bone.2005.08.007

135. Hayami T, Pickarski M, Wesolowski GA, et al. The role of subchondral bone remodeling in osteoarthritis: reduction of cartilage degeneration and prevention of osteophyte formation by alendronate in the rat anterior cruciate ligament transection model. Arthritis Rheum. 2004;50(4):1193-1206. doi:10.1002/ art.20124

136. Burr DB, Schaffler MB. The involvement of subchondral mineralized tissues in osteoarthrosis: quantitative microscopic evidence. Microsc Res Tech. 1997;37(4):343-357. doi:10.1002/ (SICI)1097-0029(19970515)37:4<343::AID-JEMT9>3.0.CO;2-L

137. Lories RJ, Luyten FP. The bone-cartilage unit in osteoarthritis. Nat Rev Rheumatol. 2011;7(1):43-49. doi:10.1038/ nrrheum.2010.197

138. Yuan XL, Meng HY, Wang YC, et al. Bone-cartilage interface crosstalk in osteoarthritis: potential pathways and future therapeutic strategies. Osteoarthritis Cartilage. 2014;22(8):1077-1089. doi:10.1016/j.joca.2014.05.023

139. Zhang W, Lian Q, Li D, et al. Cartilage repair and subchondral bone migration using $3 \mathrm{~d}$ printing osteochondral composites: a one-year-period study in rabbit trochlea. Biomed Res Int. 2014;2014:e746138. doi:10.1155/2014/746138

140. Zhu S, Zhu J, Zhen G, et al. Subchondral bone osteoclasts induce sensory innervation and osteoarthritis pain. $J$ Clin Invest. 2019;129(3):1076-1093. doi:10.1172/JCI121561

141. Zhu J, Zhen G, An S, et al. Aberrant subchondral osteoblastic metabolism modifies NaV1.8 for osteoarthritis. Elife. 2020;9. doi:10.7554/eLife.57656

142. Sousa M, Ferraresi C, Carolina A, Yoshimura E, Hamblin M. Building, testing and validating a set of home-made von Frey filaments: a precise, accurate and cost effective alternative for nociception assessment. J Neurosci Methods. 2014;232:1-5. doi:10.1016/j.jneumeth.2014.04.017 
143. Deuis JR, Dvorakova LS, Vetter I. Methods used to evaluate pain behaviors in rodents. Front Mol Neurosci. 2017;10:284. doi:10.3389/fnmol.2017.00284

144. Hawker GA, Stewart L, French MR, et al. Understanding the pain experience in hip and knee osteoarthritis-an OARSI/OMERACT initiative. Osteoarthritis Cartilage. 2008;16(4):415-422. doi:10.1016/j.joca.2007.12.017

145. Duarte RV, Raphael JH, Dimitroulas T, et al. Osteoarthritis pain has a significant neuropathic component: an exploratory in vivo patient model. Rheumatol Int. 2014;34(3):315-320. doi:10.1007/ s00296-013-2893-y

146. Valdes AM, Suokas AK, Doherty SA, Jenkins W, Doherty M. History of knee surgery is associated with higher prevalence of neuropathic pain-like symptoms in patients with severe osteoarthritis of the knee. Semin Arthritis Rheum. 2014;43(5):588-592. doi:10.1016/j.semarthrit.2013.10.001

147. Lakes EH, Allen KD. Gait analysis methods for rodent models of arthritic disorders: reviews and recommendations. Osteoarthritis Cartilage. 2016;24(11):1837-1849. doi:10.1016/j.joca.2016.03.008

148. Kalluri R, LeBleu VS. The biology, function, and biomedical applications of exosomes. Science. 2020;367(6478):eaau6977. doi:10.1126/science.aau6977

149. Gomzikova MO, James V, Rizvanov AA. Therapeutic application of mesenchymal stem cells derived extracellular vesicles for immunomodulation. Front Immunol. 2019;10:2663. doi:10.3389/ fimmu.2019.02663

150. Elahi FM, Farwell DG, Nolta JA, Anderson JD. Preclinical translation of exosomes derived from mesenchymal stem/stromal cells. Stem Cells. 2020;38(1):15-21. doi:10.1002/stem.3061

151. Robbins PD, Morelli AE. Regulation of immune responses by extracellular vesicles. Nat Rev Immunol. 2014;14(3):195-208. doi:10.1038/nri3622

152. Toma C, Wagner WR, Bowry S, Schwartz A, Villanueva F. Fate of culture-expanded mesenchymal stem cells in the microvasculature: in vivo observations of cell kinetics. Circ Res. 2009;104 (3):398-402. doi:10.1161/CIRCRESAHA.108.187724

153. Caplan AI, Dennis JE. Mesenchymal stem cells as trophic mediators. J Cell Biochem. 2006;98(5):1076-1084. doi:10.1002/ jcb. 20886

154. Beltrami AP, Cesselli D, Beltrami CA. Stem cell senescence and regenerative paradigms. Clin Pharmacol Ther. 2012;91(1):21-29. doi:10.1038/clpt.2011.262

155. Sverdlov ED, Mineev K. Mutation rate in stem cells: an underestimated barrier on the way to therapy. Trends Mol Med. 2013;19 (5):273-280. doi:10.1016/j.molmed.2013.01.004

156. Lee AS, Tang C, Rao MS, Weissman IL, Wu JC. Tumorigenicity as a clinical hurdle for pluripotent stem cell therapies. Nat Med. 2013;19(8):998-1004. doi:10.1038/nm.3267

157. Vizoso FJ, Eiro N, Cid S, Schneider J, Perez-Fernandez R. mesenchymal stem cell secretome: toward cell-free therapeutic strategies in regenerative medicine. Int $J$ Mol Sci. 2017;18 (9):1852. doi:10.3390/ijms18091852
158. Naseri Z, Oskuee RK, Jaafari MR, Forouzandeh Moghadam M. Exosome-mediated delivery of functionally active miRNA-142$3 p$ inhibitor reduces tumorigenicity of breast cancer in vitro and in vivo. Int J Nanomedicine. 2018;13:7727-7747. doi:10.2147/ IJN.S182384

159. Huyan T, Li H, Peng H, et al. Extracellular vesicles - advanced nanocarriers in cancer therapy: progress and achievements. Int $J$ Nanomedicine. 2020;15:6485-6502. doi:10.2147/IJN.S238099

160. Imai T, Takahashi Y, Nishikawa M, et al. Macrophage-dependent clearance of systemically administered B16BL6-derived exosomes from the blood circulation in mice. $J$ Extracell Vesicles. 2015;4(1):26238. doi:10.3402/jev.v4.26238

161. Lai CP, Mardini O, Ericsson M, et al. Dynamic biodistribution of extracellular vesicles in vivo using a multimodal imaging reporter. ACS Nano. 2014;8(1):483-494. doi:10.1021/nn404945r

162. Cheng J, Abdi S. Complications of joint, tendon, and muscle injections. Tech Reg Anesth Pain Manag. 2007;11(3):141-147. doi:10.1053/j.trap.2007.05.006

163. Witwer KW, Théry C. Extracellular vesicles or exosomes? On primacy, precision, and popularity influencing a choice of nomenclature. J Extracell Vesicles. 2019;8(1):1648167. doi:10.1080/ 20013078.2019.1648167

164. Haraszti RA, Miller R, Stoppato M, et al. Exosomes produced from 3D cultures of MSCs by tangential flow filtration show higher yield and improved activity. Mol Ther. 2018;26 (12):2838-2847. doi:10.1016/j.ymthe.2018.09.015

165. Pachler K, Lener T, Streif D, et al. A good manufacturing practice-grade standard protocol for exclusively human mesenchymal stromal cell-derived extracellular vesicles. Cytotherapy. 2017;19 (4):458-472. doi:10.1016/j.jcyt.2017.01.001

166. Chen T, Arslan F, Yin Y, et al. Enabling a robust scalable manufacturing process for therapeutic exosomes through oncogenic immortalization of human ESC-derived MSCs. J Transl Med. 2011;9(1):47. doi:10.1186/1479-5876-9-47

167. Lian Q, Lye E, Suan Yeo K, et al. Derivation of clinically compliant MSCs from CD105+, CD24- differentiated human ESCs. Stem Cells. 2007;25(2):425-436. doi:10.1634/stemcells.2006-0420

168. Herrmann M, Diederichs S, Melnik S, et al. Extracellular vesicles in musculoskeletal pathologies and regeneration. Front Bioeng Biotechnol. 2021;8:624096. doi:10.3389/fbioe.2020.624096

169. Sabapathy V, Kumar S. hiPSC-derived iMSCs: NextGen MSCs as an advanced therapeutically active cell resource for regenerative medicine. J Cell Mol Med. 2016;20(8):1571-1588. doi:10.1111/ jcmm. 12839
International Journal of Nanomedicine

\section{Publish your work in this journal}

The International Journal of Nanomedicine is an international, peerreviewed journal focusing on the application of nanotechnology in diagnostics, therapeutics, and drug delivery systems throughout the biomedical field. This journal is indexed on PubMed Central, MedLine, CAS, SciSearch ${ }^{\mathbb{R}}$, Current Contents ${ }^{\mathbb{B}} /$ Clinical Medicine, $^{2}$
Journal Citation Reports/Science Edition, EMBase, Scopus and the Elsevier Bibliographic databases. The manuscript management system is completely online and includes a very quick and fair peer-review system, which is all easy to use. Visit http://www.dovepress.com/ testimonials.php to read real quotes from published authors. 